\title{
Descrición, cartografía e valor de conservación dos bosques da Devesa da Rogueira (Serra do Courel, NW Península Ibérica)
}

Recibido: 11 xaneiro 2013 / Aceptado: 25 maio 2013

(C) IBADER- Universidade de Santiago de Compostela 2013

\begin{abstract}
Resumo Se presenta un estudo detallado dos tipos de bosques existentes na Devesa da Rogueira (Folgoso do Courel, Lugo, España) elaborado a partir da información previamente publicada e da realización de novos traballos de inventariación en campo. En total, recoñécense 21 comunidades diferentes de bosques, para as que se describe a súa ecoloxía, caracterización florística e distribución dentro da área de estudio. Tendo en conta a reducida extensión da superficie arborada estudiada (310 ha) e a súa elevada riqueza fitocenótica, a Devesa da Rogueira confírmase como un lugar de excepcional valor ambiental, non só dentro do contexto local ou autonómico, senón dentro da área temperada do NW Ibérico.
\end{abstract}

Palabras chave comunidades arboradas, biodiversidade, cartografía, SIX, Galicia, Cordilleira Cantábrica occidental.

\begin{abstract}
We present here a detailed study on the forest communities of the Devesa da Rogueira site (Folgoso do Courel, Lugo, Spain). It comprises previously available information as well as new collected field data that allowed the recognition and mapping of 21 types of woodlands. For each one we describe its floristic composition, the ecological features and the surface covered in the study area. Such a great variety of native tree-dominated communities growing in such a small territory ( 310 ha) confirms that the study area
\end{abstract}

Manuel Antonio Rodríguez Guitián · Rosa Romero Franco Dpto. de Produción Vexetal. Escola Politécnica Superior-USC. Campus Universitario s/n, 27002-Lugo (España)

E-mail: manuelantonio.rodriguez@usc.es

\section{Carlos Real}

Dpto. de Bioloxía Celular e Ecoloxía. Escola Politécnica SuperiorUSC. Campus Universitario s/n, 27002-Lugo (España)

Javier Ferreiro da Costa

Instituto de Biodiversidade Agraria e Desenvolvemento RuralIBADER. Campus Universitario s/n, 27002-Lugo (España) is an outstanding site in terms of vegetation and habitat richness not only at local scale but in the temperate NW Iberian context.

Key words tree-dominated communities, biodiversity, mapping, GIS, Galicia, West Cantabrian Range.

\section{Introducción e obxectivos}

A Devesa da Rogueira é un área das montañas occidentais da provincia de Lugo situado na vertente $W$ da Serra do Courel que pertence, desde o punto de vista administrativo, ao Concello de Folgoso do Courel (Figura 1). Baixo este topónimo, os habitantes locais designan un territorio de arredor de 400 ha, a maior parte de propiedade comunal, que comprende, fundamentalmente, as ladeiras que descenden cara ao $\mathrm{N}$ do cordal que une o Alto do Couto cos picos Formigueiros, Teso das Papoulas e Polín (Figuras 1 e 2).

Neste enclave atópase unha extensa masa arborada (a Devesa da Rogueira propiamente dita) que se estende entre os 850 e os $1.500 \mathrm{~m}$ de altitude e que xa chamou a atención, hai máis dun século, ao ilustre botánico Baltasar Merino (1901, 1902). Desde ese momento, e sobre todo a partir dos anos 70 e 80 do pasado século, fóronse incrementando as referencias ao seu valor naturalístico en xeral e botánico en particular (Guitián Rivera 2011). Sen embargo, a maior parte do coñecemento que se posúe sobre a súa vexetación procede da elaboración de dúas teses de doutoramento centradas na caracterización da cuberta vexetal da comarca do Courel (Amigo Vázquez 1984, Guitián Rivera 1984), das que derivaron diversos traballos parciais (Izco et al. 1985, 1986a, 1986b; Guitián et al. 1988). Completando o panorama de referencias previas que contan con información acerca das comunidades vexetais da Devesa da Rogueira e o seu entorno cabería citar, entre outros, os traballos de Giménez de Azcárate (1993), Amigo et al. (1994), Giménez de Azcárate et al. (1996) ou Rodríguez Guitián et al. (2000, 2005a, 2005b, 2009). 


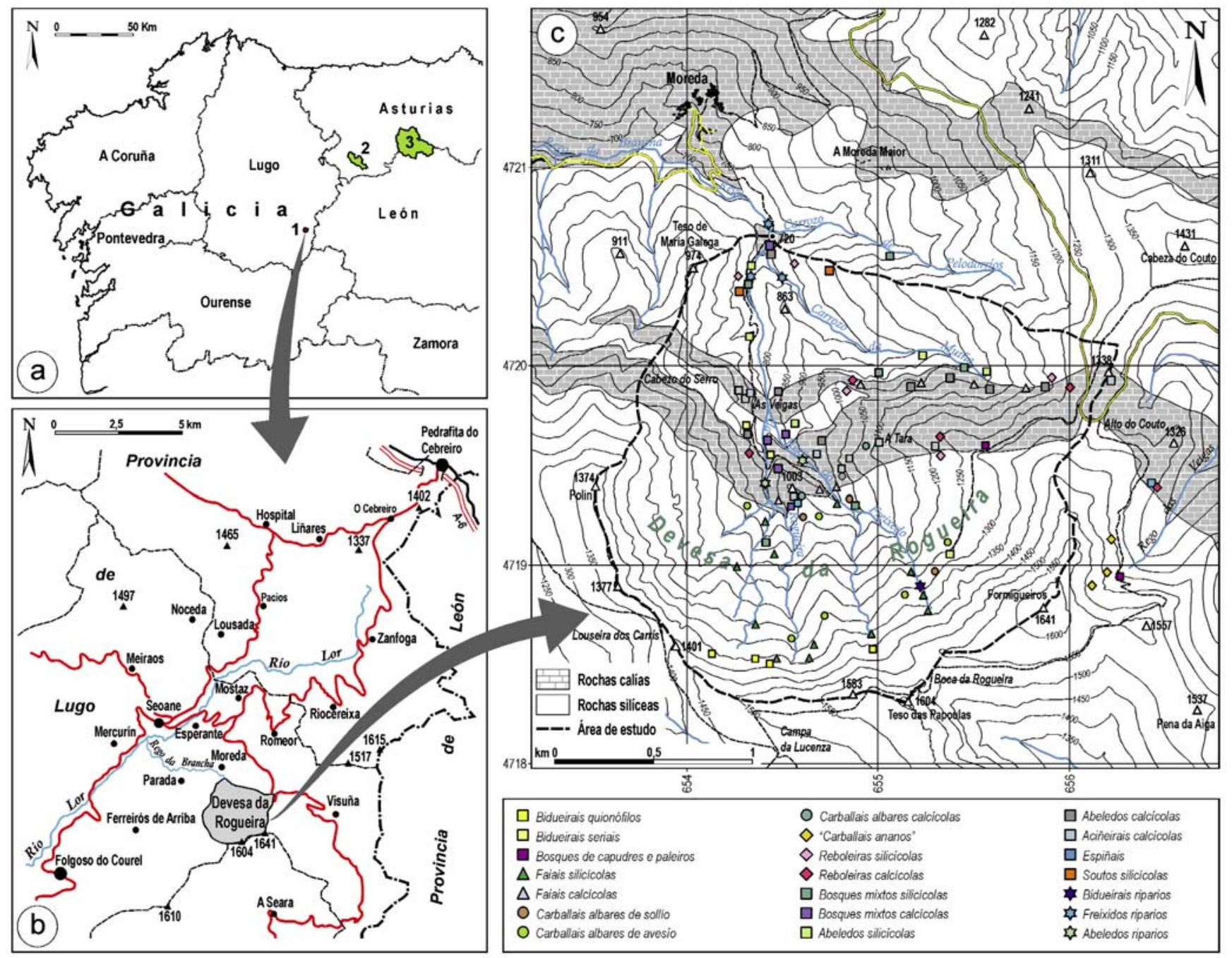

Figura 1.- a: Contextualización da área de estudio e dos territorios xeográficos citados no apartado de discusión no cuadrante NW Ibérico (1: Devesa da Rogueira, 2: Reserva Natural Integral de Muniellos, 3: Parque Natural de Somiedo); b: localización da área de estudo a escala municipal; c: esquema topográfico e litolóxico da Devesa da Rogueira e a súa contorna con indicación da localización dos inventarios florísticos utilizados para a elaboración deste traballo

A pesar do volume de información existente, até o de agora non se ten realizado un estudo detallado sobre a tipoloxía e distribución superficial da cuberta vexetal da Devesa da Rogueira. Do mesmo xeito, tampouco se dispón dunha valoración precisa de cal é a aportación deste particular enclave á conservación dos valores naturais do Courel e do contexto bioxeográfico no que se inscribe esta serra (ámbito temperado do NW Ibérico). Dada a variedade de comunidades vexetais que até o de agora se teñen recoñecido na Devesa da Rogueira e o seu entorno máis inmediato, abordamos de xeito exclusivo neste traballo a descrición botánica, caracterización ecolóxica e cartografía da súa cuberta arborada, como punto de partida para realizar unha avaliación do seu valor ambiental desde unha perspectiva bioxeográfica, tomando como referencia as áreas de montaña do extremo occidental da Cordillera Cantábrica.

\section{Área de estudo}

Aínda que a Devesa da Rogueira é un lugar ben delimitado desde o punto de vista toponímico, baixo unha perspectiva ecolóxica e cartográfica, as comunidades que compoñen a súa cuberta vexetal non se interrompen de xeito brusco nos seus límites, senón que teñen unha continuación evidente nos terreos adxacentes. Por elo, a efectos da realización deste traballo preferiuse seguir un criterio hidrolóxico para delimitar a área de traballo, tomándose como referencia a cunca hidrográfica do Rego da Rogueira, integrada na súa área de cabeceira, ademais de por este curso fluvial, por dous tributarios (Carrozo da Muíña e Rego do Freixedo) que conflúen con el pola súa marxe dereita (Figuras 1 e 2). En conxunto, trátase dunha superficie de 436 ha que se estende entre os $1.641 \mathrm{~m}$ do Pico Formigueiros e os $720 \mathrm{~m}$, a altura da confluencia do Rego da Rogueira e o Carrozo da Muíña. Este acentuado desnivel altitudinal resólvese, desde 
o punto de vista topográfico, a traveso de vertentes de forte inclinación e de abundantes escarpes rochosos, sendo extraordinariamente escasas e reducidas as área achairadas.

Os materiais litolóxicos da área de estudo son de idade cámbrica e ordovícica (541-443 m.a.)(IGME 1981, GEOVEO 2012), predominando as rochas metamórficas de tipo silíceo (lousas, xistos, areíscas, cuarcitas), entre as que se intercala un extenso estrato de rochas carbonatadas (Formación Vegadeo) que aflora configurando unha banda de anchura variable (150-550 m en proxección horizontal) que se dispón, con rumbo E-W, entre o Alto do Couto a e Cabeza do Serro (Figuras 1 e 2). En épocas xeolóxicas recentes (Plistoceno e Holoceno), o susbstrato rochoso estivo exposto a acción de diversos axentes erosivos (glaciares, fenómenos periglaciares, movementos gravitacionais, erosión fluvial, disolución polas augas de escorrentía e infiltración, etc.) responsables da formación de cubertas sedimentarias e solos de espesor e distribución moi variables, que en certos casos dificultan o recoñecemento da litoloxía subxacente.

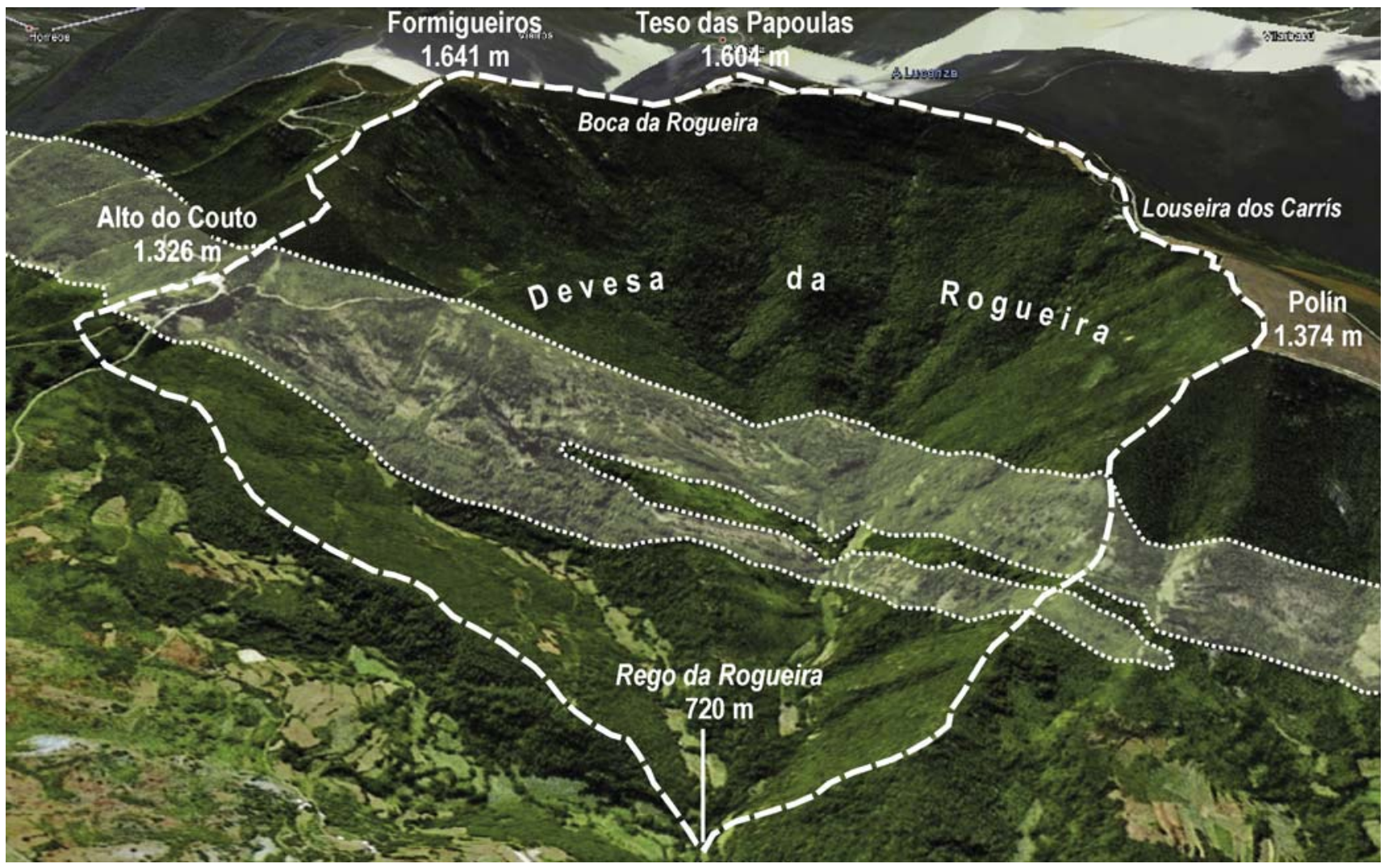

Figura 2.- Vista panorámica virtual da área de estudo (trazo discontinuo groso) desde a vertical de Moreda, a uns 2,6 km de altitude, cara ao S (tomada de Google Earth). Aprecianse as masas arboradas existentes ocupando, principalmente, vertentes avesías de gran desnivel e remarcase, entre as liñas descontinuas miúdas, o afloramento de rochas carbonatadas que se estende entre o Alto do Couto e a vertente N do Pico Polín

A inexistencia de estacións meteorolóxicas no sector axial da Serra do Courel impide coñecer con exactitude as condicións climáticas actuais deste territorio. Admitindo como válidas as extrapolacións realizadas por diferentes autores a partir da información proporcionada por estacións do entorno (Barral Silva et al. 1985, Rigueiro Rodríguez et al. 2005, Rodríguez Guitián \& Ramil Rego 2007), a área na que se encontra a Devesa da Rogueira tería condicións climáticas que levarían a incluíla, segundo a última versión da Clasificación Bioclimática de Rivas-Martínez (2011), dentro do macroclima temperado típico (sen seca estival) e un bioclima oceánico semihiperoceánico (amplitude térmica media anual entre 11 e $14^{\circ} \mathrm{C}$ ). Os ombrotipos oscilarían entre o húmido superior e o hiperhúmido superior, con precipitacións total anuais que variarían entre os 1.500 e $2.000 \mathrm{~mm}$, e os termotipos comprenderían desde o mesotemperado superior ao supratemperado superior, con unha representación marxinal $(>1.600 \mathrm{~m})$ do orotemperado inferior.

Desde o punto de vista edáfico, a formación dos solos nestas montañas está influída principalmente pola natureza química do material de partida (de carácter silíceo vs. carbonatado) e a diferenza altitudinal. Sobre os afloramentos silíceos e os sedimentos deles derivados desenvolvense solos relativamente profundos $(40-70 \mathrm{~cm})$ pero, polo xeral, moi pedregosos (Táboa 1). A pobreza en nutrientes $(\mathrm{Na}, \mathrm{K}, \mathrm{Ca}, \mathrm{Mg})$ e riqueza en Aluminio destes 
susbstratos causan unha forte acedume nos horizontes edáficos superficiais $\left(\mathrm{pH}\right.$ en $\left.\mathrm{H}_{2} \mathrm{O}: 3,5-4,5\right)$, que se ve acentuada no caso das cuarcitas, dada a súa particular riqueza en sílice (Barral Silva et al. 1985). Cara ás partes máis elevadas, o carácter frío do réxime térmico provoca un retardo na mineralización dos restos vexetais, favorecendo a formación de horizontes superficiais máis espesos e ricos en humus (Táboa 1). No caso oposto, a partir de rochas carbonatadas tenden a formarse solos menos profundos (20-45 cm polo regular) cun menor contido en materia orgánica e abundantes afloramentos rochosos. $O$ menor espesor total dos solos e a presenza nos horizontes superficiais de fragmentos líticos que liberan $\mathrm{Ca}^{+2}$ ao medio edáfico xustifican que nestes se atopen valores de $\mathrm{pH}$ superiores a 6,0 e unha elevada saturación en bases do complexo de cambio (Táboa 1), a pesar do efecto de lavado que exercen as elevadas precipitacións que teñen lugar nestas montañas (Barral Silva et al. 1985, Taboada Castro \& Silva Hermo 1999, Rodríguez Guitián et al. 2001, Merino et al. 2008). Cando os solos derivan de sedimentos nos que se dá a mestura de materiais silíceos e carbonatados presentan nunhas características intermedias, con valores de $\mathrm{pH}$ comprendidos entre 5,0 e 6,0 e unha presenza de $\mathrm{Al}$ no complexo de cambio que oscila entre o $35-50 \%$ (Rodríguez Guitián et al. 2001, Merino García \& Rodríguez Guitián 2011).
A topografía particularmente abrupta que caracteriza á área de estudio non impedíu que a Devesa da Rogueira e o seu entorno permaneceran alleos á actividade humana. Esta eliminou a cuberta arborada de amplas áreas para a instalación intermitente de cultivos (searas ou cavadas), o pastoreo con gando menor (cabras, ovellas) ou a implantación de prados de sega nos fondos dos vales. Incluso a propia vexetación arborada que actualmente se conserva amosa signos evidentes, como a abundancia de pés trasmochos e procedentes de rebentos de cepa, o predominio de árbores de diámetros normais inferiores aos $75 \mathrm{~cm}$ ou as numerosas foias de carboneo que se poden atopar polo interior do arborado, do seu aproveitamento en épocas pasadas para obter combustible co que abastecer os fogares e os abundantes mazos e ferrerías da comarca.

Desde o punto de vista bioxeográfico, o territorio obxecto de estudo sitúase no Subsector Courelao, pertencente ao Sector Orocantábrico occidental da Subprovincia Orocantábrica (Provincia Cántabro-Atlántica, Rexión Eurosiberiana), segundo a tipoloxía de unidades proposta por Rodríguez Guitián \& Ramil Rego (2008). No plano normativo, está incluido dentro do LIC "Os Ancares-O Courel", espazo integrado na Rede Natura 2000 europea e declarado igualmente como "Zona de Especial Protección dos Valores Naturais" en aplicación da Lei 9/2001 de Conservación da Natureza de Galicia (Xunta de Galicia 2001).

\begin{tabular}{lccccccccc}
\hline $\mathbf{N}^{0}$ Parcela & Altitude $(\mathbf{m})$ & $\begin{array}{c}\text { Pendente } \\
\left({ }^{\circ}\right)\end{array}$ & Orientación & Substrato & $\begin{array}{c}\text { Prof. (cm) } \\
\text { hor. A/total }\end{array}$ & $\begin{array}{c}\text { Fracción } \\
\text { grosa (\%) }\end{array}$ & $\begin{array}{c}\text { pH } \\
\mathrm{H}_{2} \mathbf{O}\end{array}$ & $\begin{array}{c}\text { Sat. Al } \\
(\%)\end{array}$ & $\begin{array}{c}\text { Clasificación } \\
\text { (FAO/UNESCO, 1998) }\end{array}$ \\
\hline Rogueira-1 & 960 & 26 & $\mathrm{NNE}$ & $\mathrm{S}$ & $18 / 72$ & 60,2 & 4,13 & 66,73 & Umbrisol húmico \\
Rogueira-2 & 970 & 36 & $\mathrm{~N}$ & $\mathrm{C}$ & $8 / 35$ & 47,7 & 6,91 & 0,73 & Cambisol eútrico \\
Rogueira-3 & 1.370 & 38 & $\mathrm{~N}$ & $\mathrm{~S}$ & $20 / 20$ & 68,8 & 4,07 & 28,89 & Umbrisol húmico \\
Rogueira-4 & 1.025 & 32 & $\mathrm{NNE}$ & $\mathrm{C}$ & $15 / 50$ & 42,8 & 6,44 & 1,37 & Cambisol eútrico \\
\hline
\end{tabular}

Táboa 1.- Características de catro perfís edáficos estudados baixo faiais na Devesa da Rogueira.(adaptado de Rodríguez Guitián et al. 2001a e Merino \& Rodríguez Guitián 2011). (S: rochas silíceas (lousas, areíscas, cuarcitas); C: rochas carbonatadas (calías, dolomías))

\section{Metodoloxía}

A efectos do presente estudo, entendemos como bosques as formacións vexetais dominadas por especies leñosas que polo xeral superan os $4 \mathrm{~m}$ de altura (árbores) e se consideran autóctonas (están presentes nun territorio dado desde antes da xeneralización das actividades humanas)(Rodríguez Guitián et al. 2012). Tamén se inclúen aquelas formacións dominadas por especies arbóreas autóctonas que, por medraren en biotopos particularmente restrictivos para o seu crecemento, como tesos rochosos, cumes moi venteados ou lugares que acumulan moita neve no inverno, presentan un aspecto achaparrado e apenas superan a talla comentada. Ademais, inclúense as plantacións forestais tradicionais típicas desta parte de Galicia, os soutos, por canto constitúen un exemplo particularmente interesante de aproveitamento dos recursos forestais compatible co mantemento duns elevados valores biólóxicos (EC 2007, Guitián et al. 2012, Rodríguez Guitián et al. 2012).
O traballo realizouse en tres fases. Unha primeira de recompilación da información existente en publicacións previas, a partir da cal elaborouse un listado inicial de tipos de bosques existentes na Devesa da Rogueira e o seu entorno máis próximo. A continuación, para completar a información sobre os tipos de bosques xa coñecidos e recoller información florística e ambiental (fisiografía, material de partida dos solos, influencia humana) dos bosques non estudados previamente, realizáronse varias campañas de campo ao longo do período 2009-2013, nas que se fixeron novos inventarios de vexetación aplicando a metodoloxía fitosociolóxica sigmatista (Braun-Blanquet 1979). Os novos datos integráronse cos primeiros construíndo táboas de inventarios florísticos, a traveso das que se avaliaron as similitudes e diferenzas existentes entre os dous bloques de información compilada, tendo en conta as referencias bibliográficas dispoñibles. Unha vez establecidas as tipoloxías de bosques recoñecidas e a relación cos factores do medio e antrópicos que inflúen na súa distribución na área de estudo, procedeuse á súa 
delimitación cartográfica empregando técnicas de fotointerpretación sobre as ortofotografías do PNOA correspondentes ao ano 2011, mediante un Sistema de Información Xeográfica (SIX). O software empregado foi ArcGIS 10.1 (ESRI 2012). A superficie non arborada da área de estudio foi teselada utilizando unidades de carácter máis xenérico e integrador (rochedos, formacións herbáceas, matogueiras, plantacións forestais). A cartografía resultante presenta unha resolución equivalente a unha escala 1:1.000, correspondendo o tamaño mínimo de tesela a 12,5 $\mathrm{m}^{2}$. A partir dela obtivéronse os valores de superficie ocupada por cada unha das unidades cartográficas definidas. Esta información utilizouse para discutir a importancia fitocenótica do enclave estudado dentro do contexto bioxeográfico no que se enmarcan as montañas do occidente da Cordillera Cantábrica.

$\mathrm{Na}$ taxonomía florística seguíronse as propostas de Flora iberica (Castroviejo 1986-2012), incluídas as modificacións e correccións taxonómicas que figuran na páxina web desta obra soportada polo CSIC (http://www.floraiberica.es/), e Flora Europea (Tutin et al. 1964-1980), adaptándose a unha notación binomial resumida os casos de taxóns cun rango inferior ao de especie (subespecies ou variedades) por razóns de economía do espazo. Nas cuestións sintaxonómicas (comunidades vexetais) tomáronse como referencia os traballos publicados por Rivas-Martínez et al. (2001, 2002, 2007, 2011) e Rodríguez Guitián et al. (2012).

\section{Resultados}

A caracterización das comunidades arboradas da área de estudo susténtase nun total de 103 inventarios fitosociolóxicos, cuxa localización se amosa na figura 1c, dos que $78(75,7 \%$ do total) foron obtidos durante a realización dos traballos de campo. A análise e confrontación desta información coa previamente existente (Amigo Vázquez 1984, Izco et al. 1986, Giménez de Azcárate 1993, Rodríguez Guitián \& Amigo Vázquez 2009b, Rodríguez Guitián et al. 2000, 2009, 2012) conduciu á discriminación dun total de 21 tipos diferentes de bosques, practicamente todos os posibles de entre os descritos para o conxunto das montañas orocantábricas occidentais do territorio galego, a excepción dos acebaiserbedais, sobreirais e as turbeiras arboradas (Rodríguez Guitián et al. 2012). Na caracterización das tipoloxías recoñecidas, que constitúe o corpo principal deste traballo, diferenciase entre bosques de carácter climatófilo (aqueles cuxa distribución está condicionada principalmente por factores climáticos) e de tipo edafo-higrófilo (aqueles cuxa distribución está asociada principalmente aos solos húmidos da beira dos cursos fluviais). Na Táboa 2 indícanse a superficie ocupada por cada tipoloxía de bosques recoñecida, precisando os tamaños mínimo e máximo de teselas delimitadas, e a porcentaxe que este valor supón con respecto ás superficies arborada e total da área de estudo. A tesela de menor tamaño delimitada cobre $34,0 \mathrm{~m}^{2}$ e pertence á categoría de "aciñeirais calcícolas"; a maior ocupa 36,2 ha e correspondese cunha "reboleira silicícola". A súa distribución espacial representase na Figura 3 . En conxunto, os bosques e plantacións tradicionais (soutos) ocupan algo máis de 310 ha, equivalente ao $71 \%$ do territorio estudado, seguidos das matogueiras (19\%), as formacións herbáceas $(8 \%)$, rochedos $(1 \%)$ e piñeirais de repoboación (<1\%).

\section{Bosques climatófilos}

\section{Bidueirais climatófilos (quionófilos)}

Bosques dominados polo bidueiro (Betula pubescens) con participación doutras especies arbóreas pioneiras ou heliófilas, como o capudre (Sorbus aucuparia), a abeleira (Corylus avellana) e o paleiro (Salix caprea). Distribúense ao longo dunha estreita faixa comprendida entre os $1.300 \mathrm{e}$ os $1.500 \mathrm{~m}$ de altitude (Figura 3), constituíndo o límite superior do arborado nas ladeiras máis avesías. Trátase dun tipo de bosque característico do piso supratemperado superior das montañas do cuadrante NW ibérico, adaptado a curtos períodos vexetativos e soportar prolongados períodos de innivación (carácter quionófilo)(Amigo Vázquez 1984, Rodríguez Guitián et al. 2000). Na Devesa da Rogueira, este tipo de bosque ocupa unhas 20 ha de vertentes de elevada inclinación e con abundantes afloramentos rochosos, sobre solos acedos moi pouco evolucionados, derivados de lousas e cuarcitas.

Son bosques de mediana talla (10-15 m de altura) e estrutura irregular dominados por árbores tortuosas e de bases curvadas debido aos derribos que causan os temporais invernais e o efecto mecánico de empuxe que provoca a acumulación e reptación de grandes espesores de neve en ladeiras de forte inclinación. Entre as especies de plantas vasculares que caracterizan o seu sotobosque pódense citar Erica arborea, Vaccinium myrtillus, Avenella flexuosa, Luzula sylvatica, Saxifraga spathularis, Lastrea limbosperma, Erythronium dens-canis ou Narcissus asturiensis, así como un extenso conxunto de grandes plantas herbáceas (megaforbias) características de solos acedos humíferos e húmidos que medran nos recháns nos que se mantén a neve até finais da primavera, como Valeriana montana, Aconitum neapolitanum, Allium victorialis, Adenostyles hybrida, etc.

Desde o punto de vista fitosociolóxico, estes bosques encádranse dentro da subasociación típica (betuletosum celtibericae) da asociación Luzulo henriquesii-Betuletum celtibericae (Izco et al. 1986a), de ampla distribución ao longo das montañas silíceas da Cordillera Cantábrica e Montañas Galaico-Durienses. Na Táboa 3 apórtase información florística detallada dos bidueirais deste tipo presentes na área de estudo.

\section{Bidueirais seriais}

A pesar de estar, como os anteriormente comentados, dominados polo bidueiro, estes bosques presentan unha fisionomía, estrutura e composición florística ben distintas debido, principalmente, a que se desenvolven en niveis altitudinais sensiblemente inferiores, entre os 800 e $1.100 \mathrm{~m}$ de altitude (termotipos mesotemperado superior e supratemperado inferior)(Figura 3). Esta peculiaridade permite que as árbores teñan uns toros moito máis esveltos, a miúdo multicaules, e acaden densidades moi elevadas. 


\begin{tabular}{|c|c|c|c|c|c|c|c|}
\hline Unidades cartográficas & $\begin{array}{c}\mathrm{N}^{0} \text { inv. } \\
\text { (prop./bib.) }\end{array}$ & $\begin{array}{l}\text { Sup. } \\
\text { (ha) }\end{array}$ & $\begin{array}{c}\text { Tamaño } \\
\text { mínimo (ha) }\end{array}$ & $\begin{array}{c}\text { Tamaño } \\
\text { máximo (ha) }\end{array}$ & $\begin{array}{c}\text { \% Sup. } \\
\text { arborada }\end{array}$ & $\begin{array}{l}\% \text { Sup. } \\
\text { total }\end{array}$ & $\begin{array}{c}\text { Tipo de hábitat } \\
\text { Anexo I DC92/437CEE }\end{array}$ \\
\hline \multicolumn{8}{|l|}{ Bosques climatófilos } \\
\hline Bidueirais quionófilos & $4(3 / 1)$ & 20,4 & 0,0169 & 19,634 & 6,6 & 4,7 & - - - \\
\hline Bidueirais seriais & $2(2 / 0)$ & 1,3 & 0,0262 & 0,4394 & 0,4 & 0,3 & -- \\
\hline Bosques de capudres e paleiros & $2(1 / 1)$ & 4,4 & 0,0369 & 1,7261 & 1,4 & 1,0 & - - - \\
\hline Faiais silicícolas & $15(5 / 10)$ & 32,8 & 0,1354 & 13,424 & 10,6 & 7,5 & 9120 \\
\hline Faiais calcícolas & $7(5 / 2)$ & 5,3 & 0,1176 & 1,7165 & 1,7 & 1,2 & 9150 \\
\hline Carballais albares heliófilos & $4(4 / 0)$ & 51,6 & 0,0178 & 19,595 & 16,5 & 11,9 & 9230 \\
\hline Carballais albares umbrófilos & $6(5 / 1)$ & 36,2 & 0,1878 & 8,4462 & 11,7 & 8,3 & 9230 \\
\hline "Carballais ananos" & $3(3 / 0)$ & 2,8 & 0,0057 & 1,0399 & 0,9 & 0,6 & 9230 \\
\hline Carballais albares calcícolas & $2(2 / 0)$ & 4,5 & 0,0361 & 1,4333 & 1,5 & 1,0 & 9230 \\
\hline Reboleiras silicícolas & $6(4 / 2)$ & 79,1 & 0,0102 & 36,203 & 25,4 & 18,2 & 9230 \\
\hline Reboleiras calcícolas & $5(4 / 1)$ & 12,0 & 0,0171 & 4,3994 & 3,9 & 2,8 & 9230 \\
\hline Bosques mixtos silicícolas & $5(5 / 0)$ & 16,3 & 0,0603 & 8,0102 & 5,3 & 3,7 & $9180^{*}$ \\
\hline Bosques mixtos calcícolas & $5(5 / 0)$ & 5,6 & 0,0215 & 2,7393 & 1,8 & 1,3 & $9180^{*}$ \\
\hline Abeledos silicícolas & $7(5 / 2)$ & 2,6 & 0,0228 & 0,7039 & 0,8 & 0,6 & $9180^{*}$ (p.p) \\
\hline Abeledos calcícolas & $11(9 / 2)$ & 13,2 & 0,0230 & 2,8538 & 4,3 & 3,0 & 9180* (p.p.) \\
\hline Aciñeirais calcícolas & $8(6 / 2)$ & 7,2 & 0,0034 & 1,4105 & 2,3 & 1,7 & 9340 \\
\hline Espiñais & $2(2 / 0)$ & 7,3 & 0,0072 & 1,3960 & 2,4 & 1,7 & - - - \\
\hline Soutos silicícolas & $2(2 / 0)$ & 2,3 & 0,0415 & 0,5683 & 0,7 & 0,5 & 9260 \\
\hline \multicolumn{8}{|l|}{ Bosques edafohigrófilos } \\
\hline Bidueirais riparios & $1(1 / 0)$ & 0,2 & 0,2482 & 0,2482 & 0,1 & $<0,1$ & 91E0* \\
\hline Freixidos riparios & $3(2 / 1)$ & 4,6 & 0,5635 & 2,9977 & 1,5 & 1,1 & 91E0* \\
\hline Abeledos riparios calcícolas & $2(2 / 0)$ & 0,6 & 0,2852 & 0,3193 & 0,2 & 0,1 & 91E0* \\
\hline Total bosques & & 310,3 & $\ldots$ & $\ldots$ & 100,0 & 71,2 & \\
\hline Rochedos & - - & 5,5 & 0,0078 & 0,2596 & $-\ldots$ & 1,2 & $-\ldots$ \\
\hline Formacións herbáceas & - - & 36,2 & 0,0289 & 7,1135 & - - - & 8,3 & $-\ldots$ \\
\hline Matogueiras & - . - & 81,6 & 0,0354 & 25,0692 & - . - & 18,7 & - - - \\
\hline Plantacións de piñeiros & - - & 2,7 & 0,3620 & 2,3290 & -- & 0,6 & -- \\
\hline Total unidades cartográficas & 102 & 436,3 & 0,0012 & 36,2028 & & 100,0 & \\
\hline
\end{tabular}

Táboa 2.- Distribución do número de inventarios utilizados na caracterización dos tipos de bosques identificados na área de estudo (entre paréntese sinalase o número de inventarios propios e obtidos de fontes bibliográficas), superficie ocupada polas unidades cartográficas representadas, tamaños mínimo e máximo das teselas, porcentaxe de cada categoría con respecto á superficie arborada e total da área de estudo e correspondencia cos tipos de hábitats do Anexo I da DC 92/43/CEE

Paralelamente, redúcese o número de pés doutras especies arbóreas presentes no nivel de copas, aparecendo de xeito puntual individuos de carballo (Quercus robur, Q. petraea), cerdeira brava (Prunus avium), freixo (Fraxinus excelsior) e, nas localizacións a menor altitude, até castiñeiro (Castanea sativa). De forma maioritaria, estes bidueirais medran sobre solos pobres en nutrientes e de $\mathrm{pH}$ acedo formados a partir de lousas e cuarcitas, aínda que en ocasións poden aparecer sobre coluvións con unha certa proporción de materiais carbonatados.

A composición florística do sotobosque destes bidueirais tamén difire da dos supratemperados, pois nel abundan as gramíneas (Holcus mollis, Agrostis capillaris, Poa nemoralis), algunhas especies gabeadoras (Hedera hibernica, Lonicera hispanica) e as silvas (Rubus sp.), como xa advertíu Amigo Vázquez (1984). Polo xeral, este tipo de bidueirais medran en áreas antigamente ocupadas por cultivos, prados de sega ou tenzas nas que se fixeron cortas a feito do arborado preexistente. O carácter pouco lonxevo do bidueiro fai que, desde o punto de vista temporal, estas formacións estean abocadas, pasados uns decenios, a verse substituídas por outras dominadas por especies de vida máis longa, como carballos, rebolos ou faias. Por esta causa se lles inclúe dentro dos denominados bosques secundarios ou seriais.

No plano fitosociolóxico pertencen á asociación Holco mollis-Betuletum celtibericae, na súa variante orocantábrica
(Amigo \& Romero 1998, Rivas-Martínez et al. 2002). A pesar de que nas montañas orientais de Galicia este tipo de bosque é frecuente, a superficie estimada que ocupan na Devesa da Rogueira é bastante reducida (algo máis de 1 ha). Algúns exemplos da composición florística e do ambiente no que medran estes bidueirais seriais amosanse na Táboa 3.

\section{Bosques de capudres e paleiros}

Son bosques de pequena talla $(6-14 \mathrm{~m})$ e fisionomicamente un tanto irregulares, dominados polo capudre (Sorbus aucuparia) e o paleiro (Salix caprea), con presenza máis puntual do bidueiro (Betula pubescens), a abeleira (Corylus avellana) e o pradairo (Acer pseudoplatanus), que medran en ladeiras e valgadas secas avesías, a miúdo nas inmediacións de faiais silicícolas. O seu ámbito bioclimático característico sitúase dentro do piso supratemperado, sobre solos relativamente fondos, a miúdo de carácter coluvial, derivados de rochas silíceas (lousas, cuarcitas, xistos). As vertentes nas que aparecen adoitan ser empinadas (26$36^{\circ}$ ). Como no caso dos bidueirais seriais, este tipo de bosques considérase un tipo particular de bosque secundario ou fase de recuperación do arborado dentro do dominio dos faiais silicícolas que se comentarán máis adiante (Rodríguez Guitián et al. 2005a).

O sotobosque deste tipo de formacións arbóreas caracterízase por unha elevada riqueza en especies 
herbáceas, entre as que salientan pola súa constancia Viola riviniana, Stellaria holostea, Ranunculus tuberosus, Poa nemoralis, Lilium martagon, Daphne laureola, Omphalodes nitida, Pteridium aquilinum ou Potentilla erecta. O feito de situárense en ambientes avesíos e de se desintegraren doadamente os restos foliares das especies arbóreas dominantes favorece a presenza de xeófitos habituais noutros tipos de bosques presentes tamén na Rogueira, como Mercurialis perennis, Paris quadrifolia, Polygonatum verticillatum ou Dryopteris dilatata.
A unidade fitosociolóxica que integra este tipo de bosques é a asociación Sorbo aucupariae-Salicetum capreae, exclusiva das montañas de Ancares, O Cebreiro e O Courel. Aínda que son relativamente frecuentes nesta última serra (cf. Rodríguez Guitián et al. 2005a), na Devesa da Rogueira concéntranse formando pequenos núcleos (total de 4,4 ha) no seu extremo $\mathrm{E}$ (Figura 3 ). Na Táboa 3 adxuntase información acerca da composición florística e condicións ambientais nas que medran algúns dos rodais estudados deste tipo de bosque.

Táboa 3.- Composición florística de bidueirais quionófilos (inv. 1-4), bidueirais seriais (inv. 5-6) e bosques de capudres e paleiros (inv. 7-8)

\begin{tabular}{|c|c|c|c|c|c|c|c|c|}
\hline $\mathrm{N}^{\circ}$ de orde & 1 & 2 & 3 & 4 & 5 & 6 & 7 & 8 \\
\hline Área $\left(m^{2}\right)$ & 300 & 300 & 300 & 314 & 300 & 300 & 120 & 100 \\
\hline Altura $E_{1}(m)$ & 10 & 12 & 18 & 15 & 14 & 18 & 6 & 8 \\
\hline Cob. $E_{1}(>4,0 \mathrm{~m})(\%)$ & 60 & 100 & 100 & 80 & 100 & 100 & 70 & 100 \\
\hline Cob. $E_{2}(1,5-4,0 \mathrm{~m})(\%)$ & --- & 20 & 20 & 20 & 35 & 10 & 60 & 30 \\
\hline Cob. $E_{3}(<1,5 \mathrm{~m})(\%)$ & --- & 90 & 80 & 60 & 60 & 100 & 80 & 100 \\
\hline Altitude (m) & 1400 & 1360 & 1350 & 1335 & 850 & 890 & 1295 & 1415 \\
\hline Pendente $\left({ }^{\circ}\right)$ & 60 & 32 & 38 & 35 & 30 & 30 & 36 & 26 \\
\hline Orientación & $\mathrm{N}$ & NE & $\mathrm{N}$ & $\mathrm{N}$ & NE & WSW & NNW & NNE \\
\hline $\mathrm{N}^{0}$ taxóns & 17 & 24 & 30 & 18 & 28 & 18 & 30 & 38 \\
\hline \multicolumn{9}{|c|}{$E_{1}(>4,0 \mathrm{~m})+E_{2}(>1,5-4,0 \mathrm{~m}):$} \\
\hline Betula pubesc & 2 & 5 & 4 & 4 & 5 & 5 & $\cdot$ & 1 \\
\hline Sorbus aucupa & 2 & 1 & 1 & 2 & + & . & 5 & 2 \\
\hline Erica arborea & 3 & 1 & + & 1 & 1 & 1 & . & + \\
\hline Corylus avellana & r & 1 & 1 & 1 & 1 & 1 & . & . \\
\hline Quercus x rosacea & 2 & · & 1 & 2 & · & $\cdot$ & 1 & . \\
\hline Ilex aquifolium & $\cdot$ & 1 & 2 & 4 & + & . & · & · \\
\hline Fagus sylvatica & $\cdot$ & 1 & 1 & 2 & + & . & · & . \\
\hline Salix caprea & $\cdot$ & $\cdot$ & 1 & · & 1 & · & · & 4 \\
\hline Quercus pyrenaica & $\cdot$ & - & - & · & + & 1 & 1 & . \\
\hline \multicolumn{9}{|c|}{ Taxóns característicoas de asociacións } \\
\hline Vaccinium myrtillus & 3 & 1 & 2 & 2 & . & . & $\cdot$ & 1 \\
\hline Luzula sylvatica & 2 & 5 & 3 & 3 & · & · & . & 1 \\
\hline Teucrium scorodonia & . & + & + & . & 1 & 2 & 1 & . \\
\hline Saxifraga spathularis & 2 & $\cdot$ & 1 & 2 & $\cdot$ & $\cdot$ & · & 1 \\
\hline Oxalis acetosella & $\cdot$ & 1 & 1 & 1 & $\cdot$ & · & · & 3 \\
\hline Dryopteris dilatata & + & 1 & 1 & . & . & . & . & 1 \\
\hline
\end{tabular}

\begin{tabular}{|c|c|c|c|c|c|c|c|c|}
\hline $\mathbf{N}^{0}$ de orde & 1 & 2 & 3 & 4 & 5 & 6 & 7 & 8 \\
\hline Dryopteris filix-mas & $\cdot$ & 1 & 1 & $\cdot$ & $\cdot$ & + & $\cdot$ & 1 \\
\hline Polygonatum verticillatum & + & + & 1 & . & . & . & . & 1 \\
\hline Crepis lampsanoides & $\cdot$ & + & + & 1 & . & . & $\cdot$ & 1 \\
\hline Lonicera hispanica & . & 1 & $\cdot$ & + & + & + & . & 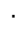 \\
\hline Athyrium filix-femina & · & 1 & 1 & & $\cdot$ & . & . & 2 \\
\hline Avenella flexuosa & . & 1 & 1 & $0^{\circ}$ & + & . & . & . \\
\hline \multicolumn{9}{|c|}{ Taxóns característicos do orde Fagetalia sylvaticae } \\
\hline Daphne laureola & $\cdot$ & $\cdot$ & + & . & $\cdot$ & $\cdot$ & + & 1 \\
\hline Lilium martagon & $\cdot$ & $\cdot$ & $\cdot$ & . & $\cdot$ & $\cdot$ & + & + \\
\hline \multicolumn{9}{|c|}{ Taxóns característicos da clase Querco-Fagetea } \\
\hline Viola riviniana & $\cdot$ & $\cdot$ & $\cdot$ & 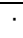 & 1 & $\cdot$ & 1 & 1 \\
\hline Poa nemoralis & . & . & . & . & . & + & + & + \\
\hline Stellaria holostea & . & . & . & . & . & . & 1 & 1 \\
\hline Euphorbia dulcis & . & . & + & . & . & · & + & . \\
\hline Ajuga reptans & . & . & . & . & + & . & . & + \\
\hline Ranunculus tuberosus & 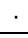 & . & $\cdot$ & · & $\cdot$ & $\cdot$ & + & + \\
\hline \multicolumn{9}{|c|}{ Taxóns característicos da clase Salici-Populetea } \\
\hline Polystichum setiferum & ${ }^{\circ}$ & $\cdot$ & $\cdot$ & . & + & 1 & $\cdot$ & . \\
\hline \multicolumn{9}{|l|}{ Outros taxóns } \\
\hline Pteridium aquilinum & . & + & $\cdot$ & . & 1 & 2 & 1 & 1 \\
\hline Valeriana montana & 1 & + & 1 & . & · & · & · & 1 \\
\hline Rubus sp. & . & . & + & . & 1 & + & + & 1 \\
\hline Allium victorialis & 1 & 2 & 1 & . & . & . & $\cdot$ & · \\
\hline Omphalodes nitida & + & . & . & · & . & . & 1 & 1 \\
\hline Doronicum pubescens & 1 & . & + & . & . & . & - & 1 \\
\hline
\end{tabular}

\section{Taxóns de baixa frecuencia:}

En $\mathbf{E}_{1}+\mathrm{E}_{2}$ : Acer pseudoplatanus: + en 6 e + en 7; Castanea sativa: 1 en 6; Crataegus monogyna: 1 en 5 e 1 en 8 ; Fraxinus excelsior: + en 5; Prunus spinosa: + en 5; Quercus petraea: 1 en 2 e 1 en 6; Quercus robur: 1 en 5; Salix atrocinerea: + en 5 e 1 en 8 ; Taxus baccata: + en 1 e 1 en 4.

$\mathrm{E}_{3}$ : Característicos de asociación: Anemone nemorosa: + en 3 e 1 en 4; Holcus mollis: 2 en 6 e + en 7; Polypodium vulgare: + en 3 e + en 4. Característicos de Fagetalia sylvaticae: Epilobium montanum: + en 8; Mercurialis perennis: 1 en 7; Paris quadrifolia: + en 8; Potentilla sterilis: + en 7; Primula acaulis: 1 en 7; Scrophularia alpestris: r en 8. Característicos de Quercetalia roboris: Blechnum spicant: + en 3; Hypericum pulchrum: + en 6; Lathyrus linifolius: + en 7; Melampyrum pratense: 1 en 1. Característicos de Querco-Fagetea: Aquilegia vulgaris: + en 7; Dryopteris affinis: 1 en 4; Euphorbia amygdaloides: + en 4; Hedera hibernica: 4 en 6; Helleborus foetidus: + en 7; Hyacinthoides non-scripta: + en 7; Poa chaixii: 1 en 8; Polystichum aculeatum: + en 7. Outros taxóns: Adenostyles hybrida: r en 8; Agrostis capillaris: 1 en 5; Alchemilla sp.: $r$ en 8; Angelica major: + en 8; Arnica montana: + en 2; Brachypodium rupestre: 1 en 5 e 3 en 7; Carex sp.: r en 8; Clinopodium vulgare: + en 7; Cruciata glabra: + en 8; Dactylis glomerata: + en 5 e + en 7; Digitalis purpurea: r en 3 e + en 6; Eupatorium cannabinum: + en 5; Festuca rubra: + en 1; Fragaria vesca: + en 5 e + en 8; Heracleum sphondylium: 1 en 8; Lamium maculatum: + en 8; Lastrea limbosperma: + en 2; Narcissus asturiensis: + en 2 e + en 3; Polygonatum odoratum: + en 7; Potentilla erecta: 1 en 7 e + en 8; Ranunculus platanifolius: 1 en 8; Rumex acetosa: + en 5 e + en 7; Thalictrum minus: + en 7; Urtica dioica: + en 8; Veronica chamaedrys: + en 5 e + en 7.

Localidades (a notación numérica entre paréntese indica a situación na cuadrícula UTM de $1 \mathrm{~km}$, fuso 29T): 1: Lu: Folgoso do Courel, Devesa de Rogueira, 654/4718 [Amigo Vázquez (1984): táb. 11: inv. 4]. 2: Lu: Folgoso do Courel, Moreda, Devesa da Rogueira, extremo W, baixo o camiño, 654/4718. 3: Lu: Folgoso do Courel, Moreda, Devesa da Rogueira, biduedo entre os dous camiños, por baixo das Augas, 654/4718. 4: Lu: Folgoso do Courel, Devesa da Rogueira, parte superior, 654/4718. 5: Lu: Folgoso do Courel, Moreda, entrada inferior da Devesa de Rogueira, 654/4719. 6: Lu: Folgoso do Courel, Moreda, entrada inferior da Devesa de Rogueira, 654/4719. 7: Lu: Folgoso do Courel, inmediacións de A Tara, 655/4719. 8: Lu: Folgoso do Courel, Vertente NE do Monte Formigueiros, 656/4719 [Rodríguez Guitián et al. (2005a): táb. 1: inv. P04]. 


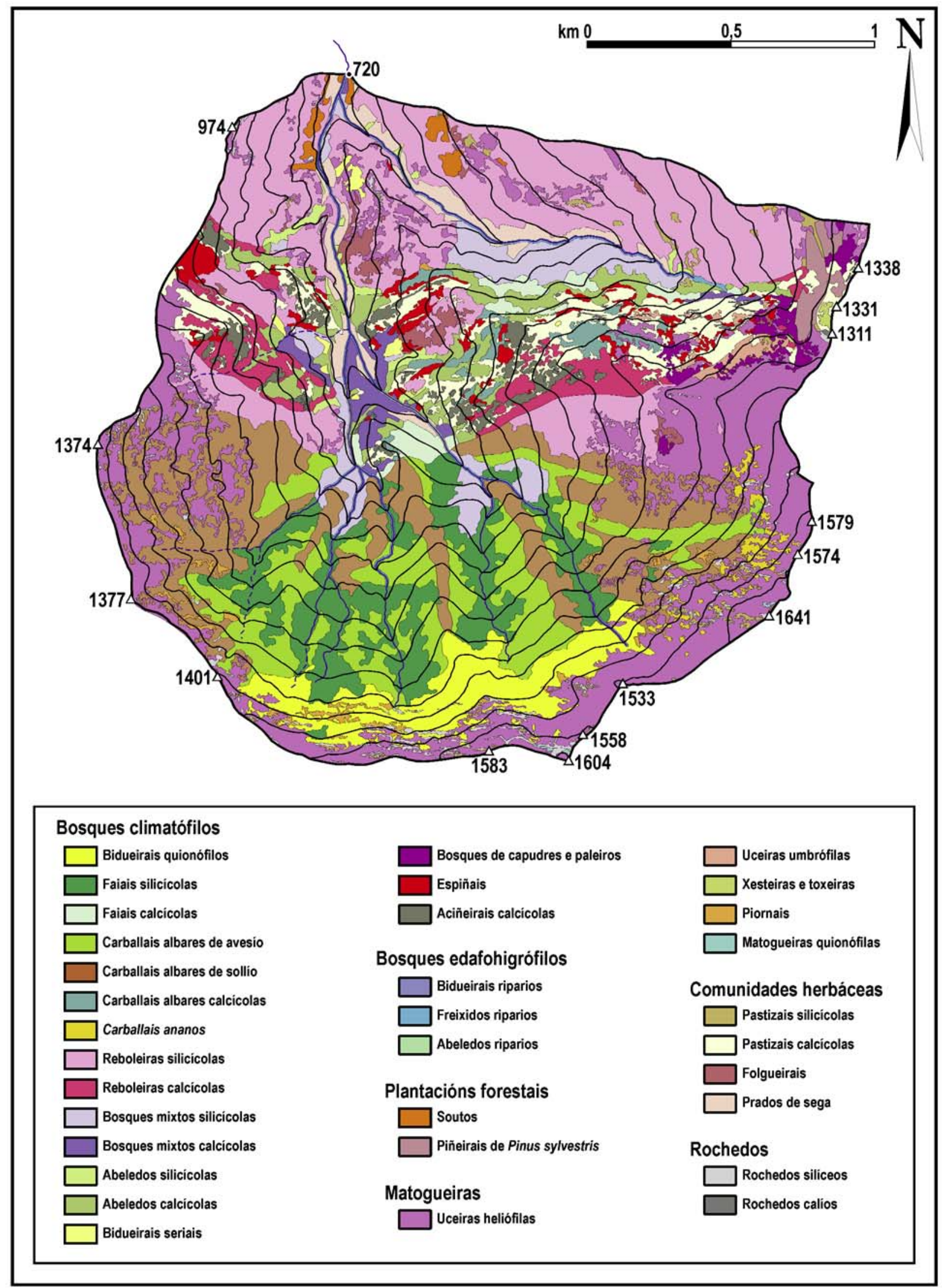

Figura 3.- Cartografía da cuberta vexetal da área de estudo. Equidistancia das curvas de nivel: $50 \mathrm{~m}$ 


\section{Faiais silicícolas (acidófilos ou oligotrofos)}

Bosques dominados pola faia (Fagus sylvatica) que medran en solos pobres en nutrientes, derivados de lousas, xistos, areíscas e cuarcitas. A faia tende a ser a árbore exclusiva no nivel de copas nos rodais máis vellos e menos afectados polo derribos, pero nos enclaves máis elevados ou cando se trata de fragmentos que estiveron sometidos a cortas ou aproveitamentos para leñas até hai poucos decenios, non é rara a presenza de pés doutras especies, como capudres (Sorbus aucuparia), bidueiros (Betula pubescens) ou carballos albares (Quercus petraea). Tamén é frecuente nestas situacións que se forme un subpiso con abundante acebo (Ilex aquifolium) mentres nas partes máis elevadas da Rogueira faise abundante o teixo (Taxus baccata).

Estes faiais medran na Devesa da Rogueira entre os 980 e os $1.425 \mathrm{~m}$ de altitude (pisos bioclimáticos mesotemperado superior e supratemperado), sendo máis abundantes na faixa dos 1.150-1.300 m (Figura 3). Os solos sobre os que se asentan adoitan ser pedregosos e de fondura moi irregular $(10-40 \mathrm{~cm})$, cun característico espeso manto orgánico de follas e restos de pólas miúdas (Táboa 1). A estrutura e forma das árbores varía moito ao longo do gradiente de altitude comentado, pois nas partes baixas, máis abrigadas e menos propensas a cargarse de neve, os fustes tenden a ser máis altos e esveltos, mentres que no seu límite superior predominan árbores moi ramificadas desde a porción media do toro, debido ás mesmas causas que se comentaron para o caso dos bidueirais quionófilos.

A flora que caracteriza o sotobosque destes faiais está composta, principalmente, por algunhas matas (Vaccinium myrtillus, Daphne laureola) e un amplo grupo de plantas bulbosas e rizomatosas (Luzula sylvatica, Mercurialis perennis, Anemone nemorosa, Dryopteris filixmas, Euphorbia dulcis, Galium odoratum, Lilium martagon, Oxalis acetosella, Polystichum setiferum), xunto a Milium effusum, Crepis lampsanoides, Omphalodes nitida, Sanicula europea ou Saxifraga spathularis.

Desde o punto de vista fitosociolóxico, estes faiais inclúese na asociación Omphalodo nitidae-Fagetum sylvaticae, cuxa área de distribución restrinxese ás montañas do extremo occidental cantábrico, ao $\mathrm{W}$ da Reserva Integral de Muniellos (Asturias). Trátase do tipo de faial máis amplamente representado en Galicia (Rodríguez Guitián \& Ferreiro da Costa 2011) e na Devesa da Rogueira, onde cobre arredor das 33 ha. $\mathrm{Na}$ Táboa 4 adxuntanse diversos inventarios deste tipo de bosque recollidos na área de estudo.

\section{Faiais calcícolas (neutro-basófilos ou meso-eutrofos)}

Faiais que medran sobre solos derivados da alteración in situ de rochas carbonatadas (calías, dolomías) ou coluvións nos que estas litoloxías son predominantes. Na Devesa da Rogueira aparecen de xeito exclusivo na súa parte baixa, así como na vertente avesía do val do Carrozo da Muíña, entre os $980-1.150 \mathrm{~m}$ de altitude, no límite dos pisos bioclimáticos mesotemperado superior e supratemperado inferior (Figura 3). Os solos que sustentan estes faiais son moi pedregosos e con abundantes afloramentos rochosos, pero cunha disponibilidade de nutrientes maior que nos de tipo silíceo.

Os principais acompañantes da faia no estrato superior deste tipo de bosque son diferentes aos do caso anterior: pradairos (Acer pseudoplatanus), freixos (Fraxinus excelsior), espiños (Crataegus monogyna) e abeleiras (Corylus avellana). Tamén hai diferenzas nas especies do sotobosque, no que Galium odoratum, Polysticum setiferum, Hedera hibernica e Mercurialis perennis adoitan formar mestos e extensos tapices entre os que se intercalan numerosas especies herbáceas ausentes ou dificiles de atopar nos faiais sobre solos pobres, como Ornithogalum pyrenaicum, Corydalis cava, Neottia nidus-avis, Allium ursinum, Phyllitis scolopendrium, Clematis vitalba, Epipactis helleborine ou Ruscus aculeatus. $\mathrm{Na}$ actualidade, os faiais calcícolas ocupan arredor de 5 ha na área de estudo, principalmente no val do Carrozo da Muíña e no treito final do Regueiro do Freixedo.

A asociación vexetal que engloba os faiais calcícolas existentes na Serra do Courel recibe o nome de Neottio nidiavis-Fagetum sylvaticae (Rodríguez Guitián et al. 2009a); trátase dun tipo de bosque exclusivo desta área montañosa e dos Montes do Cebreiro, cuxos "parentes" máis próximos, pertencentes xa a outra asociación diferente (Carici sylvaticae-Fagetum sylvaticae), encontranse a case $50 \mathrm{~km}$ en liña recta cara ó NE, na vertente setentrional do Alto de Rañadoiro (Cangas de Narcea, Asturias)(Rodríguez Guitián \& Amigo 2009a, Díaz González 2010). Na Táboa 4 reuniuse a información dispoñible sobre este tipo de faiais na área de estudo.

\section{Carballais albares de sollío}

Carballais situados en tesos (divisorias de augas) e ladeiras fortemente insoladas dominados polo carballo albar (Quercus petraea) e os seus híbridos co carballo común (Quercus x rosacea) e o rebolo (Quercus x trabutii). É un tipo de bosque cunha ampla representación nas montañas do occidente da Cordilleira Cantábrica, entre os 1.200 e $1.500 \mathrm{~m}$ de altitude, como acontece na Serra dos Ancares. $\mathrm{Na}$ Devesa da Rogueira cubren gran parte do baixante que conforma a marxe dereita do Rego do Freixedo e a vertente oriental do Pico Polín, así como os tesos que delimitan as microcuncas existentes na cara $\mathrm{N}$ do Pico Formigueiros (Figura 3).

Trátase de bosques pouco mestos, debido ás características pedregosas e pouco favorables para o en raizamento dos terreos onde medran e a elevada insolación que reciben. As árbores capaces de sobrevivir nestas condicións presentan un aspecto chaparro (raramente superan os 8-10 m) e moi ramificado, sobre todo cando colonizan as posicións de teso. Acompañando aos diferentes tipos de carballos presentes poden atoparse capudres (Sorbus aucuparia) e, á sua sombra, piornos (Genista florida) e uces (Erica arborea). Por debaixo medra un tapiz discontinuo dominado por gramíneas (Festuca merinoi, Festuca paniculata, Avenella flexuosa, Holcus mollis), Linaria triornithophora, Stellaria holostea, Lonicera hispanica, Vaccinium myrtillus e Asphodelus macrocarpus. 
Táboa 4.- Composición florística de faiais silicícolas (oligotrofos)(inv. 1-15) e calcícolas (neutro-basófilos)(inv. 16-22)

\begin{tabular}{|c|c|c|c|c|c|c|c|c|c|c|c|c|c|c|c|c|c|c|c|c|c|c|}
\hline $\mathrm{N}^{0}$ de orde & 1 & 2 & 3 & 4 & 5 & 6 & 7 & 8 & 9 & 10 & 11 & 12 & 13 & 14 & 15 & 16 & 17 & 18 & 19 & 20 & 21 & 22 \\
\hline Área $\left(m^{2}\right)$ & 350 & 400 & 300 & 150 & 120 & 120 & 314 & 314 & 400 & 300 & 400 & 314 & 300 & 314 & 314 & 300 & 300 & 300 & 400 & 300 & 400 & 400 \\
\hline Altura $E_{1}(m)$ & --- & --- & --- & --- & --- & --- & 20 & 15 & 19 & 16 & 20 & 20 & 18 & 15 & 20 & 18 & 20 & 26 & 24 & 24 & 28 & 22 \\
\hline Cob. $E_{1}(>4,0 \mathrm{~m})(\%)$ & 90 & 90 & 95 & 95 & 95 & 100 & 100 & 100 & 100 & 100 & 100 & 100 & 100 & 90 & 100 & 100 & 100 & 100 & 100 & 100 & 100 & 100 \\
\hline Cob. $E_{2}(1,5-4,0 \mathrm{~m})(\%)$ & --- & --- & --- & --- & --- & --- & 10 & 75 & 35 & 35 & 15 & 20 & 25 & 60 & 10 & --- & --- & 15 & 20 & 15 & 20 & 30 \\
\hline Cob. $E_{3}(<1,5 \mathrm{~m})(\%)$ & 95 & 85 & 90 & 60 & 75 & 60 & 85 & 80 & 40 & 75 & 30 & 25 & 80 & 50 & 55 & 75 & 75 & 95 & 85 & 80 & 40 & 70 \\
\hline Altitude $(m)$ & 1300 & 950 & 1120 & 1320 & 1250 & 1200 & 1370 & 960 & 1320 & 1000 & 1325 & 1235 & 1200 & 1130 & 1030 & 970 & 1025 & 910 & 935 & 950 & 1060 & 1150 \\
\hline Pendente $\left({ }^{\circ}\right)$ & 45 & 30 & 30 & 30 & 30 & 25 & 38 & 30 & 20 & 40 & 30 & 25 & 40 & 34 & 55 & 38 & 32 & 36 & 36 & 38 & 40 & 42 \\
\hline Orientación & NE & $\mathrm{NE}$ & $\mathrm{N}$ & $\mathrm{N}$ & NW & NW & $\mathrm{N}$ & NNE & NNW & NNE & $\mathrm{N}$ & $\mathrm{NE}$ & $\mathrm{N}$ & $\mathrm{N}$ & $\mathrm{N}$ & NE & NNW & SW & SW & $\mathrm{NE}$ & NNE & NW \\
\hline $\mathrm{N}^{0}$ de taxóns & 25 & 28 & 21 & 26 & 26 & 25 & 25 & 24 & 34 & 37 & 31 & 20 & 38 & 26 & 31 & 43 & 37 & 47 & 51 & 47 & 35 & 53 \\
\hline \multicolumn{23}{|c|}{$E_{1}(>4,0 \mathrm{~m})+E_{2}(>1,5-4,0 \mathrm{~m}):$} \\
\hline Fagus sylvatica & 5 & 3 & 5 & 4 & 5 & 5 & 5 & 5 & 5 & 4 & 5 & 5 & 5 & 4 & 5 & 5 & 5 & 5 & 5 & 5 & 5 & 5 \\
\hline Ilex aquifolium & 1 & 2 & 2 & 1 & + & + & 2 & 4 & 1 & 2 & 2 & 4 & 1 & 3 & 2 & 2 & 1 & + & 1 & 1 & 2 & + \\
\hline Corylus avellana & . & 3 & $r$ & 1 & + & & + & 2 & 1 & 2 & . & . & 1 & 1 & 1 & 3 & 2 & 1 & 2 & 2 & 1 & 2 \\
\hline Sorbus aucuparia & 1 & 1 & + & 1 & . & . & 1 & 1 & 1 & & + & 1 & 1 & 1 & + & 1 & . & . & + & ${ }^{\circ}$ & + & 1 \\
\hline Acer pseudoplatanus & . & + & . & e & . & . & 1 & . & + & 2 & $r$ & . & . & . & + & 1 & + & 1 & 1 & + & . & . \\
\hline Taxus baccata & 1 & . & 1 & . & + & + & . & . & 3 & 1 & 5 & 1 & . & . & . & . & . & + & + & . & . & . \\
\hline Crataegus monogyna & . & . & . & . & . & . & . & . & . & . & . & 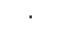 & . & . & + & 1 & 1 & 1 & 1 & 1 & 1 & 1 \\
\hline Quercus $\times$ rosacea & . & + & . & . & . & . & 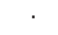 & 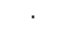 & . & 1 & . & . & . & 2 & + & 1 & . & 1 & & 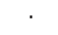 & & . \\
\hline Prunus avium & . & . & . & . & . & . & . & . & . & 1 & r & & . & 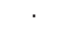 & + & . & . & . & + & . & . & . \\
\hline Quercus petraea & 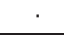 & . & 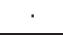 & . & . & . & . & 1 & . & & . & & $r$ & & . & . & . & . & 1 & . & . & . \\
\hline
\end{tabular}

Quercus petraea

$\mathrm{E}_{3}(<1,5 \mathrm{~m})$ :

Taxóns diferenciais de asociacións

Dryopteris dilatata

Dryopteris affinis

Vaccinium myrtillus

Valeriana montana

Omphalodes nitida

Blechnum spicant

Betula pubescens

Polystichum aculeatum

Avenella flexuosa

Neottia nidus-avis

Helleborus foetidus

Melittis melissophyllum

Ornithogalum pyrenaicum

Brachypodium rupestre

Mycelis muralis

Corydalis cava

Epipactis helleborine

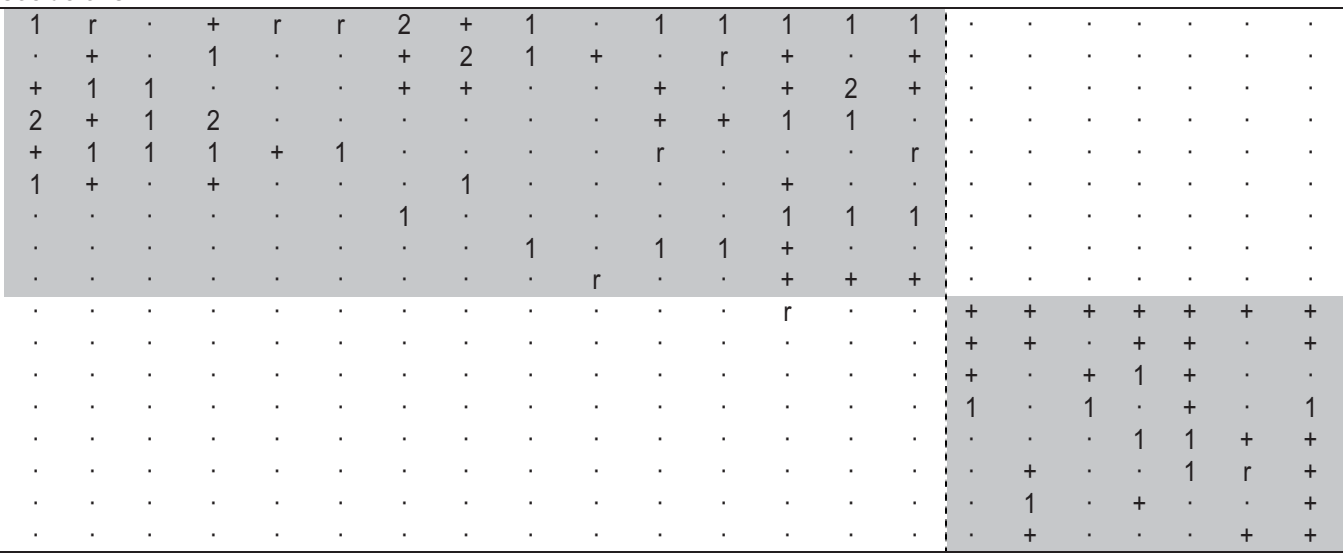

Taxóns característicos de asociacións

\begin{tabular}{|c|c|c|c|c|c|c|c|c|c|c|c|c|c|c|c|c|c|c|c|c|c|c|}
\hline Luzula sylvatica & 4 & 3 & 3 & 1 & 2 & 2 & 4 & 3 & 2 & 1 & + & 1 & 5 & 3 & 3 & 2 & + & & $\cdot$ & + & 1 & \\
\hline Daphne laureola & + & 1 & 1 & 1 & 1 & 1 & & 1 & 1 & 1 & + & + & . & . & + & 1 & + & 1 & 1 & 1 & 1 & 1 \\
\hline Galium odoratum & + & + & + & 1 & 3 & 4 & & . & & & 1 & 1 & + & . & & 1 & 1 & 2 & 2 & 1 & & 2 \\
\hline Hedera hibernica & 1 & 1 & 1 & . & 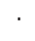 & . & . & 3 & & & & & & + & 3 & 3 & 2 & 2 & 3 & 1 & + & 1 \\
\hline Saxifraga spathularis & 1 & 1 & . & + & + & + & + & 1 & 1 & & + & & + & + & & + & 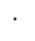 & + & . & r & & \\
\hline Euphorbia dulcis & 1 & + & + & 1 & 2 & + & . & + & & + & + & . & + & . & . & + & . & 1 & 1 & 1 & + & \\
\hline Lilium martagon & + & . & . & 2 & . & 1 & + & . & + & + & + & $r$ & + & . & 1 & + & + & 1 & + & . & . & + \\
\hline Polystichum setiferum & . & . & . & . & 1 & 2 & & 1 & & & + & & & . & 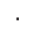 & 2 & 2 & 3 & 2 & 3 & 1 & 2 \\
\hline Oxalis & 1 & . & + & + & 1 & 2 & . & + & & & + & & & + & & . & + & . & . & & . & \\
\hline is filix-mas & + & 1 & 1 & . & + & . & 2 & . & 2 & & 1 & & & 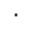 & & + & . & . & 1 & & + & + \\
\hline Polypodium vulgare & + & . & . & . & . & . & r. & + & + & + & + & . & + & $r$ & . & 1 & + & + & 1 & 1 & $\cdot$ & + \\
\hline Anemone nemorosa & + & . & . & + & 1 & + & 1 & + & . & 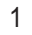 & + & . & + & 1 & + & . & . & . & . & $\cdot$ & + & \\
\hline Mercurialis perennis & . & + & . & . & + & + & . & . & + & 2 & . & . & . & . & . & 2 & 2 & 3 & 2 & 2 & 1 & \\
\hline uropaea & + & . & + & 1 & + & 2 & . & + & 1 & & + & . & & . & 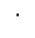 & . & & 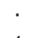 & + & & . & + \\
\hline iola & . & . & + & + & + & + & . & ${ }^{\prime}$ & & + & $x^{\prime}$ & . & - & . & . & + & + & 1 & + & + & . & \\
\hline Primuls & . & + & . & $\cdot$ & . & . & . & + & · & 1 & . & . & + & . & . & 1 & 1 & 1 & 2 & 1 & 1 & \\
\hline Hyacinthoides non-scripta & . & . & . & . & 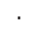 & ${ }^{\circ}$ & $r$ & . & + & 1 & . & . & . & . & + & 1 & 1 & 1 & + & 2 & 1 & \\
\hline
\end{tabular}

Taxóns fiferenciais de subas. tametosum communis

Tamus communis

Ruscus aculeatus

Phyllitis scolopendrium

Asplenium onopteris

Taxóns característicos do orde Fagetalia sylvaticae

Paris quadrifolia

Festuca altissima

Melica uniflora

Milium effusum

Moehringia trinervia 


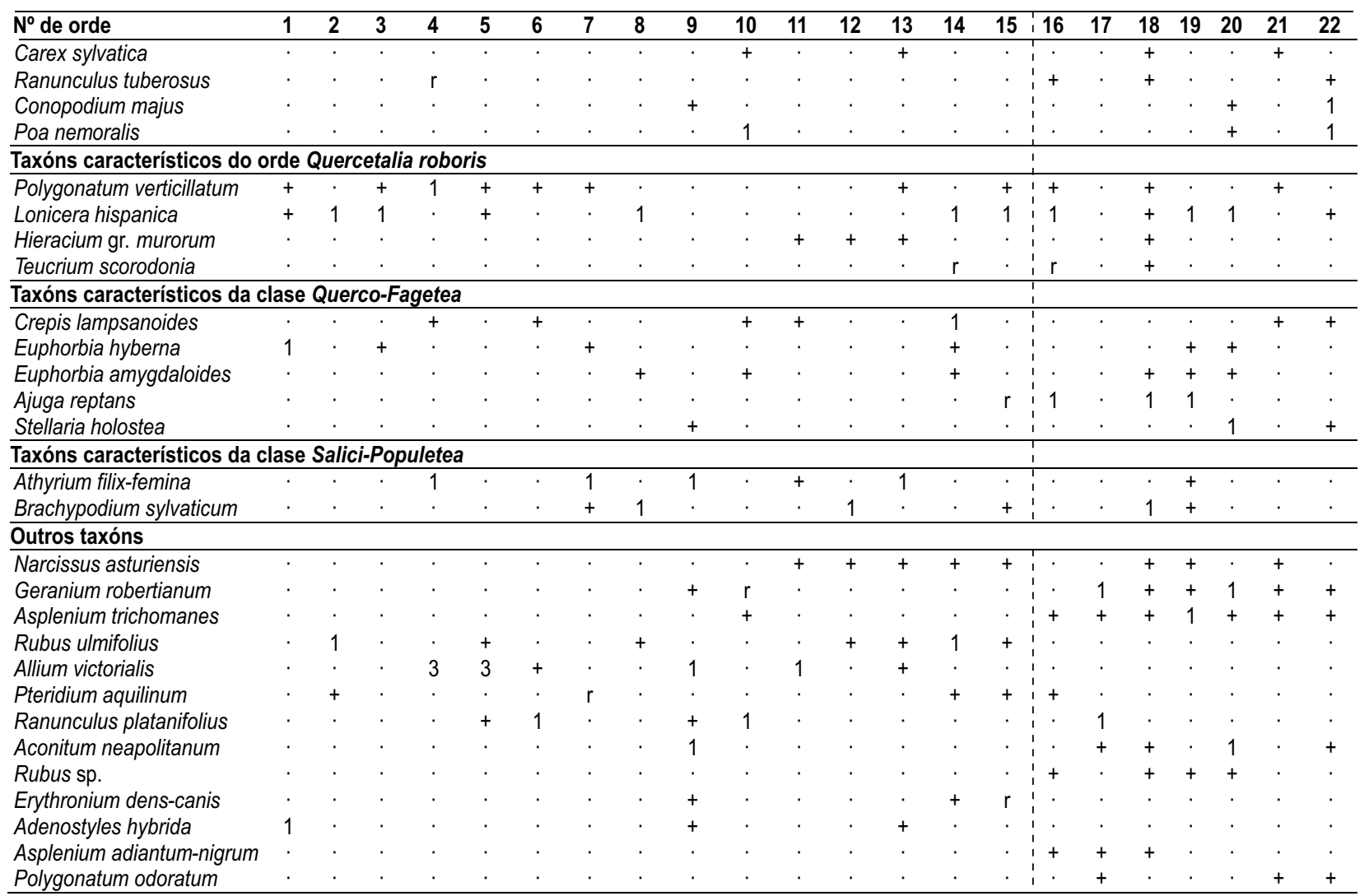

\section{Taxóns de baixa frecuencia:}

En $\mathrm{E}_{\mathbf{1}}+\mathrm{E}_{\mathbf{2}}$ : Cytisus scoparius: $r$ en 19; Erica arborea: + en 2; Frangula alnus:+ en 2; Fraxinus excelsior: + en 16 e + en 18; Genista florida:+ en 2; Quercus pyrenaica: 1 en 10 e 1 en 20; Rosa micrantha: + en 20; Rosa canina: + en 16 e + en 19; Ulmus glabra: + en 21 e 1 en 22.

$\mathrm{E}_{3}$ : Característicos de Fagetalia sylvaticae: Allium ursinum: 3 en 18 e + en 22; Cardamine impatiens: + en 20: Epilobium montanum: + en 20 e + en 22; Potentilla sterilis: + en 16 e + en 22; Veronica montana: + en 17. Característicos de Quercetalia roboris: Ceratocapnos claviculata: + en 7; Galium rotundifolium: + en 16; Lathyrus linifolius: r en 21; Melampyrum pratense: $r$ en 12 e + en 14; Physospermum cornubiense: + en 10; Poa chaixii: + en 13. Característicos de Querco-Fagetea: Doronicum plantagineum: 1 en 20; Euphorbia hiberna: + en 18 e + en $19 ;$ Melittis melissophyllum: + en 22. Outros taxóns: Ajuga pyramidalis: $r$ en 11; Angelica major. $r$ en 9; Arabis alpina: + en 22; Bromus ramosus: + en 19; Carex depauperata: + en 18; Chaerophyllum hirsutum: 1 en 17; Cystopteris fragilis: + en 21 e + en 22; Dactylorhiza sp.: + en 16; Doronicum pubescens: + en 7; Festuca merinoi: + en 22; Festuca gr. rubra: + en 22; Fragaria vesca: + en 22; Galium aparine: + en 17 e 1 en $20 ;$ Heracleum sphondylium: + en 19 e + en 20; Lapsana communis: + en 19; Laserpitium eliasii: + en 22; Lastrea limbosperma: 1 en $13 ;$ Narcissus pseudonarcissus: 1 en 9; Pimpinella major: 1 en 18 e + en 22; Polypodium cambricum: + en 22; Rumex acetosa: + en 22; Silene vulgaris: + en 19; Torilis arvensis: + en 22; Umbilicus rupestris: r en 10; Urtica dioica: + en 17 e + en 20; Veronica chamaedrys: + en 6; Vicia sepium: + en 19.

Localidades (a notación numérica entre paréntese indica a situación na cuadrícula UTM de $1 \mathrm{~km}$, fuso 29T): 1: Lu: Folgoso do Courel, Devesa de Rogueira; de Campa dos Carlistas a As Augas (653/4719) [lzco et al. (1986a): táboa1: inv.1]; 2: Lu: Folgoso do Courel, Devesa de Rogueira; bastante abajo, camino en zig-zag (653/4720) [lzco et al. (1986a): táboa 1: inv. 2]; 3: Lu: Folgoso do Courel, Devesa de Rogueira; bajando por el camino central (653/4720) [lzco et al. (1986a): táboa 1: inv. 4]; 4: Lu: Folgoso do Courel, Devesa de de Rogueira; por el camino de As Augas hacia a Lomba (653/4719) [lzco et al. (1986a): táboa 1: inv. 7]; 5: Lu: Folgoso do Courel, Devesa de Rogueira; unos $80 \mathrm{~m}$. por debajo de As Augas (653/4719) [lzco et al. (1986a): táboa 1: inv. 15]; 6: Lu: Folgoso do Courel, Devesa de Rogueira; unos 50 m. por debajo de As Augas, más arriba del no 15 por el camino (653/4719) [lzco et al. (1986a): táboa 1: inv. 16]; 7: Lu: Folgoso do Courel, Moreda, parte superior da Devesa da Rogueira. (655/4719) [Rodríguez Guitián et al. (2009): táboa 2: inv. 4]; 8: Lu: Folgoso do Courel, Moreda, Devesa da Rogueira, parte inferior (654/4719) [Rodríguez Guitián et al. (2009): táboa 2: inv. 8]; 9: Lu: Folgoso do Courel, Moreda, parte superior de la Devesa da Rogueira (654/4718) [Rodríguez Guitián et al. (2011): inv. páx. 323]; 10: Lu: Folgoso do Courel, Devesa da Rogueira, Val do Carrozo da Muiña (655/4720) [Rodríguez Guitián et al. (2000): táboa 2: inv. 10]; 11: Lu: Folgoso do Courel, Devesa da Rogueira, perto do desvío a As Augas (654/4718); 12: Lu: Folgoso do Courel, Devesa da Rogueira, parte superior por baixo do camiño á Louseira dos Carrís (654/4718); 13: Lu: Folgoso do Courel, Moreda, Devesa da Rogueira, ladeira a carón do primeiro rego, polo camiño da cabana de pastores (655/4718); 14: Lu: Folgoso do Courel, Devesa da Rogueira, parte media (654/4718); 15: Lu: Folgoso do Courel, Devesa da Rogueira, parte inferior antes do tramo calío (654/4719); 16: Lu: Folgoso do Courel, Moreda, Devesa da Rogueira, parte inferior (654/4719) [Rodríguez Guitián et al. (2009): táboa 3: inv. 23]; 17: Lu: Folgoso do Courel, Moreda, Carrozo da Muiña (655/4720) [Rodríguez Guitián et al. (2009): táboa 3: inv. 22]; 18: Lu: Folgoso do Courel, Moreda, Devesa da Rogueira, vertente W do teso calío, en contacto co Rego da Rogueira, augas abaixo da Fervenza (654/4719); 19: Lu: Folgoso do Courel, Moreda, Devesa da Rogueira, extremo inferior de A Tara, en contacto co Rego do Freixedo (654/4719); 20: Lu: Folgoso do Courel, Moreda, Carrozo da Muiña, extremo inferior (654/4719); 21: Lu: Folgoso do Courel, Moreda, Carrozo da Muiña, extremo superior (655/4719); 22: Lu: Folgoso do Courel, Moreda, Carrozo da Muiña, parte superior (655/4719). 
Este tipo de carballal ocupa na área de estudo algo máis de 51 ha, entre os 950 e os $1.500 \mathrm{~m}$ de altitude, principalmente dentro do piso bioclimático supratemperado. Inicialmente, considerouse incluír este tipo de bosques nunha comunidade particular baixo a denominación inédita de Sorbo aucupariae-Quercetum roboris (Amigo 1984), pero máis adiante optouse por asimilalos coa asociación orocantábrica Linario triornithophorae-Quercetum petraeae (Izco et al. 1999), descrita das montañas de Muniellos (Fernández Prieto \& Vázquez 1987). Na Táboa 5 reúnese a información recompilada sobre estes bosques na área de estudo.

\section{Carballais albares de avesío}

Trátase doutro tipo de bosque de ampla distribución nas montañas silíceas da Cordilleira Cantábrica, desde as inmediacións dos Picos de Europa até as montañas do Courel. Na Devesa da Rogueira conforman tiras alongadas que se intercalan entre os tesos e ladeiras solleiras colonizados polos carballais heliófilos e as proximidades das valgadas polas que discorren os regatos, na maior parte dos casos ocupadas por outros tipos de bosques dominados por especies máis esixentes en humidade, como bidueirais, faiais ou abeledos (Figura 3).

Desde o punto de vista fisionómico, son bosques máis cerrados que os de tipo heliófilo, con árbores corpulentas e relativamente esveltas, sobre todo nas proximidades de valgadas abrigadas. O nivel de copas, habitualmente situado entre os $12-20 \mathrm{~m}$ de altura, está dominado polo carballo albar (Quercus petraea) e o híbrido con $Q$. robur ( $Q$. $x$ rosacea), sendo habitual no caso da Devesa da Rogueira a presenza de faias, teixos, capudres e acibos. O estrato inferior está dominado por especies pouco tolerantes á luz directa do sol, como Luzula sylvatica, Vaccinium myrtillus, Saxifraga spathularis, Valeriana montana, Avenella flexuosa, Dryopteris dilatata ou D. filix-mas, ás que se unen outras especies frecuentes en bosques acidófilos (Lonicera hispanica, Hedera hibernica, Teucrium scorodonia, Pteridium aquilinum, etc.).

Estes carballais integranse na asociación fitosociolóxica Luzulo henriquesii-Quercetum petraeae, que se distribúe ao longo das vertentes silíceas avesías da Cordilleira Cantábrica (Díaz González \& Fernández Prieto 1994, Rodríguez Guitián et al. 2000). Na área de estudo, exténdense entre os 1.000 e os $1.450 \mathrm{~m}$ de altitude (piso supratemperado), cobrindo unhas 37 ha. Información detallada acerca destes carballais amósase na Táboa 5 .

\section{Carballais albares calcícolas}

Trátase de bosques dominados polo carballo albar que medran sobre solos ricos en nutrientes derivados da alteración de rochas carbonatadas (calías, dolomías). Presentan un nivel de copas irregular, cunha talla media que oscila entre os 8 e $16 \mathrm{~m}$ de altura. No seu estrato superior, ademais de Quercus petraea pódense atopar Q. x rosacea, Corylus avellana, Sorbus aucuparia e Ilex aquifolium; máis puntualmente aparecen Q. pyrenaica, Fagus sylvatica ou Taxus baccata. Por baixo presentase un sotobosque que garda moito parecido co dos faiais e bosques mixtos calcícolas, no que dominan especies como Daphne laureola, Mercurialis perennis, Hedera hibernica, Primula acaulis, Polystichum setiferum, Melica uniflora, Sanicula europaea, Poa nemoralis, Teucrium scorodonia, Lathyrus linifolius, Melittis melissophyllum, Stellaria holostea, Asplenium trichomanes, Brachypodium rupestre, Polygonatum odoratum ou Vicia sepium.

Este tipo de carballais é extremadamente raro en Galicia; aparece nunhas poucas localidades concentradas no cuadrante SE da provincia de Lugo, ligadas aos afloramentos de rochas carbonatadas que se atopan nas montañas de As Nogais, Cebreiro, O Courel e Triacastela. No entorno da Devesa da Rogueira existen pequenos rodais na súa parte inferior e na vertente $\mathrm{W}$ do monte $\mathrm{A}$ Tara, entre os e os 900 e $1.200 \mathrm{~m}$ de altitude (termotipos mesotemperado superior e supratemperado inferior)(Figura $3)$. En conxunto cobren arredor de 4,5 ha.

Aínda que nun recente traballo Rodríguez Guitián et al. (2012) describen a composición florística básica e a área de distribución en Galicia de carballais albares calcícolas como os aquí comentados, está pendente a discusión e posible proposta formal dunha asociación vexetal particular na que incluílos. Datos acerca da ecoloxía e composición florística das representacións existentes na área aquí tratada amosanse na Táboa 5.

\section{"Carballais ananos" supratemperados}

Ao longo das montañas silíceas da mitade occidental da Cordillera Cantábrica, macizos de Queixa e TrevincaSanabria e Montes de León é frecuente observar por riba dos $1.300 \mathrm{~m}$ unhas formacións vexetais leñosas de baixo porte (2-10 $\mathrm{m}$ de altura) ás que se podería calificar como "carballais ananos". Estas formacións arboradas están dominadas por unha raza peculiar de carballo, capaz de medrar en medios particularmente hostís, como a periferia de pedrizas e canchais, esporóns rochosos ou ladeiras de forte inclinación intensamente soleadas ao longo do todo o ano. Segundo algúns autores (Rivas-Martínez et al. 2002), trataríase dun carballo diferente aos que aparecen no resto dos carballais xa comentados, pero que presenta unha difícil separación morfolóxica con respecto a Quercus robur e Quercus petraea, ao que denominan Quercus orocantabrica. Salvo un par de inventarios recollidos por Silva-Pando (1990) na Serra dos Ancares, non existe máis información acerca deste tipo de microformacións arbóreas en Galicia que a aportada na Táboa 5, consistente en tres inventarios tomados na vertente NE do Pico Formigueiros. Como se pode observar, trátase dunha comunidade vexetal de baixa talla $(2,5-4 \mathrm{~m})$, claramente dominada polos "carballos ananos" e os seus híbridos con outras especies de Quercus, cunha estrutura moi enmarañada que proporciona abeiro a especies habituais nos carballais albares de sollío e nas uceiras que os orlan, como Erica arborea, Vaccinium mytillus, Teucrium socorodonia, Physospermum cornubiense, Luzula lactea, Erythronium dens-canis, etc. 
Táboa 5.- Composición florística de carballais albares de avesío (inv. 1-6), carballais albares de sollío (inv. 7-10), "carballais ananos" (inv. 11-13) e carballais albares calcifilos (inv. 14-15)

\begin{tabular}{|c|c|c|c|c|c|c|c|c|c|c|c|c|c|}
\hline $\mathrm{N}^{\circ}$ de orde & 1 & 2 & 3 & 4 & 5 & 6 & 7 & 8 & 9 & 10 & 11 & 12 & 13 \\
\hline Área $\left(m^{2}\right)$ & 300 & 300 & 400 & 300 & 300 & 150 & 300 & 400 & 300 & 300 & 240 & 200 & 200 \\
\hline Alt. $E_{1}(m)$ & 16 & 16 & $12-20$ & $8-14$ & 16 & 9 & $8-12$ & 14 & $10-14$ & 20 & 4 & 3 & 2,5 \\
\hline Cob. $E_{1}(\%)$ & 100 & 100 & 100 & 85 & 100 & 90 & 90 & 95 & 80 & 90 & --- & --- & -- \\
\hline Cob. $E_{2}(\%)$ & 15 & 25 & 35 & 20 & 20 & -- & 30 & 25 & 20 & 20 & 95 & 95 & 100 \\
\hline Cob. $E_{3}(\%)$ & 75 & 90 & 95 & 95 & 70 & 100 & 95 & 85 & 95 & 60 & 95 & 100 & 100 \\
\hline Altitude (m) & 960 & 1025 & 1215 & 1250 & 1300 & 1020 & 1250 & 1240 & 1030 & 940 & 1390 & 1420 & 1475 \\
\hline Pendente $\left({ }^{\circ}\right)$ & 32 & 34 & 38 & 42 & 28 & 30 & 36 & 22 & 32 & 40 & 32 & 30 & 16 \\
\hline Orientación & NE & NNE & NW & NNE & NW & NE & WNW & NW & WSW & SW & ENE & ESE & ESE \\
\hline $\mathrm{N}^{\circ}$ de taxóns & 39 & 21 & 24 & 30 & 30 & 17 & 37 & 29 & 22 & 41 & 17 & 12 & 19 \\
\hline$E_{1}(>4,0 \mathrm{~m})+E_{2}(>1,5-4,0 \mathrm{~m}):$ & & & & & & & & & & & & & \\
\hline Ilex aquifolium & 1 & 1 & 1 & 1 & 2 & 2 & 1 & 1 & 1 & 1 & . & . & . \\
\hline Quercus petraea & 4 & 5 & 4 & 4 & 4 & . & 1 & 4 & 3 & 4 & . & . & . \\
\hline Corylus avellana & 1 & 1 & 1 & 1 & 2 & + & 1 & + & . & 2 & . & . & . \\
\hline Sorbus aucuparia & . & 1 & 1 & 1 & 1 & 3 & + & 1 & 1 & 1 & . & . & . \\
\hline Fagus sylvatica & 1 & 1 & 1 & . & 1 & 1 & . & $r$ & . & 1 & . & . & . \\
\hline Quercus x rosacea & . & 1 & . & . & . & 4 & 4 & 2 & 3 & 1 & . & . & . \\
\hline Taxus baccata & . & . & $r$ & . & . & . & . & . & . & . & . & . & . \\
\hline Rosa gr. canina & + & . & . & . & . & . & . & . & . & . & . & . & . \\
\hline Crataegus monogyna & + & . & . & . & . & . & . & $\cdot$ & . & $\cdot$ & . & . & . \\
\hline Cytisus scoparius & $\cdot$ & $\cdot$ & $\cdot$ & $\cdot$ & $\cdot$ & $\cdot$ & $\cdot$ & $\cdot$ & . & + & + & + & $\cdot$ \\
\hline $\mathrm{E}_{3}(<1,5 \mathrm{~m}):$ & & & & & & & & & & & & & \\
\hline Diferenciais de asociacións & & & & & & & & & & & & & \\
\hline Vaccinium myrtillus & 2 & 2 & 4 & 4 & 1 & 5 & 1 & 3 & 1 & $\cdot$ & 4 & 3 & 4 \\
\hline Erica arborea & + & + & . & 2 & . & 3 & 1 & 2 & 1 & 2 & 2 & 2 & 1 \\
\hline Avenella flexuosa & 1 & 1 & 1 & 2 & . & . & 2 & 2 & 4 & + & . & . & . \\
\hline Genista florida & . & . & + & + & + & + & 1 & . & + & + & . & . & . \\
\hline Betula pubescens & . & 1 & 1 & 2 & 2 & $r$ & . & . & . & 1 & . & . & . \\
\hline Saxifraga spathularis & + & + & + & 1 & + & $\cdot$ & + & . & . & $\cdot$ & . & · & · \\
\hline Valeriana montana & + & + & 2 & 2 & + & . & . & . & . & . & . & . & . \\
\hline Dryopteris dilatata & . & 1 & . & 1 & 1 & . & . & . & . & . & . & . & . \\
\hline Polygonatum verticillatum & . & . & + & + & + & . & . & . & . & . & . & . & . \\
\hline Doronicum pubescens & . & . & . & . & + & 1 & . & . & . & . & . & . & . \\
\hline Athyrium filix-femina & . & . & & + & + & . & . & . & . & . & . & . & . \\
\hline Luzula lactea & $\cdot$ & . & . & . & $\cdot$ & . & 1 & 1 & 2 & . & 1 & + & 1 \\
\hline Holcus mollis & $\cdot$ & . & . & . & . & . & + & 1 & 1 & 1 & + & . & . \\
\hline Frangula alnus & 1 & . & . & . & . & . & . & . & 1 & 2 & . & . & . \\
\hline Pyrus cordata & . & . & . & . & . & . & . & . & 1 & 1 & . & . & . \\
\hline Quercus orocantabrica (?) & . & . & . & . & $\cdot$ & $\cdot$ & $\cdot$ & $\cdot$ & $\cdot$ & $\cdot$ & 5 & 5 & 5 \\
\hline Avenella iberica (?) & · & · & . & · & . & . & . & . & · & · & 1 & 3 & 2 \\
\hline Prunus avium & . & . & . & . & . & . & . & . & . & . & . & . & . \\
\hline Prunus spinosa & . & . & . & . & . & . & . & . & . & . & . & . & . \\
\hline Neottia nidus-avis & . & . & . & . & . & . & . & . & . & . & . & . & . \\
\hline Corydalis cava & . & . & . & . & . & . & . & . & . & . & . & . & . \\
\hline Laserpitium nestleri & . & . & . & . & . & . & . & . & . & . & . & . & . \\
\hline Trifolium medium & . & . & $\cdot$ & . & . & . & . & $\cdot$ & . & $\cdot$ & . & $\cdot$ & $\cdot$ \\
\hline Taxóns característicos de asoci & cións & & & & & & & & & & & & \\
\hline Teucrium scorodonia & + & $\cdot$ & 1 & + & + & . & 2 & + & + & 1 & + & + & + \\
\hline Lonicera hispanica & 1 & 1 & 1 & 1 & 1 & 2 & 1 & 1 & 1 & 1 & + & . & . \\
\hline Luzula sylvatica & 2 & 4 & 2 & 2 & 3 & 1 & $\cdot$ & 1 & + & $\cdot$ & . & . & $\cdot$ \\
\hline Linaria triornithophora & $\cdot$ & $\cdot$ & $\cdot$ & + & $\cdot$ & $\cdot$ & + & + & + & 1 & $\cdot$ & $\cdot$ & $\cdot$ \\
\hline Taxóns característicos do orde & ageta & ia sylva & ticae & & & & & & & & & & \\
\hline Daphne laureola & 1 & $\cdot$ & 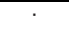 & + & + & $\cdot$ & $\cdot$ & $\cdot$ & $\cdot$ & + & 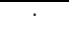 & $\cdot$ & 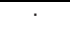 \\
\hline Lilium martagon & . & + & . & . & 1 & . & . & $\cdot$ & . & . & . & . & + \\
\hline Melica uniflora & + & . & . & . & + & . & . & $\cdot$ & . & . & . & . & . \\
\hline Taxóns característicos do orde & Querc & talia ro & boris & & & & & & & & & & \\
\hline Physospermum cornubiense & + & . & . & . & . & . & . & + & . & . & 1 & + & + \\
\hline Lathyrus linifolius & + & $\cdot$ & . & $\cdot$ & · & · & + & $\cdot$ & · & $\cdot$ & · & $\cdot$ & + \\
\hline Galium rotundifolium & + & . & $\cdot$ & $\cdot$ & . & . & . & $\cdot$ & . & + & . & . & $\cdot$ \\
\hline Taxóns característicos da clase & Quer & o-Faget & & & & & & & & & & & \\
\hline Hedera hibernica & 1 & + & + & . & 1 & $\cdot$ & . & $\cdot$ & . & 1 & . & . & . \\
\hline Dryopteris filix-mas & 2 & . & . & 1 & 1 & $\cdot$ & + & + & . & 2 & . & . & $\cdot$ \\
\hline Polypodium vulgare & . & + & . & + & . & . & + & . & + & . & . & . & . \\
\hline Stellaria holostea & + & . & . & . & . & . & + & 1 & 1 & 1 & . & . & . \\
\hline Viola riviniana & + & . & . & . & . & . & + & . & . & . & . & . & . \\
\hline Melittis melissophyllum & + & . & $\cdot$ & . & . & . & + & . & . & . & . & . & . \\
\hline Solidago virgaurea & . & . & . & . & . & . & . & + & . & + & + & . & + \\
\hline Polystichum setiferum & 1 & $\cdot$ & . & . & $\cdot$ & . & $\cdot$ & . & . & 2 & $\cdot$ & . & $\cdot$ \\
\hline Dryopteris affinis & . & 1 & . & 1 & 1 & . & . & . & . & . & . & . & . \\
\hline Anemone nemorosa & . & . & + & + & 1 & . & . & . & . & . & . & . & . \\
\hline Poa nemoalis & 1 & . & . & . & . & . & . & . & . & + & . & . & . \\
\hline Euphorbia hyberna & $\cdot$ & $\cdot$ & + & + & . & $\cdot$ & . & + & $\cdot$ & $\cdot$ & $\cdot$ & . & $\cdot$ \\
\hline Outros taxóns & & & & & & & & & & & & & \\
\hline Pteridium aquilinum & 1 & + & 1 & 1 & $r$ & 3 & $\cdot$ & 1 & $\cdot$ & 1 & $\cdot$ & . & 1 \\
\hline Rubus sp. & + & $r$ & + & + & . & . & 1 & + & + & + & . & . & . \\
\hline Asphodelus macrocarpus & . & . & . & . & . & . & + & + & 1 & . & 1 & 1 & + \\
\hline Polygonatum odoratum & . & . & . & . & . & . & + & + & . & . & . & . & + \\
\hline Pseudarrhentaherum longifolium & . & . & . & $\cdot$ & . & . & 1 & . & . & . & 1 & + & 1 \\
\hline Arenaria montana & . & $\cdot$ & . & $\cdot$ & . & . & + & . & . & 1 & 1 & . & $\cdot$ \\
\hline Ruscus aculeatus & + & . & . & . & . & . & . & . & . & . & . & . & . \\
\hline Festuca merinoi & . & . & . & . & . & . & 2 & . & . & . & + & . & . \\
\hline Brachypodium rupestre & · & $\cdot$ & · & $\cdot$ & $\cdot$ & . & + & · & $\cdot$ & $\cdot$ & $\cdot$ & · & $\cdot$ \\
\hline Peucedanum gallicum & + & $\cdot$ & . & $\cdot$ & . & . & 1 & . & $\cdot$ & . & $\cdot$ & . & + \\
\hline Erythronium dens-canis & . & . & . & · & . & . & . & . & . & . & + & + & + \\
\hline Silene nutans & . & . & . & . & . & . & + & + & . & . & . & . & + \\
\hline
\end{tabular}


Taxóns de baixa frecuencia:

En $\mathbf{E}_{1}+\mathrm{E}_{\mathbf{2}}$ : Acer pseudoplatanus: 2 en 1 e + en 10; Fraxinus excelsior: 1 en 14; Quercus orocantabrica x Quercus pyrenaica: 1 en 1; Quercus pyrenaica: 1 en 12; Quercus x trabutii: 1 en 1 e 1 en 10; Salix caprea: 1 en 3 e 1 en 10; Sorbus aria: 1 en 14.

$\mathrm{E}_{3}$ : Característicos de Fagetalia sylvaticae: Euphorbia dulcis: 1 en 1 e + en 8; Galium odoratum: 1 en 5 e + en 15; Mercurialis perennis: 1 en 14 e 2 en 15; Milium effusum: + en 15; Mycelis muralis: + en 10; Primula acaulis: + en 14 e 2 en 15; Sanicula europea: + en 15. Característicos de Quercetalia roboris: Ceratocapnos claviculata: + en 5; Hieracium umbellatum: + en 7 e 1 en 13; Hypericum pulchrum: + en 7 e + en 10; Melampyrum pratense: 1 en 6. Característicos de Querco-Fagetea: Ajuga reptans: + en 14; Crepis lampsanoides: + en 4 e + en 5; Helleborus foetidus: + en 14 e + en 15; Oxalis acetosella: + en 1 e 1 en 5; Tamus communis: + en 15; Vicia sepium: + en 15. Outros taxóns: Agrostis capillaris: 1 en 9 e 1 en 10; Angelica major: + en 4; Anthoxanthum odoratum: + en 10; Antirrhinum braun-blanquetii: + en 14; Asplenium adiantum-nigrum: + en 14 e + en 15; Asplenium onopteris: + en 1 e + en 15; Asplenium trichomanes: + en 14 e 1 en 15; Avenula sulcata: + en 7; Carex pilulifera: + en 8 e + en 10; Clinopodium vulgare: + en 10; Cruciata glabra: + en 7 e 1 en 14; Digitalis purpurea: + en 9 e + en 10; Festuca rubra: + en 6; Fragaria vesca: + en 15; Galium saxatile: 1 en 3 e + en 6; Geranium robertianum: + en 1 e + en 14; Glandora difussa: + en 14; Hypericum linariifolium: + en 10; Lastrea limbosperma: + en 4; Narcissus asturiensis: + en 3 e + en 8; Narcissus triandrus: + en 7; Omphalodes nitida: + en 1 e + en 10; Phalacrocarpon oppositifolium: + en 7; Pterospartum cantabricum: 1 en 12; Ranunculus platanifolius: + en 5; Coincya setigera: + en 7 e + en 10; Rubus ulmifolius: $r$ en 6; Rumex acetosa: + en 4; Rumex acetosella: r en 8; Umbilicus rupestris: + en 1; Vicia orobus: + en 13.

Localidades (a notación numérica entre paréntese indica a situación na cuadrícula UTM de $1 \mathrm{~km}$, fuso 29T): 1: Lu: Folgoso do Courel, Moreda, parte inferior da Devesa da Rogueira, ao final dunha antiga vía de saca, 654/4719. 2: Lu: Folgoso do Courel, Moreda, Devesa da Rogueira, ladeira abaixo da primeira revolta entrando por As Veigas, 654/4719. 3: Lu: Folgoso do Courel, Moreda, Devesa da Rogueira, antes do zig-zag das escaleiras, 654/4718. 4: Lu: Folgoso do Courel, Moreda, Devesa da Rogueira, revoltas antes do desvío ás Águas, $654 / 4718$. 5: Lu: Folgoso do Courel, Devesa da Rogueira, 655/4718. 6: Lu: Folgoso do Courel, Devesa de Rogueira, camino de subida desde Moreda, 654/4719 [Amigo Vázquez (1984): táb. 8: inv. 1]. 7: Lu: Folgoso so Courel, Moreda, Devesa da Rogueira, primeiro teso á entrada, $655 / 4718$. 8: Lu: Folgoso do Courel, Moreda, Devesa da Rogueira, entrada E, 655/4719. 9: Lu: Folgoso do Courel, Moreda, Devesa da Rogueira, parte superior do teso rochoso do extremo inferior, 654/4719. 10: Lu: Folgoso do Courel, Moreda, Devesa da Rogueira, extremo inferior da Tara, sobre coluvión de lousa, 654/4719. 11: Lu: Folgoso do Courel, Visuña, vertente NE do Pico Formigueiros, 656/4719. 12: Lu: Folgoso do Courel, Visuña, vertente NE do Pico Formigueiros, 656/4718. 13: Lu: Folgoso do Courel, Visuña, vertente NE do Pico Formigueiros, 656/4718. 14: Lu: Folgoso do Courel, Moreda, teso calío inferior da Devesa da Rogueira, 654/4719. 15: Lu: Folgoso do Courel, Moreda, A Tara, parte media, $654 / 4719$.

De admitirse a condición taxonómica comentada para o carballo que caracteriza a estas formacións, estas poderían incluírse, desde o punto de vista fitosociolóxico, na asociación Avenello ibericae-Quercetum orocantabricae, cuestión que precisaría dun estudio máis amplo e pormenorizado que o aquí realizado. No conxunto da área de estudo, este tipo de carballais ocupan algo menos de 3 ha concentradas na vertente NW do Pico Formigueiros (Figura 3).

\section{Reboleiras silicícolas}

Bosques dominados por Quercus pyrenaica (vulgarmente coñecido como rebolo ou rebola) que se asentan sobre solos relativamente fondos, pero pedregosos, desenvolvidos a partir de lousas, areíscas e cuarcitas. Se trata do tipo de bosque máis amplamente estendido nas montañas courelás, entre os 800 e $1.500 \mathrm{~m}$ de altitude, principalmente en vertentes con orientación $\mathrm{S}$ ou $\mathrm{W}$. Na Devesa da Rogueira concentranse na vertente setentrional do Val do Carrozo da Muíña (Figura 3), entre os 750 e os $1.300 \mathrm{~m}$ de altitude (termotipos mesotemperado superior a supratemperado superior), ocupando unhas 79 ha, que veñen a representar a cuarta parte da superficie arborada da área de estudo (Táboa 2).

Son bosques moi uniformes desde o punto de vista estrutural, nos que destaca o marcado predominio do rebolo no estrato superior que, ocasionalmente, comparte o dosel con carballos híbridos ( $Q$. x rosacea, Q. x trabutii), castiñeiros (Castanea sativa), Prunus avium ou algún capudre (Sorbus aucuparia). A altura que acadan os pés dominantes nestas formacións arboradas é moi variable (4$18 \mathrm{~m}$ ) e adoita ser inversamente proporcional á distancia á que se encontran dos núcleos habitados, pois este foi o tipo de bosque utilizado principalmente pola poboación local para abastecerse de madeira e leñas dun xeito máis intenso e continuado, xa que o rebolo produce unha madeira moi apreciada como combustible. A foliación tardía de Quercus pyrenaica, cuxas ponlas raramente agroman antes de primeiros do mes de xuño, permite a chegada ao sotobosque dunha elevada cantidade de radiación solar durante a primavera e inicios do verán, razón pola que neste nivel podense atopar un gran número de especies arbustivas e herbáceas tolerantes á luz, como Cytisus scoparius, Erica arborea, Holcus mollis, Linaria triornithophora, Teucrium scorodonia, Physospermum cornubiense, Hypericum pulchrum, Stellaria holostea, Clinopodium vulgare, etc., xunto a Anemone nemorosa, Viola riviniana ou Polypodium vulgare.

As reboleiras silicícolas pertencen á asociación fitosociolóxica Linario triornithophorae-Quercetum pyrenaicae, de ampla distribución ao longo da Cordilleira Cantábrica, particularmente no seu extremo centrooccidental (Amigo Vázquez 1984, Rivas-Martínez et al. 1984, Silva-Pando 1990). Na Táboa 6 reúnese información sobre a ecoloxía e composición florística deste tipo de bosques dentro do ámbito de estudo.

\section{Reboleiras calcícolas}

Bosques dominados por Quercus pyrenaica que medran sobre solos, polo xeral pouco profundos, derivados da alteración de rochas carbonatadas (calías, dolomías). Aínda que tradicionalmente se considera que o rebolo é unha especie tipicamente acidófila (Silva Pando \& Rigueiro Rodríguez 1992, Ruíz de la Torre 2006), non é raro observar nas montañas courelás e do Cebreiro reboleiras sobre afloramentos de rochas calías, como xa advertiron Amigo Vázquez (1984) e Giménez de Azcárate (1993). 
Táboa 6.- Composición florística de reboleiras silicícolas (inv. 1-4) e calcícolas (inv. 5-7)

\begin{tabular}{|c|c|c|c|c|c|c|c|}
\hline $\mathrm{N}^{0}$ de orde & 1 & 2 & 3 & 4 & 5 & 6 & 7 \\
\hline Área $\left(m^{2}\right)$ & 400 & 300 & 350 & 300 & 300 & 400 & 200 \\
\hline Altura $E_{1}(m)$ & 16 & 12 & 10 & 8,5 & 6 & $8-12$ & 9 \\
\hline Cob. $E_{1}(>4,0 \mathrm{~m})(\%)$ & 90 & 100 & 90 & 90 & 100 & 100 & 85 \\
\hline Cob. $E_{2}(1,5-4,0 \mathrm{~m})(\%)$ & 30 & 20 & --- & --- & 35 & 30 & --- \\
\hline Cob. $E_{3}(<1,5 \mathrm{~m})(\%)$ & 95 & 85 & 100 & 100 & 95 & 95 & 100 \\
\hline Altitude (m) & 1225 & 800 & 760 & 900 & 1275 & 1245 & 880 \\
\hline Pendente $\left({ }^{\circ}\right)$ & 14 & 32 & 50 & 35 & 30 & 14 & 40 \\
\hline Orientación & WSW & I SW & $E$ & WNW & SSE & WNW & $\sqrt{ } E$ \\
\hline $\mathrm{N}^{0}$ de taxóns & 29 & 30 & 22 & 34 & 40 & 46 & 26 \\
\hline \multicolumn{8}{|c|}{$E_{1}(>4,0 \mathrm{~m})+E_{2}(>1,5-4,0 \mathrm{~m}):$} \\
\hline Quercus pyrenaica & 5 & 5 & 5 & 4 & 5 & 5 & 5 \\
\hline Crataegus monogyna & 1 & + & & + & 1 & 1 & + \\
\hline Cytisus scoparius & + & + & 2 & 1 & + & . & . \\
\hline Erica arborea & 3 & 2 & + & . & 1 & 1 & · \\
\hline Corylus avellana & . & 1 & . & + & 1 & . & 1 \\
\hline Sorbus aucuparia & 1 & . & . & . & + & + & . \\
\hline Fagus sylvatica & 1 & . & . & . & . & $r$ & . \\
\hline Ilex aquifolium & + & . & . & . & . & 1 & \\
\hline Taxus baccata & + & . & & . & . & + & \\
\hline
\end{tabular}

Taxus baccata

$\mathrm{E}_{3}(<1,5 \mathrm{~m})$ :

Taxóns diferenciais de asociacións

Pyrus cordata

Linaria triornithophora

Frangula alnus

Pseudarrhenatherum longifolium 3

Laserpitium nestleri

Geranium sanguineum

Origanum virens

Vicia orobus

Thalictrum minus

Glandora diffusa

Rosa gr. canina

Dianthus hyssopyfolius

Taxóns característicos de asociacións

Holcus mollis

Teucrium scorodonia

\section{Taxóns de baixa frecuencia:}

$\mathrm{E}_{1}+\mathrm{E}_{2}$ : Castanea sativa: 1 en 2; Fraxinus excelsior: + en 2; Malus sylvestris: 1 en 1; Prunus avium: 1 en 2; Quercus petraea: + en 6; Quercus x andegavensis: 2 en 4; Quercus x rosacea: 1 en 2; Quercus x trabutii: 1 en 2.

$\mathrm{E}_{3}$ : Característicos de asociación: Arenaria montana: + en 2; Avenella flexuosa: + en 4; Hieracium murorum: $r$ en 4; Hieracium umbellatum: + en 6; Lonicera hispanica: 1 en 4; Melampyrum pratense: r en 3. Característicos de Fagetalia sylvaticae: Daphne laureola: 1 en 5; Ornithogalum pyrenaicum: + en 6; Primula acaulis: + en 6. Característicos de Querco-Fagetea: Dryopteris filix-mas: 1 en 2; Euphorbia amygdaloides: $r$ en 4; Euphorbia hyberna: + en 4; Helleborus foetidus: + en 5; Hyacinthoides non-scripta: + en 6; Polystichum setiferum: 1 en 2; ; Ranunculus tuberosus: + en 6; Tamus communis: 1 en 7. Outros taxóns: Allium sphaerocephalon: + en 5; Andryala integrifolia: + en 3; Angelica major: + en 1, Anthoxanthum odoratum: + en 4; Anthyllis alpestris: + en 5; Arrhenatherum bulbosum: 1 en 6 ; Asphodelus macrocarpus: 1 en 6; Avenula sulcata: + en 6; Campanula adsurgens: + en 5; Ceterach officinarum: + en 5; Cirsium arvense: + en 5; Clematis vitalba: + en 7; Colchicum autumnale: + en 6; Digitalis purpurea: + en 3; Epipactis helleborine: 1 en 7; Festuca merinoi: + en 3; Fragaria vesca: + en 5; Galium lucidum: 1 en 5; Galium mollugo: + en 2; Gentiana aurantiaca: + en 1; Hypericum perforatum: + en 7; Xiphion latifolium: + en 6; Jasione montana: + en 3; Lotus corniculatus: + en 3; Luzula lactea: + en 1; Prunella grandiflora: 1 en 5; Rubus ulmifolius: + en 7; Sanguisorba minor. + en 5; Simettis mattiazzii: 1 en 1; Trifolium pratense: 1 en 7; Vicia orobus: + en 1; Viola suavis: 1 en 5 .

Localidades (a notación numérica entre paréntese indica a situación na cuadrícula UTM de $1 \mathrm{~km}$, fuso 29T): 1: Lu: Folgoso do Courel, Moreda, Devesa da Rogueira, entre a Tara e Campa dos Carlistas, 655/4719. 2: Lu: Folgoso do Courel, Moreda, Teso dos Pariceiros, 654/4720. 3: Lu: Folgoso do Courel, de Moreda hacia A Rogueira, 654/4720 [Amigo Vázquez (1984): táb. 9: inv. 5]. 4: Lu: Folgoso do Courel, Devesa da Rogueira; subiendo hacia Campa dos Carlistas, 654/4720 [Amigo Vázquez (1984): táb. 9: inv. 18]. 5: Lu: Folgoso do Courel, Visuña, Céramo, por baixo da pista do Couto a Formigueiros, 656/4719. 6: Lu: Folgoso do Courel, Devesa da Rogueira, A Tara, rechán na divisoria de augas, 655/4719. 7: Lu: Folgoso do Courel, Moreda, camino de Rogueira a la derecha y ladera arriba, 654/4720 [Amigo Vázquez (1984): táb. 10: inv. 12].

\begin{tabular}{|c|c|c|c|c|c|c|c|}
\hline $\mathrm{N}^{0}$ de orde & 1 & 2 & 3 & 4 & 5 & 6 & 7 \\
\hline Physospermum cornubiense & 1 & . & $\mathrm{r}$ & + & & + & + \\
\hline Hypericum pulchrum & + & . & + & 1 & . & + & . \\
\hline Lathyrus linifolius & . & . & . & + & + & + & . \\
\hline Stellaria holostea & . & + & . & + & . & $\cdot$ & . \\
\hline \multicolumn{8}{|c|}{ Taxóns característicos do orde Fagetalia sylvaticae } \\
\hline Lilium martagon & $\mathrm{r}$ & 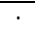 & 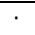 & ${ }^{\circ}$ & . & . & + \\
\hline Mercurialis perennis & . & . & . & . & 1 & 1 & . \\
\hline \multicolumn{8}{|c|}{ Taxóns característicos da clase Querco-Fagetea } \\
\hline Viola riviniana & + & + & . & + & + & 1 & + \\
\hline Polypodium vulgare & . & + & + & $\mathrm{r}$ & & . & . \\
\hline Melittis melissophyllum & + & . & . & . & 1 & + & . \\
\hline Anemone nemorosa & 1 & . & . & + & . & . & . \\
\hline Crepis lampsanoides & . & . & . & + & . & + & . \\
\hline \multicolumn{8}{|l|}{ Outros taxóns } \\
\hline Pteridium aquilinum & 2 & 2 & 3 & 4 & 2 & . & 2 \\
\hline Brachypodium rupestre & . & + & 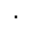 & + & 4 & 4 & 3 \\
\hline Silene nutans & + & . & + & + & . & + & 1 \\
\hline Clinopodium vulgare & . & + & . & . & + & + & + \\
\hline Cruciata glabra & + & . & . & . & 1 & 1 & . \\
\hline Rubus ulmifolius & . & + & + & 1 & & . & . \\
\hline Potentilla erecta & + & . & . & . & + & + & . \\
\hline Vicia sepium & + & . & . & . & + & + & . \\
\hline Rubus sp. & + & . & 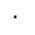 & . & $r$ & + & . \\
\hline Agrostis capillaris & . & + & . & . & & 2 & . \\
\hline Agrostis castellana & . & . & 1 & 1 & & . & . \\
\hline Festuca sp. & . & . & . & . & 1 & 1 & . \\
\hline Omphalodes nitida & . & + & . & 1 & & . & . \\
\hline Epilobium parviflorum & . & + & & 1 & & . & . \\
\hline Polygonatum odoratum & . & . & . & . & & 1 & + \\
\hline Centaurea nigra & + & . & . & . & . & + & . \\
\hline Asplenium adiantum-nigrum & . & + & . & . & + & . & . \\
\hline Rumex acetosa & . & . & . & + & + & . & . \\
\hline Euphorbia angulata & . & . & . & + & & . & + \\
\hline Picris hieracioides & . & . & . & 1 & & . & 1 \\
\hline Campanula lusitanica & 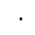 & . & + & . & & . & $\mathrm{r}$ \\
\hline
\end{tabular}


No estrato superior, aparte da clara dominancia do rebolo, non é rara a presenza de Sorbus aucuparia, xunto a outras árbores, como Taxus baccata, Fagus sylvatica ou Quercus petraea, polo xeral ausentes das reboleiras de tipo silicícola; por debaixo, a dominancia corresponde á argana (Brachypodium rupestre), entre a que é habitual atopar especies como Mercurialis perennis, Laserpitium nestleri, Geranium sanguineum, Thalictrum minus, Glandora diffusa, Origanum virens ou Dianthus hyssopyfolius, diferenciais con respecto ás reboleiras sobre solos pobres. Completan a súa composición florística especies de ampla distribución nos bosques do territorio estudado, como Teucrium scorodonia, Viola riviniana, Physospermum cornubiense, Holcus mollis, Melittis melissophyllum, Polygonatum odoratum, Pteridium aquilinum, Cruciata glabra ou Vicia sepium.

As reboleiras calcícolas ocupan, de xeito fragmentado e seguindo fielmente a banda calía que atravesa de $\mathrm{E}$ a W a área de estudo, arredor de 12 has, entre os 900 e os 1.280 $\mathrm{m}$ de altitude (Figura 3 ), dentro dos termotipos mesotemperado superior e supratemperado inferior. A pesar de recoñecer certas particularidades florísticas a este tipo de reboleiras, tanto Amigo Vázquez (1984) como Giménez de Azcárate (1993) incluíronas dentro de asociacións de bosques de carácter silicícola (Linario triornithophoraeQuercetum pyrenaicae, Holco mollis-Quercetum pyrenaicae). Máis recentemente, Rodríguez Guitián et al. (2012) propuxeron a súa separación das reboleiras sobre solos pobres en nutrientes, aínda que deixando pendente unha análise detallada desde 0 punto de vista fitosociolóxico. Até que esta non se realice, a efectos do presente traballo reunimos este tipo de reboleiras baixo a denominación que encabeza este apartado. Na Táboa 6 amósase a información dispoñible para este tipo de bosque dentro da área de estudo.

\section{Bosques mixtos silicícolas}

Formacións arboradas que presentan un estrato superior conformado por unha mestura de especies arbóreas ausentes ou de presenza marxinal noutros tipos de bosques, como freixos (Fraxinus excelsior), pradairos (Acer pseudoplatanus), cerdeiras bravas ou cereixais (Prunus avium) e abeleiras (Corylus avellana), sendo minoritaria a participación de carballos (Quercus robur, Q. petraea), rebolos (Quercus pyrenaica) e faias (Fagus sylvatica); outras árbores de aparición más ou menos frecuente son lameiros (Ulmus glabra), teixos (Taxus baccata), espiños (Crataegus monogyna), capudres (Sorbus aucuparia) e castiñeiros bravos (Castanea sativa).

Desde o punto de vista ecolóxico, a súa distribución está ligada a partes baixas de ladeiras de forte inclinación, gorxas fluviais e pedrizas situadas ao pé de paredes rochosas, sen unha preferencia clara por unha orientación determinada. Nestes biotopos abundan os afloramentos rochosos e os solos caracterizanse por ter un escaso espesor, unha pedregosidade moi elevada e unha gran inestabilidade, características que limitan o enraizamento e o acceso de moitos vexetais ás capas subsuperficiais de auga. Igualmente, estas condicións favorecen os derribos causados polos temporais, sendo por elo frecuente que as árbores presenten toros bifurcados, un aspecto tortuoso e tendencia a rebrotar das cepas, configurando bosques de fisionomía irregular e talla modesta (12-20 m de altura). Raramente aparecen por riba dos 1.100-1.200 m de altitude, atopando o seu óptimo no oriente galego dentro do piso bioclimático mesotemperado $(600-900 \mathrm{~m})$. As representacións deste tipo de bosque na Devesa da Rogueira encontranse nas vertentes máis abruptas e pedregosas da súa metade inferior, particularmente nas proximidades dos regos do Freixedo e da Rogueira, así como ao pé de pequenas paredes rochosas existentes no Val do Carrozo da Muíña (Figura 3). En conxunto, a súa extensión ronda as 16 ha.

A pesar das peculiaridades edáficas comentadas, a rápida mineralización dos restos vexetais que producen anualmente as árbores dominantes destes bosques favorece a formación dun horizonte edáfico superficial que, aínda que descontinuo, permite o enraizamento dun amplo conxunto de especies herbáceas e leñosas de baixo porte, con apetencias ecolóxicas diversas. Así, no nivel inferior adoitan aparecer especies frecuentes noutros tipos de bosques avesíos silicícolas sobre solos ricos en humus xa descritos, como Hedera hibernica, Viola riviniana, Polystichum setiferum, Melica uniflora, Primula acaulis, Mercurialis perennis, Dryopteris filix-mas, Saxifraga spathularis, Luzula sylvatica, Sanicula europaea, Lilium martagon, Moehringia trinervia, Galium odoratum ou Hyacinthoides non-scripta, xunto a outras características de ambientes rochosos, como Asplenium trichomanes. Son igualmente frecuentes alguhas especies nitrófilas, como Geranium robertianum, Urtica dioica ou Lamium maculatum, mentras que nas microvalgadas que surcan as áreas abarrancadas medran especies herbáceas zumentas de gran tamaño, como Valeriana pyrenaica, Meconopsis cambrica ou Ranunculus platanifolius.

Desde unha perspectiva fitosociolóxica, os bosques mixtos silicícolas existentes ao longo das montañas silíceas do occidente da Cordilleira Cantábrica, incluídos os da Serra do Courel, pertencen á asociación Luzulo henriquesiiAceretum pseudoplatani (Díaz González \& Fernández Prieto 1994, Rodríguez Guitián et al. 2000, Rodríguez Guitián 2011). Datos concretos sobre a ecoloxía e a composición florística detallada destes bosques dentro do ámbito de estudo amósanse na Táboa 7.

\section{Bosques mixtos calcícolas}

Moi semellantes aos anteriores desde o punto de vista fisionómico e ecolóxico, os bosques mixtos calcícolas medran, como é fácil deducir, en enclaves abruptos e non excesivamente elevados nos que afloran as rochas carbonatadas (calías, dolomías). Desde o punto de vista estrutural tenden a ser algo máis complexos e enmarañados que os silicícolas, debido fundamentalmente á maior cobertura que acadan algunhas especies arbóreas de pequena talla, como a abeleira (Corylus avellana) e o espiño (Crataegus monogyna), así como a maior abundancia coa que se presentan diversas especies gabeadoras (Hedera hibernica, Lonicera hispanica, Tamus communis ou Clematis vitalba). Tamén, por ocupar lugares algo máis resgardados e menos batidos polos temporais, acadan alturas algo superiores (14-24 m). Florísticamente 
se diferencian, ademais de pola baixa representación, cando non ausencia total, das especies acidófilas (Luzula sylvatica, Saxifraga spathularis, Blechnum spicant, Vaccinium myrtillus, etc.), pola presenza doutras típicas de solos ricos en nutrientes, como Laserpitium nestleri, Viola suavis, Ornithogalum pyrenaicum, Prunus spinosa, Ruscus aculeatus ou Neottia nidus-avis. Trátase do tipo de bosque presente na área de estudo cun valor promedio de especies por inventario máis elevado (47 taxóns).

Táboa 7.- Composición florística de bosques mixtos silicícolas (inv. 1-5) e bosques mixtos calcícolas (inv. 6-10)

\begin{tabular}{|c|c|c|c|c|c|c|c|c|c|}
\hline $\mathrm{N}^{0}$ de orde & 1 & 2 & 3 & 4 & $5: 6$ & 7 & 8 & 9 & 10 \\
\hline Área $\left(\mathrm{m}^{2}\right)$ & 300 & 300 & 300 & 300 & 314,300 & 500 & 300 & 600 & 300 \\
\hline Altura $E_{1}(m)$ & 24 & $10-18$ & 820 & 20 & $12: 22$ & $14-18$ & 16 & $10-16$ & $18-2$ \\
\hline Cob. $E_{1}(>4 \mathrm{~m})(\%)$ & 100 & 95 & 95 & 100 & $70: 100$ & 100 & 100 & 100 & 90 \\
\hline Cob. $E_{2}(1,5-4 \mathrm{~m})(\%)$ & 20 & 15 & 15 & 30 & $50: 25$ & 25 & 15 & 30 & 40 \\
\hline Cob. $E_{3}(<1,5 \mathrm{~m})(\%)$ & 70 & 85 & 95 & 70 & $60: 90$ & 80 & 80 & 90 & 85 \\
\hline Altitude $(\mathrm{m})$ & 760 & 885 & 925 & 950 & 1040,740 & 840 & 870 & 920 & 980 \\
\hline Pendente $\left({ }^{\circ}\right)$ & 36 & 40 & 44 & 40 & $12: 38$ & 48 & 40 & 44 & 38 \\
\hline Orientación & ENE & $\mathrm{N}$ & $\mathrm{N}$ & W & $N: W$ & NW & WNW & VWSW & SSW \\
\hline $\mathrm{N}^{0}$ de taxóns & 60 & 44 & 48 & 44 & $51: 59$ & 49 & 50 & 40 & 52 \\
\hline \multicolumn{3}{|c|}{$E_{1}(>4,0 \mathrm{~m})+E_{2}(>1,5-4,0 \mathrm{~m}):$} & & & 1 & & & & \\
\hline Corylus avellana & 2 & 2 & 2 & 2 & $3: 3$ & 4 & 3 & 3 & 3 \\
\hline Acer pseudoplatanus & 3 & 4 & 4 & 4 & 23 & 2 & 4 & 2 & 2 \\
\hline Crataegus monogyna & + & 1 & + & . & $1: 1$ & 1 & 1 & 1 & 2 \\
\hline Ilex aquifolium & + & . & . & 1 & $1 i+$ & 1 & 1 & 1 & + \\
\hline Fraxinus excelsior & 3 & 3 & . & . & $2: 3$ & 1 & 1 & 2 & 3 \\
\hline Fagus sylvatica & . & . & 1 & 2 & $3:$ & 3 & 1 & 2 & 2 \\
\hline Prunus avium & 2 & 1 & 1 & . & . 2 & . & . & 2 & . \\
\hline Salix caprea & . & 1 & . & 1 & $\begin{array}{ll}1 & 1\end{array}$ & 2 & 2 & . & . \\
\hline Quercus pyrenaica & 1 & 1 & 1 & . & - : 1 & 1 & 1 & . & . \\
\hline Betula pubescens & . & 1 & 1 & 1 & $\begin{array}{c}1 \\
\cdot 1\end{array}$ & 1 & . & 1 & . \\
\hline Castanea sativa & 3 & . & . & . & $\begin{array}{l}1 \\
\cdot 12\end{array}$ & $r$ & . & . & . \\
\hline Quercus petraea & . & . & · & 1 & . 1. & 1 & . & 2 & . \\
\hline Sorbus aucuparia & . & . & · & 1 & $\cdot \begin{array}{l}1 \\
\cdot\end{array}$ & 1 & . & 1 & . \\
\hline Rosa gr. canina & 1 & . & . & . & $\begin{array}{ll}r \\
\end{array}$ & . & . & . & + \\
\hline
\end{tabular}

\section{$\mathrm{E}_{3}(<1,5 \mathrm{~m})$}

\section{Taxóns diferenciais de asociacións}

\begin{tabular}{|c|c|c|c|c|c|c|c|c|c|}
\hline Luzula sylvatica & 1 & 1 & 2 & 1 & $21 \cdot$ & 1 & . & . & . \\
\hline Saxifraga spathularis & + & 1 & 2 & . & $1:$ & . & . & . & . \\
\hline Epilobium montanum & + & + & . & + & $r:$ & . & . & . & . \\
\hline Holcus mollis & + & . & 1 & 1 & $\cdot 1$. & . & . & . & · \\
\hline Doronicum pubescens & $\cdot$ & . & . & . & +1. & . & . & . & · \\
\hline Dryopteris dilatata & $\cdot$ & . & . & . & $+i$. & . & . & . & . \\
\hline Avenella flexuosa & $\cdot$ & . & 1 & . & . & . & . & . & . \\
\hline Genista florida & $\cdot$ & . & . & + & . 1. & . & . & . & · \\
\hline Vaccinium myrtillus & $\cdot$ & + & . & . & . 1. & . & . & . & 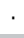 \\
\hline Clematis vitalba & 1 & . & . & $\cdot$ & $\cdot 1$ & 1 & 2 & + & · \\
\hline Viola suavis & $\cdot$ & . & . & . & - $1+$ & . & + & + & 1 \\
\hline Prunus spinosa & $\cdot$ & . & . & . & . 1 & . & . & . & + \\
\hline Neottia nidus-avis & $\cdot$ & . & . & $\cdot$ & . & + & + & . & . \\
\hline Laserpitium nestleri & $\cdot$ & . & . & . & . 1. & . & . & . & + \\
\hline Campanula adsurgens & $\cdot$ & . & . & $\cdot$ & - $1+$ & . & . & . & . \\
\hline Saxifraga hirsuta & $\cdot$ & . & $\cdot$ & $\cdot$ & $\cdot 1+$ & $\cdot$ & . & . & . \\
\hline \multicolumn{10}{|c|}{ Taxóns característicos de asociacións } \\
\hline Hedera hibernica & 1 & 3 & 1 & 2 & $1: 2$ & 3 & 2 & 2 & 1 \\
\hline Polystichum setiferum & 2 & 2 & 4 & 2 & 13 & 2 & 2 & 3 & 2 \\
\hline Melica uniflora & 2 & + & 1 & 1 & $1: 1$ & 1 & 2 & 1 & 1 \\
\hline Primula acaulis & 2 & 1 & 2 & 1 & +11 & 1 & 2 & 1 & + \\
\hline Mercurialis perennis & 2 & + & 1 & 1 & $1: 4$ & 2 & + & 3 & 2 \\
\hline Tamus communis & 1 & 1 & 1 & . & +11 & 1 & 2 & + & 1 \\
\hline Viola riviniana & 1 & + & + & 1 & +1 & 1 & + & . & 1 \\
\hline Stellaria holostea & + & 1 & 1 & 1 & $+1+$ & 2 & . & 1 & + \\
\hline Lonicera hispanica & + & 1 & 1 & 1 & $\begin{array}{c:c}\cdot 1 \\
\cdot 1\end{array}$ & 1 & 1 & 1 & 1 \\
\hline Daphne laureola & 1 & . & 1 & + & $\cdot 1$ & 1 & 1 & 1 & 1 \\
\hline
\end{tabular}

\begin{tabular}{|c|c|c|c|c|c|c|c|c|c|c|}
\hline $\mathrm{N}^{0}$ de orde & 1 & 2 & 3 & 4 & 5 & 6 & 7 & 8 & 9 & 10 \\
\hline Dryopteris filix-mas & 1 & 1 & + & 2 & 1 & + & 1 & $\cdot$ & + & $\cdot$ \\
\hline Lilium martagon & 1 & 1 & 1 & ${ }^{\circ}$ & + & 1 & 1 & . & 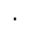 & 1 \\
\hline Sanicula europaea & . & ' & 1 & · & 1 & 1 & . & 2 & 1 & $\cdot$ \\
\hline Ruscus aculeatus & $\cdot$ & 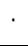 & . & ${ }^{\circ}$ & $\cdot$ & 1 & 1 & + & 1 & 3 \\
\hline \multicolumn{11}{|c|}{ Característicos do orde Fagetalia sylvaticae } \\
\hline Euphorbia dulcis & 1 & 1 & 1 & $\cdot$ & $\cdot$ & 2 & 1 & 1 & 1 & + \\
\hline Poa nemoralis & $\cdot$ & 1 & . & + & $\cdot$ & 1 & . & 1 & . & 1 \\
\hline Mycelis muralis & . & $\cdot$ & . & 1 & $\cdot$ & + & . & + & 1 & 1 \\
\hline Galium odoratum & $\cdot$ & $\cdot$ & $\cdot$ & 2 & 2 & . & . & $\cdot$ & 1 & + \\
\hline Ranunculus tuberosus & + & $\cdot$ & 1 & . & + & + & . & $\cdot$ & $\cdot$ & $\cdot$ \\
\hline Ornithogalum pyrenaicum & + & $\cdot$ & + & . & $\cdot$ & 1 & . & $\cdot$ & $\cdot$ & + \\
\hline Allium ursinum & 1 & $\cdot$ & . & · & 1 & 1 & . & $\cdot$ & . & $\cdot$ \\
\hline Phyllitis scolopendrium & 1 & . & $\cdot$ & · & $\cdot$ & 1 & . & 1 & . & $\cdot$ \\
\hline Carex sylvatica & $\cdot$ & $\cdot$ & · & · & $\cdot$ & + & 1 & 1 & . & $\cdot$ \\
\hline Moehringia trinervia & . & 1 & $\cdot$ & · & 1 & . & . & . & . & + \\
\hline Milium effusum & + & $\cdot$ & $\cdot$ & · & 1 & . & . & 1 & . & $\cdot$ \\
\hline Conopodium majus & + & $\cdot$ & $\cdot$ & · & $\cdot$ & 1 & . & . & . & + \\
\hline Veronica montana & $\cdot$ & ${ }^{\circ}$ & $\cdot$ & - & 1 & + & . & 1 & $\cdot$ & $\cdot$ \\
\hline \multicolumn{11}{|c|}{ Taxóns característicos do orde Quercetalia roboris } \\
\hline Teucrium scorodonia & & + & + & 1 & $\cdot$ & & 1 & $\cdot$ & + & + \\
\hline Polygonatum verticillatum & 1 & . & + & · & $r$ & . & 2 & 1 & . & $\cdot$ \\
\hline Hieracium murorum & $\cdot$ & $\cdot$ & . & 1 & $r$ & $\cdot$ & . & $\cdot$ & . & + \\
\hline Galium rotundifolium & . & . & 1 & . & $\cdot$ & . & + & $\cdot$ & $\cdot$ & + \\
\hline \multicolumn{11}{|c|}{ Taxóns característicos da clase Querco-Fagetea } \\
\hline Melittis melisophyllum & + & + & 1 & + & $r$ & . & + & $\cdot$ & 1 & + \\
\hline Helleborus foetidus & + & + & + & · & + & + & + & 1 & . & + \\
\hline Polypodium vulgare & 1 & + & 1 & + & $\cdot$ & + & + & . & + & + \\
\hline Hyacinthoides non-scripta & + & 2 & 1 & · & + & 1 & . & 1 & . & 1 \\
\hline Ajuga reptans & + & $\cdot$ & . & + & $\cdot$ & . & + & + & + & + \\
\hline Crepis lampsanoides & + & + & + & . & $\cdot$ & 1 & . & + & . & + \\
\hline Euphorbia amygdaloides & + & $\cdot$ & $\cdot$ & + & $r$ & r & + & . & . & + \\
\hline Anemone nemorosa & $\cdot$ & + & 2 & · & + & . & . & . & . & + \\
\hline Doronicum plantagineum & $\cdot$ & + & 2 & · & $\cdot$ & + & . & . & . & . \\
\hline Dryopteris affinis & 1 & . & 1 & . & $\cdot$ & . & 1 & . & . & . \\
\hline Oxalis acetosella & $\cdot$ & . & 1 & . & 1 & . & . & + & . & . \\
\hline Euphorbia hyberna & + & $\cdot$ & $\cdot$ & $\cdot$ & + & . & $\cdot$ & . & $\cdot$ & + \\
\hline \multicolumn{11}{|c|}{ Taxóns característicos da clase Salici-Populetea } \\
\hline Brachypodium sylvaticum & + & 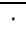 & $\cdot$ & 1 & $\cdot$ & 1 & $\cdot$ & 1 & . & . \\
\hline Athyrium filix-femina & 1 & . & + & + & + & . & $\cdot$ & . & $\cdot$ & . \\
\hline \multicolumn{11}{|l|}{ Outros taxóns } \\
\hline Geranium robertianum & 1 & 1 & 1 & + & 1 & 1 & $\cdot$ & 1 & + & + \\
\hline Brachypodium rupestre & 1 & 1 & 1 & 1 & $\cdot$ & 2 & . & + & 2 & 1 \\
\hline Rubus sp. & $\cdot$ & . & + & + & 1 & & + & + & $\cdot$ & + \\
\hline Asplenium trichomanes & + & + & $\cdot$ & · & $\cdot$ & + & + & . & + & + \\
\hline Omphalodes nitida & 1 & + & + & 1 & $\cdot$ & + & . & . & . & . \\
\hline Vicia sepium & 1 & . & $\cdot$ & · & + & & + & + & . & + \\
\hline Heracleum sphondylium & + & + & + & + & $\cdot$ & & . & + & . & . \\
\hline Pteridium aquilinum & $\cdot$ & . & . & + & $\cdot$ & 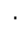 & + & + & + & . \\
\hline Asplenium adiantum-nigrum & $\cdot$ & . & . & + & . & & . & + & + & 1 \\
\hline Galium aparine & $\cdot$ & + & 1 & · & $r$ & & . & + & . & \\
\hline Asplenium onopteris & $\cdot$ & + & + & . & $\cdot$ & + & . & + & . & \\
\hline Urtica dioica & + & + & . & . & + & + & . & . & . & \\
\hline
\end{tabular}

Taxóns de baixa frecuencia:

$\mathbf{E}_{\mathbf{1}}+\mathbf{E}_{\mathbf{2}}$ : Cytisus scoparius: + en 4; Juglans regia: r en 1; Quercus robur: + en 6; Quercus x rosacea: 1 en 8 e 2 en 10 ; Quercus x trabutii: 1 en 9; Rosa micrantha: + en 1; Taxus baccata: 1 en 7; Ulmus glabra: 1 en 6 .

E $_{3}$ : Característicos de Fagetalia sylvaticae: Bromus ramosus: + en 6 e + en 9; Cardamine impatiens: + en 5 ; Corydalis cava: 1 en 5 e + en 9; Festuca altissima: 1 en 8. Característicos de Quercetalia roboris: Arenaria montana: + en 10; Blechnum spicant: + en 7; Lathyrus linifolius: + en 1 e + en 7; Luzula 
forsteri: + en 1 e + en 7; Physospermum cornubiense: + en 4 e + en 7. Característicos de Querco-Fagetea: Aquilegia vulgaris: + en 6. Característicos de Salici-Populetea: Arum italicum: + en 1 e + en 8; Circaea lutetiana: + en 1; Ranunculus ficaria: + en 1 e + en 6. Outros taxóns: Clinopodium vulgare: + en 10; Colchicum autumnale: + en 10; Cystopteris fragilis: + en 2; Digitalis purpurea: + en 4; Erythronium dens-canis: r en 5; Festuca sp.: + en 7; Fragaria vesca: + en 10; Geum urbanum: + en 8; Lamium maculatum: + en 5 e + en 6; Linaria triornithophora: + en 4; Meconopsis cambrica: r en 5; Narcissus asturiensis: + en 5 e + en 9; Narcissus triandrus: + en 2; Pentaglottis sempervirens: + en 1; Polygonatum odoratum: 1 en 6 e 1 en $8 ;$ Rumex acetosa: + en 10; Silene dioica: + en 3 ; Valeriana pyrenaica: + en 5 e + en 6.

Localidades (a notación numérica entre paréntese indica a situación na cuadrícula UTM de 1 km, fuso 29T): 1: Lu: Folgoso do Courel, Moreda, inicio do camiño á Devesa da Rogueira, augas arriba da Ponte de Vellos (654/4720); 2: Lu: Folgoso do Courel, Moreda, Teso dos Pariceiros (655/4720); 3: Lu: Folgoso do Courel, Moreda, Teso de Romeán, vertente N (654/4719); 4: Lu: Folgoso do Courel, Moreda, Devesa da Rogueira, val do Rego da Rogueira (654/4719); 5: Lu: Folgoso do Courel, Devesa da Rogueira, parte inferior (654/4719); 6: Lu: Folgoso do Courel, Moreda, inicio do camiño á Devesa da Rogueira, por riba da Cova de Vellos (654/4720); 7: Lu: Folgoso do Courel, Moreda, Devesa da Rogueira, extremo inferior (654/4719); 8: Lu: Folgoso do Courel, Moreda, Teso de Romeán, extremo inferior, por riba dos prados de sega (654/4719); 9: Lu: Folgoso do Courel, Moreda, parte inferior da Devesa da Rogueira, aos pés do teso baixo do rodal de aciñeiras, por riba do camiño (654/4719); 10: Lu: Folgoso do Courel, Moreda, Devesa da Rogueira (654/4719).

Dada a distribución que teñen as rochas carbonatadas na área de estudio e o particular ambiente no que medran, estes bosques só se atopan na área de confluencia dos regos do Freixedo e da Rogueira (Figura 3), cubrindo algo menos de 6 ha, no límite entre o piso mesotemperado superior e o supratemperado inferior. Pertencen á unha subasociación particular (quercetosum petraeae) da asociación Omphalodo nitidae-Coryletum avellanae, cuxa distribución restrínxese ás áreas de afloramentos calíos das montañas situadas ao $\mathrm{S}$ da Serra dos Ancares (Rodríguez Guitián et al. 2000, Rodríguez Guitián et al. 2012). Na Táboa 7 aportase información detallada sobre a ecoloxía e a composición florística destes bosques dentro do ámbito de estudo.

\section{Abeledos silicícolas}

Trátase de bosques de pequena talla $(6-10 \mathrm{~m})$, ou microbosques, dominados pola abeleira (Corylus avellana) que medran sobre solos de $\mathrm{pH}$ acedo derivados de rochas lousas, cuarcitas e areíscas. Cara ás partes baixas de $A$ Rogueira, estes bosques adoitan atoparse en situacións topográficas moi semellantes ás dos bosques mixtos, como fondos de valgadas secas e partes baixas de ladeiras, sobre solos moi pedregosos; nas partes altas tenden a intercalarse, principalmente, entre os faiais e os carballais umbrófilos (Figura 3). Non é raro atopar no interior destas formacións tocóns de árbores (carballos, rebolos, faias) taladas hai décadas para aproveitar a súa madeira ou elaborar carbón vexetal para abastecer as numerosas ferrerías e fraguas que estiveron activas até inicios do século XX no entorno da Rogueira. Por estas razóns, os abeledos consideranse bosques que substitúen a outros tipos de formacións arboradas que perderon as súas primitivas especies dominantes debido a unha forte presión antrópica, e dicir, son bosques de carácter serial ou secundario.

Compañeiros habituais da abeleira nestes bosques son o capudre (Sorbus aucuparia) e o acibo (Ilex aquifolium), e máis esporadicamente, a faia (Fagus sylvatica), o pradairo (Acer pseudoplatanus), o espiño (Crataegus monogyna), o bidueiro (Betula pubescens) e os carballos (Quercus petraea, Q. x rosacea). No sotobosque abundan as especies acidófilas, como Saxifraga spathularis, Luzula sylvatica ou Dryopteris dilatata, ás que se unen outras, como Lonicera hispanica, Hedera hibernica, Viola riviniana, Oxalis acetosella, Anemone nemorosa, Omphalodes nitida, D. filix-mas, Dryopteris affinis, Stellaria holostea,
Hyacinthoides non-scripta, Polypodium vulgare, Euphorbia hyberna, Milium effusum, Lilium martagon ou Carex sylvatica. Aínda que a composición florística global destes bosques é próxima á dos bosques mixtos, adoitan ter un número medio de especies por inventario sensiblemente inferior a estes, cunha maior presenza de especies escionitrófilas (Geranium robertianum, Galium aparine, Lapsana communis, Urtica dioica, etc.).

$\mathrm{Na}$ área de traballo, este tipo de abeledos pódense atopar entre os 750 e os $1.250 \mathrm{~m}$ de altitude, ao longo dos pisos mesotemperado superior e supratemperado inferior, ocupando, en conxunto, algo máis de 2 ha. Este tipo de bosques foi interpretado como un aspecto particular dos faiais silicícolas máis extendidos nestas montañas, baixo a denominación de Luzulo henriquesii-Fagetum sylvaticae subas. coryletosum avellanae (Izco et al. 1986a). Non obstante, o seu comportamento como comunidade serial e o feito de estar dinámicamente vinculados a diversos tipos de bosques poderían avalar outras posibles interpretacións, como a realizada por Rivas-Martínez et al. (2002) para abeledos silicícolas semellantes a estes presentes na área centro-oriental dal da Cordillera Cantábrica, que se consideran unha asocición vexetal independiente (Linario triornithophorae-Coryletum avellanae). $\mathrm{Na}$ Táboa 7 reuniuse a información ecolóxica e florística dispoñible sobre este tipo de bosques.

\section{Abeledos calcícolas}

Bosques de pequena talla (microbosques) de abeleira (Corylus avellana) que medran en valgadas, partes baixas das ladeiras e o pé de cantís rochosos, sobre solos pedregosos derivados de rochedos carbonatados (calías, dolomías). Acompañan á especie directriz comentada outras árbores como freixos (Fraxinus excelsior), pradairos (Acer pseudoplatanus), espiños (Crataegus monogyna), acibos (Ilex aquifolium) e capudres (Sorbus aucuparia). O sotobosque garda parecido co que presentan os abeledos silicícolas, aínda que tende a ser máis rico en especies, gañando presenza plantas como Mercurialis perennis, Polystichum setiferum, Primula acaulis, Daphne laureola, Melica uniflora, Lilium martagon, Helleborus foetidus, Hyacinthoides non-scripta ou Potentilla sterilis. Faltan ou son moi escasas neste tipo de abeledos as especies máis típicamente acidófilas, como Luzula sylvatica, Saxifraga spathularis, Vaccinium myrtillus, Avenella flexuosa ou Holcus mollis. 
Táboa 8.- Composición florística de abeledos seriais silicícolas (inv. 1-7) e calcícolas (inv. 8-18)

Area $(\mathrm{m}<)$

Altura $E_{1}(m)$

Cob. $E_{1}(>4,0 \mathrm{~m})(\%)$

Cob. $E_{2}(1,5-4,0 \mathrm{~m})(\%)$

Cob. $E_{3}(<1,5 \mathrm{~m})(\%)$

Altitude (m)

Pendente $\left({ }^{\circ}\right)$

Orientación

$N^{\circ}$ de taxóns

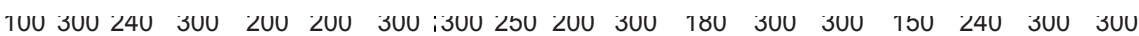
$\begin{array}{llllll:llllllllllll}--- & --- & 10 & 8-12 & 8-10 & 6-10 & 6-10 & --- & --- & 6-10 & 8-12 & 6 & 8-17 & 9 & 8 & 6-10 & 12 & 6-10\end{array}$

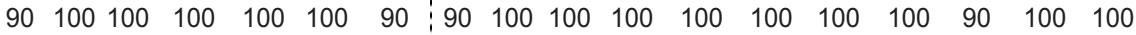

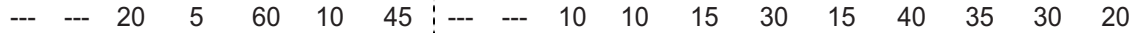

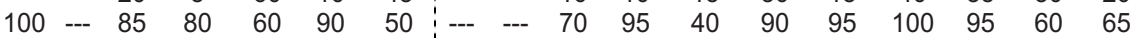

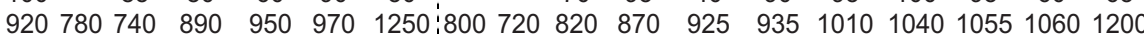
$\begin{array}{lllllll:lllllllllll}10 & 35 & 46 & 36 & 38 & 42 & 30 & 45 & 40 & 32 & 30 & 32 & 36 & 40 & 50 & 30 & 22 & 32\end{array}$ $\mathrm{N} N W$ E WNW $\mathrm{N}$ ENE NNW $\mathrm{W}$ W $\mathrm{E}$ E WSW NE NNW NNE $\mathrm{N}$ NW \begin{tabular}{llllllllllllllllll}
33 & 38 & 36 & 33 & 27 & 37 & 40 & 49 & 41 & 48 & 41 & 35 & 37 & 46 & 41 & 51 & 44 & 47 \\
\hline
\end{tabular}

$\mathrm{E}_{1}(>4,0 \mathrm{~m})+\mathrm{E}_{2}(>1,5-4,0 \mathrm{~m})$ :

Corylus avellana

Crataegus monogyna

llex aquifolium

Acer pseudoplatanus

Sorbus aucuparia

Fraxinus excelsior

Prunus avium

Rosa gr. canina

Fagus sylvatica

Quercus pyrenaica

Cytisus scoparius

Erica arborea

Salix caprea

Castanea sativa

\begin{tabular}{rllllll|lllllllllll}
5 & 4 & 5 & 5 & 5 & 5 & 5 & 4 & 5 & 5 & 5 & 5 & 5 & 5 & 5 & 4 & 5 & 5 \\
. & 2 & 1 & + & 1 & + & $\cdot$ & 1 & + & 1 & 1 & 1 & 1 & 1 & + & 2 & 1 & 1
\end{tabular}

$\mathrm{E}_{3}(<1,5 \mathrm{~m})$ :

Taxóns diferenciais de asociacións

Dryopteris dilatata

Avenella flexuosa

Ornithogalum pyrenaicum

Potentilla sterilis

Viola suavis

Clematis vitalba

Doronicum plantagineum

Cardamine impatiens

Neottia nidus-avis

Prunus spinosa

Laserpitium nestleri

Epipactis helleborine

Taxóns característicos de asociacións

Hedera hibernica

Polystichum setiferum

Melica uniflora

Primula acaulis

Stellaria holostea

Viola riviniana

Mercurialis perennis

Daphne laureola

Hyacinthoides non-scripta

Tamus communis

Lonicera hispanica

Lilium martagon

Luzula sylvatica

Galium odoratum

Dryopteris filix-mas

Sanicula europaea

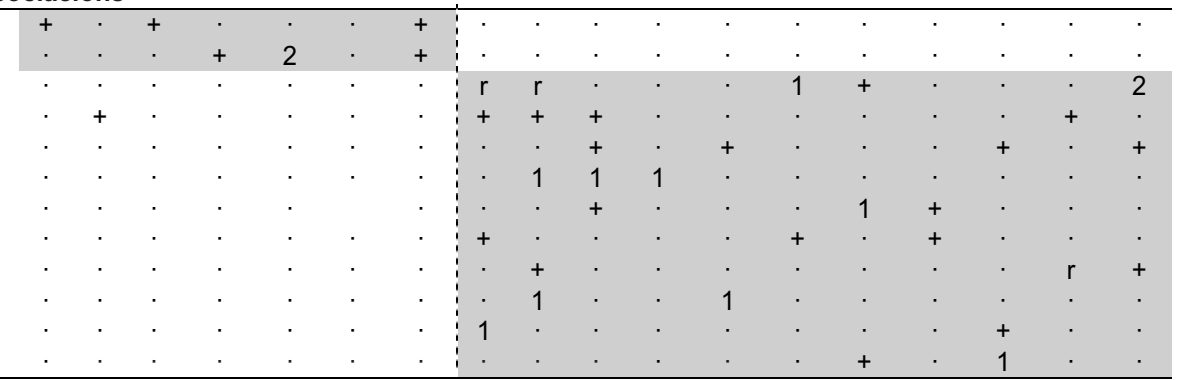

Taxóns característicos do orde Fagetalia sylvaticae

Euphorbia dulcis

Poa nemoralis

Mycelis muralis

Moehringia trinervia

Conopodium majus

Carex sylvatica

Corydalis cava

\begin{tabular}{|c|c|c|c|c|c|c|c|c|c|c|c|c|c|c|c|c|c|}
\hline+ & + & 2 & 2 & + & 1 & + & 3 & 3 & 1 & 4 & 2 & 4 & 1 & 3 & 1 & 1 & + \\
\hline . & 1 & 2 & 1 & + & 3 & . & 1 & 4 & 1 & 3 & 1 & 3 & 2 & 2 & 1 & 2 & 2 \\
\hline 1 & 2 & 1 & 1 & $\cdot$ & 1 & $\cdot$ & 1 & 2 & 1 & 1 & 1 & + & 1 & 1 & 1 & + & 1 \\
\hline+ & 1 & 1 & + & $\cdot$ & 2 & . & 1 & 1 & 1 & 1 & $\cdot$ & 2 & 2 & 1 & 2 & 2 & 1 \\
\hline 1 & 1 & 1 & 2 & 1 & 1 & 1 & 1 & 1 & + & . & 1 & $\cdot$ & 1 & + & 2 & 1 & + \\
\hline+ & + & + & $\cdot$ & + & + & $\cdot$ & + & + & + & + & + & $r$ & + & + & 1 & $\cdot$ & + \\
\hline$\cdot$ & 1 & 2 & + & $\cdot$ & . & $\cdot$ & 1 & 1 & + & 3 & 2 & 1 & 2 & 3 & 3 & 3 & 4 \\
\hline . & + & $\cdot$ & + & $r$ & 1 & $\cdot$ & 1 & + & 1 & 2 & . & 1 & 1 & + & 1 & 1 & + \\
\hline . & 1 & 1 & + & 1 & 1 & 2 & $\cdot$ & $\cdot$ & + & + & 1 & 1 & 2 & 1 & 2 & 1 & + \\
\hline . & 1 & 1 & + & $\cdot$ & . & $\cdot$ & 1 & 1 & 1 & + & 2 & 1 & 1 & 1 & 1 & 1 & $\cdot$ \\
\hline 1 & $\cdot$ & 1 & 1 & 2 & 1 & + & + & 1 & 1 & $\cdot$ & $\cdot$ & + & + & $\cdot$ & + & + & $\cdot$ \\
\hline+ & 1 & + & $\cdot$ & $\cdot$ & $\cdot$ & 1 & + & 1 & + & . & $\cdot$ & + & 2 & 1 & 1 & 1 & + \\
\hline+ & $\cdot$ & 2 & $\cdot$ & $\cdot$ & . & 1 & 1 & $\cdot$ & $\cdot$ & . & $\cdot$ & 2 & 1 & 1 & . & $\cdot$ & . \\
\hline 1 & $\cdot$ & . & $\cdot$ & $\cdot$ & 1 & . & $\cdot$ & $\cdot$ & $\cdot$ & 1 & $\cdot$ & + & . & $\cdot$ & 1 & 1 & + \\
\hline$\cdot$ & $\cdot$ & . & $\cdot$ & 1 & . & 1 & $\cdot$ & $\cdot$ & $\cdot$ & . & . & + & + & 1 & . & + & 1 \\
\hline+ & . & $\cdot$ & . & $\cdot$ & . & . & $\cdot$ & 1 & $\cdot$ & + & . & . & + & . & . & $\cdot$ & . \\
\hline
\end{tabular}

Taxóns característicos do orde Quercetalia roboris

Teucrium scorodonia

Saxifraga spathularis

Polygonatum verticillatum

Luzula forsteri

Holcus mollis

\begin{tabular}{lllllll|llllllllllll}
+ & 1 & $\cdot$ & 1 & $\cdot$ & $\cdot$ & $\cdot$ & 1 & 1 & 1 & 1 & $\cdot$ & + & 1 & + & + & $\cdot$ & 1 \\
1 & + & $\cdot$ & $\cdot$ & $\cdot$ & $\cdot$ & + & 1 & 1 & $\cdot$ & $\cdot$ & 1 & $\cdot$ & 1 & $\cdot$ & $\cdot$ & $\cdot$ & + \\
1 & 1 & $\cdot$ & $\cdot$ & $\cdot$ & $\cdot$ & $\cdot$ & $\cdot$ & + & $\cdot$ & + & $\cdot$ & $\cdot$ & $\cdot$ & + & + & $\cdot$ & + \\
$\cdot$ & $\cdot$ & $\cdot$ & $\cdot$ & $\cdot$ & 1 & $\cdot$ & $\cdot$ & $\cdot$ & + & + & $\cdot$ & $\cdot$ & + & $\cdot$ & $\cdot$ & + & 1 \\
$\cdot$ & $\cdot$ & $\cdot$ & $\cdot$ & $\cdot$ & + & 1 & $\cdot$ & $\cdot$ & $\cdot$ & $r$ & $\cdot$ & $\cdot$ & $\cdot$ & $\cdot$ & + & + & 1 \\
$r$ & + & $\cdot$ & $\cdot$ & $\cdot$ & $\cdot$ & $\cdot$ & + & $\cdot$ & + & 1 & $\cdot$ & $\cdot$ & $\cdot$ & $\cdot$ & $\cdot$ & + & $\cdot$ \\
$\cdot$ & $\cdot$ & $\cdot$ & $\cdot$ & $\cdot$ & + & $\cdot$ & $\cdot$ & $\cdot$ & $\cdot$ & + & $\cdot$ & $\cdot$ & $\cdot$ & $\cdot$ & $\cdot$ & + & +
\end{tabular}

\begin{tabular}{|c|c|c|c|c|c|c|c|c|c|c|c|c|c|c|c|c|c|}
\hline$\cdot$ & $r$ & 1 & + & . & . & . & + & + & + & + & $\cdot$ & $\cdot$ & $\cdot$ & . & + & $\cdot$ & $\cdot$ \\
\hline 1 & + & + & . & 2 & + & 1 & $\cdot$ & + & $\cdot$ & . & $\cdot$ & + & . & + & . & $\cdot$ & $\cdot$ \\
\hline . & . & . & $\cdot$ & . & $\cdot$ & + & + & 1 & $\cdot$ & + & . & $\cdot$ & + & + & $\cdot$ & $\cdot$ & $\cdot$ \\
\hline$\cdot$ & $r$ & . & + & $\cdot$ & $\cdot$ & $\cdot$ & $\cdot$ & $\cdot$ & + & $\cdot$ & $\cdot$ & . & $\cdot$ & $\cdot$ & + & + & $\cdot$ \\
\hline . & . & 1 & 3 & 2 & + & . & . & $\cdot$ & . & . & . & . & . & . & . & + & + \\
\hline
\end{tabular}




\begin{tabular}{|c|c|c|c|c|c|c|c|c|c|c|c|c|c|c|c|c|c|c|}
\hline $\mathrm{N}^{0}$ de orde & 1 & 2 & 3 & 4 & 5 & 6 & 7 & 8 & 9 & 10 & 11 & 12 & 13 & 14 & 15 & 16 & 17 & 18 \\
\hline \multicolumn{19}{|c|}{ Taxóns característicos da clase Querco-Fagetea } \\
\hline Helleborus foetidus & $\cdot$ & 1 & $\cdot$ & 1 & $\cdot$ & . & $\cdot$ & . & + & + & + & + & . & + & + & + & . & + \\
\hline Crepis lampsanoides & . & + & + & + & . & + & . & + & + & . & . & . & . & + & + & + & + & . \\
\hline Melittis melisophyllum & $\cdot$ & . & + & $\cdot$ & . & + & $\cdot$ & + & . & + & . & + & . & + & . & + & . & + \\
\hline Euphorbia amygdaloides & . & + & . & . & . & . & . & . & + & + & . & . & . & + & 1 & + & . & . \\
\hline Anemone nemorosa & $\cdot$ & . & . & $\cdot$ & 1 & . & 2 & + & . & $\cdot$ & . & . & + & 1 & 1 & . & . & . \\
\hline Ajuga reptans & . & . & . & + & . & . & $\cdot$ & + & . & 1 & . & . & + & . & . & . & + & . \\
\hline Polypodium vulgare & . & . & + & . & + & . & . & . & . & . & . & . & . & + & + & . & . & . \\
\hline Dryopteris affinis & . & . & 1 & . & 1 & . & + & . & . & . & . & . & . & . & + & . & . & . \\
\hline Euphorbia hyberna & $\cdot$ & . & . & $\cdot$ & . & + & 1 & . & . & . & . & + & . & + & . & . & . & . \\
\hline Oxalis acetosella & + & . & . & . & . & . & + & . & + & . & . & . & . & . & . & . & + & . \\
\hline \multicolumn{19}{|c|}{ Taxóns característicos da clase Salici-Populetea } \\
\hline Brachypodium sylvaticum & $\cdot$ & + & $\cdot$ & + & $\cdot$ & $\cdot$ & $\cdot$ & 1 & $\cdot$ & . & . & $\cdot$ & 1 & 2 & 2 & 1 & + & . \\
\hline \multicolumn{19}{|l|}{ Outros taxóns } \\
\hline Geranium robertianum & + & 5 & 1 & $\cdot$ & $\cdot$ & 1 & $\cdot$ & + & + & 1 & 1 & 1 & . & 1 & + & + & + & + \\
\hline Rubus sp. & 1 & . & . & $\mathrm{r}$ & 1 & + & . & + & 1 & 1 & + & . & + & + & . & + & + & 1 \\
\hline Vicia sepium & + & + & . & $\cdot$ & · & . & $\cdot$ & + & . & $r$ & + & . & $r$ & . & + & + & + & + \\
\hline Pteridium aquilinum & $\cdot$ & + & . & + & + & + & + & + & . & . & . & + & . & . & . & 1 & + & . \\
\hline Omphalodes nitida & + & . & . & . & + & . & + & + & + & 1 & . & . & . & 1 & . & 1 & . & . \\
\hline Polygonatum odoratum & $\cdot$ & + & . & $\cdot$ & $r$ & . & + & . & . & + & . & + & . & + & + & + & . & 1 \\
\hline Brachypodium rupestre & $\cdot$ & . & 2 & $\cdot$ & · & . & $\cdot$ & · & . & 2 & 2 & 2 & . & 1 & . & 2 & . & 2 \\
\hline Heracleum sphondylium & $\cdot$ & . & $\cdot$ & + & $r$ & + & $\cdot$ & · & $\cdot$ & $\cdot$ & $r$ & + & . & + & $r$ & . & $r$ & · \\
\hline Asplenium trichomanes & $\cdot$ & . & + & . & . & + & . & . & . & + & . & + & . & . & + & + & + & 1 \\
\hline Galium aparine & + & + & $\cdot$ & $\cdot$ & · & 1 & . & . & . & . & . & . & . & 1 & + & 1 & + & 1 \\
\hline Ruscus aculeatus & . & . & + & $\cdot$ & · & $\cdot$ & . & 2 & . & . & + & 1 & 1 & + & + & . & . & . \\
\hline Rumex acetosella & + & $r$ & . & $\cdot$ & 1 & . & . & + & $r$ & $\cdot$ & . & . & . & . & . & . & . & . \\
\hline Asplenium adiantum-nigrum & . & . & . & $\cdot$ & · & . & $\cdot$ & · & . & + & + & . & + & + & + & . & + & . \\
\hline Fragaria vesca & . & . & $\cdot$ & $\cdot$ & · & . & $\cdot$ & . & . & + & . & . & + & . & 1 & 2 & . & . \\
\hline Lapsana communis & . & 1 & + & $\cdot$ & · & + & $\cdot$ & · & . & $\cdot$ & + & + & . & . & . & . & . & . \\
\hline Asplenium onopteris & . & . & + & $\cdot$ & · & . & . & + & . & + & . & + & . & . & . & . & . & · \\
\hline Lamium maculatum & . & . & $\cdot$ & $\cdot$ & · & + & $\cdot$ & · & $r$ & $\cdot$ & + & + & . & . & . & . & . & + \\
\hline Cystopteris fragilis & . & . & + & $\cdot$ & · & + & $\cdot$ & . & $\cdot$ & . & . & . & . & . & $r$ & . & . & + \\
\hline
\end{tabular}

Taxóns de baixa frecuencia:

$\mathrm{E}_{1}+\mathrm{E}_{2}$ : Betula pubescens: 1 en 4, 1 en 7 e 1 en 11; Quercus petraea: 1 en 7 e 1 en 11; Quercus robur: 1 en 8 ; Quercus x rosacea: 1 en 12; Rosa micrantha: + en 12; Sorbus aria: 1 en 18; Taxus baccata: 1 en 16.

$\mathbf{E}_{3}$ : Característicos de Fagetalia sylvaticae: Allium ursinum: + en 9 e + en 11; Milium effusum: 1 en 1 , + en 7 e + en 18; Phyllitis scolopendrium: 1 en 9; Ranunculus tuberosus: $r$ en 2, 1 en 14 e 1 en 16. Característicos de Quercetalia roboris: Ceratocapnos claviculata: + en 7; Galium rotundifolium: + en 10 e + en 16; Hieracium murorum: + en 8; Lathyrus linifolius: + en 14; Melampyrum pratense: + en 7; Poa chaixii: 1 en 7;. Característicos de Querco-Fagetea: Aquilegia vulgaris: + en 2; Conopodium pyrenaeum: + en 1. Característicos de Salici-Populetea: Arum italicum: + en 2; Athyrium filix-femina: 1 en 7; Circaea lutetiana: 1 en 2 e + en 9; Ranunculus ficaria: + en 6 e+ en 17. Outros taxóns: Allium victorialis: + en 7; Angelica major: + en 7; Arabis alpina: + en 12; Arrhenatherum bulbosum: r en 8 e + en 12; Cardamine flexuosa: + en 18; Carex pilulifera: + en 18; Ceterach officinarum: + en 10; Cruciata glabra: + en 10 e 1 en 16; Digitalis purpurea: + en 3 e 1 en 4; Doronicum pubescens: 1 en 7 e + en 8; Epilobium obscurum: 1 en 1; Epilobium parviflorum: 1 en 2, + en 8 e + en 9; Erythronium dens-canis: + en 5 e + en 7; Festuca sp.: 1 en 8, + en 14 e + 16; Galium mollugo: + en 4 e + en 12; Galium papillosum: + en 16; Gentiana aurantiaca: + en 7; Geranium lucidum: + en 6, + en 12 e + en 18; Geranium sanguineum: + en 8; Geum urbanum: 1 en 1 e + en 2; Myosotis sp.: + en 18; Narcissus asturiensis: + en 18; Narcissus triandrus: + en 15; Pentaglottis sempervirens: + en 3, + en 12 e + en 18; Pimpinella major: + en 11 e r en 13; Pritzelago auerwsaldii: + en 17; Ranunculus platanifolius: 1 en 7 e + en 15; Rumex acetosa: + en 7, r en 10 e + en 18; Saxifraga granulata: + en 6 e + en 17; Silene dioica: + en 6; Silene vulgaris: + en 6 e + en 12; Torilis arvensis: + en 16; Umbilicus rupestris: + en 3; Urtica dioica: + en 1, + en 2 e + en 18; Valeriana montana: + en 7 e + en 13; Vincetoxicum nigrum: + en 10.

Localidades (a notación numérica entre paréntese indica a situación na cuadrícula UTM de $1 \mathrm{~km}$, fuso 29T): 1: Lu: Folgoso do Courel, Devesa de Rogueira, entre dos regatos hacia su parte Oeste (653/4720) [lzco et al. (1986): táb. 2: inv. 2]; 2: Lu: Folgoso do Courel, between Moreda and Rogueira (654/4721) [Amigo et al. (1994): táb. 2: inv. 8]; 3: Lu: Folgoso do Courel, Moreda, inicio do camiño á Devesa da Rogueira, augas arriba da Ponte de Vellos (654/4720); 4: Lu: Folgoso do Courel, Moreda, Teso de Romeán, extremo inferior, por riba dos prados de sega (654/4719); 5: Lu: Folgoso do Courel, Moreda, Carrozo da Muiña (655/4720); 6: Lu: Folgoso do Courel, Moreda, val do Carrozo da Muiña (655/4720); 7: Lu: Folgoso do Courel, Devesa da Rogueira, entrada desde O Couto, por riba da cabana de pastores (655/4719); 8: Lu: Folgoso do Courel, between Moreda and Devesa de Rogueira (654/4721) [Amigo et al. 1994): táb. 2: inv. 3]; 9: Lu: Folgoso do Coaurel, between Moreda and Devesa de Rogueira (654/4721) [Amigo et al. 1994): táb. 2: inv. 4]; 10: Lu: Folgoso do Courel, Moreda, camiño de acceso aos pados da base da Devesa da Rogueira (654/4719); 11: Lu: Folgoso do Courel, Moreda, camiño de acceso á Devesa da Rogueira (654/4719); 12: Lu: Folgoso do Courel, Moreda, Teso de Romeán (654/4719); 13: Lu: Folgoso do Courel, Moreda, Devesa da Rogueira, taro calío da parte baixa (654/4719); 14: Lu: Folgoso do Courel, Moreda, Teso de Romeán, parte media (655/4719); 15: Lu: Folgoso do Courel, Moreda, Teso de Romeán, parte media (655/4719); 16: Lu: Folgoso do Courel, Moreda, Teso de Romeán, parte media (655/4719); 17: Lu: Folgoso do Courel, Moreda, Val do Carrozo da Muiña, enfrente ao último prado (655/4719); 18: Lu: Folgoso do Courel, Moreda, Carrozo da Muíña, extremo superior (655/4719). 
Ao igual que o resto de bosques calcícolas xa tratados, a superficie ocupada por estes abeledos é relativamente pequena con relación ao total das masas arboradas presentes na área de estudo (13,2 ha), distribuíndose entre os 800 e $1.200 \mathrm{~m}$ de altitude (pisos mesotemperado superior e supratemperado inferior)(Figura 3). Desde o punto de vista fitosociolóxico, este tipo de abeledos incluiríanse, segundo o criterio de Amigo et al. (1994) e Rodríguez Guitián et al. (2000) dentro da subasociación típica (coryletosum avellanae) da asociación Ompalodo nitidae-Coryletum avellanae. Non obstante, nun recente traballo Rodríguez Guitián (2011) plantexa, de xeito provisional, a súa separación nunha nova asociación vexetal (Daphno laureolae-Coryletum avellanae), en parte aplicando criterios fisionómicos e dinámicos utilizados por Rivas-Martínez et al (2002) na caracterización dos abeledos seriais calcícolas do centro-oriente da Cordillera Cantábrica. Na Táboa 7 reúnese a información recompilada para os abeledos calcícolas dentro do ámbito territorial deste traballo.

\section{Aciñeirais}

A presenza de bosques dominados pola aciñeira (Quercus ilex subsp. ballota) no cerne das montañas courelás explícase pola capacidade que ten esta especie para resistir invernos rigorosos até cotas altas $(>1200 \mathrm{~m})$ en posicións topográficas que reciban unha elevada radiación solar e evacúen facilmente as elevadas precipitacións que reciben. No entorno da Devesa da Rogueira estes enclaves concrétanse en abas de forte inclinación e orientadas principalmente cara o $\mathrm{S}$ e $\mathrm{W}$ asentadas sobre litosolos e afloramentos rochosos calíos (Figura 3).

Desde o punto de vista fisionómico, trátase maioritariamente de bosques mestos de pequena talla (4-8 $\mathrm{m})$, que se transforman de xeito progresivo en formacións máis abertas e achaparradas, de entre 1 e $2 \mathrm{~m}$ conforme se sitúan a maior altitude. Esténdense desde os $825 \mathrm{~m}$ (termotipo mesotemperado superior), nas proximidades da unión dos regos do Freixedo e da Rogueira, até os $1.335 \mathrm{~m}$ (termotipo supratemperado superior), no cumio do Alto do Couto, cubrindo algo máis de 7 ha.

Outras especies arbóreas de pequena talla, como Crataegus monogyna, llex aquifolium, Prunus spinosa ou Corylus avellana adoitan acompañar á aciñeira neste tipo de formacións. Por debaixo deste dosel aparece un amplo conxunto de especies adaptado a fortes oscilacións térmicas, moitas delas características de comunidades herbáceas calcícolas que crecen formando mosaico cos propios aciñeirais, como Brachypodium rupestre, Laserpitium nestleri, Glandora diffusa, Polygonatum odoratum, Clinopodium vulgare, Galium mollugo, Biscutella valentina, Arabis hirsuta, Origanum virens, Scabiosa columbaria, Sedum album, Ceterach officinarum, Erysimum linifolium ou Ligusticum lucidum. Xunto a estas, nas áreas baixas e abrigadas aparecen outras frecuentes en varios dos tipos de bosques caducifolios calcícolas descritos noutros apartados, como Ruscus aculeatus ou Tamus communis. Spiraea obovata é unha especies exclusiva deste tipo de bosques dentro do ámbito estudado.
Os aciñeirais calcícolas comentados inclúense na asociación fitosociolóxica Genisto falcatae-Quercetum rotundifoliae (Izco et al. 1990), exclusiva das montañas calías do extremo occidental da Cordillera Cantábrica, descrita hai máis de 60 anos por Bellot (1951). Na Táboa 8 apórtase a información dispoñible para este tipo de bosques dentro da área de estudio.

\section{Espiñais calcícolas}

Bosques de pequena talla (microbosques, 2-6 m de altura) caracterizados polo dominio de especies pinchudas que se desenvolven preferentemente sobre solos ricos en nutrientes, particularmente os formados a partir de rochas carbonatadas (calías, dolomías). Son especies leñosas típicas destas microformacións forestais Crataegus monogyna e Prunus spinosa así como diversas especies dos xéneros Rosa (silvamachas ou roseiras bravas), como Rosa canina, $R$. micrantha, $R$. corymbifera ou $R$. villosa, e Rubus (Giménez de Azcárate et al. 1996, Rodríguez Guitián \& Amigo 2009b). A gran tendencia que presentan estes vexetais a ramificarse abundantemente en ambientes con elevada insolación fai que a estrutura destas comunidades sexa especialmente enmarañada, dificultando grandemente o tránsito, tanto humano como da fauna silvestre e doméstica, polo seu interior.

Ao abeiro proporcionado polas especies do nivel superior medran un gran número de plantas de requirimentos ecolóxicos variados, desde especies típicas de pastizais abertos sobre solos crioturbados (afectados fortemente polas xeadas invernais)(Scabiosa columbaria, Anthylis vulneraria subsp. alpestris), até plantas características do nivel inferior dos bosques calcícolas comentados noutros apartados, como Primula acaulis, Mercurialis perennis ou Daphne laureola, pasando por outras típicas de formacións herbáceas densas de carácter mesófilo (Brachypodium rupestre, Thalictrum minus, Laserpitium nestleri) ou orlas herbáceas de borde de bosque (Geranium sanguineum, Trifolium medium, Melittis melissophyllum). Nos espiñais situados nos niveis inferiores da Devesa da Rogueira adoitan integrarse certas plantas termófilas, como Ruscus aculeatus, Tamus communis ou Clematis vitalba, ausentes dos niveis superiores, nos que, contrariamente, é frecuente atopar Sorbus aucuparia e Rosa villosa.

Os espiñais son relativamente abundantes na área de estudio, se ben adoitan configurar formacións a modo de estreitas bandas que forman mosaico ou se intercalan entre o resto de comunidades calcícolas descritas previamente (Figura 7). Por esta razón, a súa cartografía en detalle resulta particularmente complicada, sendo habitual que a súa presenza nun determinado territorio resulte minusvalorada. Na cartografía elaborada, a superficie que ocupa este tipo de bosque sitúase en torno ás 7 has. En conxunto, estes microbosques aparecen dentro do intervalo no que afloran os materiais carbonatados $(850-1.300 \mathrm{~m})$, cuxos límites extremos poden asimilarse aos establecidos para o caso dos aciñeirais, bosques cos que é habitual que os espiñais entren en contacto. Consecuentemente, cobren un amplo intervalo bioclimático, que vai desde o piso mesotemperado superior até o límite inferior do supratemperado superior. 
Táboa 9.- Composición florística de aciñeirais (inv. 1-8), espiñais (inv. 9-10) e soutos (invs. 11-12)

\begin{tabular}{|c|c|c|c|c|c|c|c|c|c|c|c|c|}
\hline $\mathrm{N}^{0}$ de orde & 1 & 2 & 3 & 4 & 5 & 6 & 7 & $8:$ & 9 & 10 & 11 & 12 \\
\hline Área $\left(m^{2}\right)$ & 75 & 150 & 300 & 300 & 140 & 240 & 300 & $\begin{array}{l:}50 \\
50\end{array}$ & 400 & 100 & 300 & $\overline{400}$ \\
\hline Altura $E_{1}(m)$ & -- & -- & $4-6$ & $4-8$ & $4-6$ & 3 & $4-6$ & $3: 0$ & $0,5-2,0$ & $2-3,5$ & 26 & 18 \\
\hline Cob. $E_{1}(>4 \mathrm{~m})(\%)$ & 90 & 90 & 25 & 90 & 40 & -- & 30 & --. 1 & -- & -- & 90 & 85 \\
\hline Cob. $E_{2}(1,5-4 \mathrm{~m})(\%)$ & --- & -- & 100 & 40 & 100 & 70 & 100 & 100 & 30 & 80 & 30 & 0 \\
\hline Cob. $E_{3}(<1,5 \mathrm{~m})(\%)$ & 50 & 75 & 90 & 85 & 85 & 90 & 95 & 85 & 90 & 100 & 90 & 95 \\
\hline Altitude (m) & 840 & 880 & 835 & 995 & 1015 & 1150 & 1225 & 1335 & 1005 & 1300 & 770 & 885 \\
\hline Pendente $\left({ }^{\circ}\right)$ & 30 & 30 & 36 & 40 & 32 & 38 & 28 & 32 & 8 & 24 & 30 & 22 \\
\hline Orientación & SE & $E$ & ESE & SW & SSW & WNW & SW & SW & SW & SSE & NE & W \\
\hline $\mathrm{N}^{0}$ taxones & 23 & 30 & 49 & 41 & 44 & 33 & 39 & $18 i$ & 35 & 23 & 46 & 48 \\
\hline \multicolumn{13}{|c|}{$E_{1}(>4,0 \mathrm{~m})+E_{2}(>1,5-4,0 \mathrm{~m}):$} \\
\hline Cytisus scoparius & + & + & + & + & + & + & + & $\cdot$ & + & 1 & 1 & 1 \\
\hline Quercus ballota & 5 & 5 & 5 & 5 & 5 & 5 & 5 & 5 & + & . & 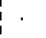 & . \\
\hline Crataegus monogyna & + & + & 2 & 1 & 1 & . & 1 & · & 3 & 5 & 1 & $\cdot$ \\
\hline Prunus spinosa & . & . & . & 2 & 1 & . & + & 2 & 3 & 1 & . & $\cdot$ \\
\hline Rosa gr. canina & . & . & 1 & 1 & $\cdot$ & 1 & 1 & . & . & . & + & $\cdot$ \\
\hline Ilex aquifolium & . & $r$ & + & . & + & . & . & . & . & . & + & $\cdot$ \\
\hline Corylus avellana & . & . & 1 & . & 1 & . & . & . & 1 & . & 2 & $\cdot$ \\
\hline Quercus pyrenaica & . & . & . & . & . & . & 1 & . & . & 1 & r & 1 \\
\hline Fraxinus excelsior & . & . & + & 1 & . & . & $\cdot$ & $\cdot$ & . & . & 2 & $\cdot$ \\
\hline Sorbus aucuparia & . & . & . & . & . & . & . & $+i$ & . & . & + & + \\
\hline Castanea sativa & . & . & . & . & . & . & . & . & . & . & 5 & 5 \\
\hline
\end{tabular}

\section{$\mathrm{E}_{3}(<1,5 \mathrm{~m})$ :}

Taxóns característicos da clase Quercetea ilicis

Ruscus aculeatus

Asplenium onopteris

+12
$+\quad+1+$

5

Taxóns característicos da orde Quercetalia roboris

\begin{tabular}{llllllll:ll:l}
\hline Teucrium scorodonia & 1 & 1 & 1 & 1 & $1+1$ & 1 & 1 & 1 & 1
\end{tabular}

Arenaria montana

Lonicera hispanica

Taxóns característicos da orde Fagetalia sylvaticae

\begin{tabular}{|c|c|c|c|c|c|c|c|c|c|c|c|c|}
\hline Daphne laureola & $\cdot$ & & 1 & & . & $\cdot$ & . & $\cdot$ & + & . & + & $\cdot$ \\
\hline \multicolumn{13}{|c|}{ Taxóns característicos da clase Querco-Fagetea } \\
\hline Melittis melissophyllum & 1 & 1 & 1 & 1 & + & $\cdot$ & + & . & + & ${ }^{\circ}$ & 1 & . \\
\hline Tamus communis & + & 1 & 1 & 1 & 2 & 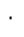 & . & . & . & . & + & . \\
\hline Viola riviniana & . & $\cdot$ & 1 & r. & . & $\cdot$ & + & . & + & + & 1 & . \\
\hline Polypodium vulgare & . & . & 1 & + & + & . & . & . & . & . & + & . \\
\hline Hedera hibernica & . & . & + & $\cdot$ & + & . & . & .1 & + & & 1 & . \\
\hline
\end{tabular}

\begin{tabular}{|c|c|c|c|c|c|c|c|c|c|c|c|c|}
\hline $\mathrm{N}^{0}$ de orde & 1 & 2 & 3 & 4 & 5 & 6 & 7 & 8 & 9 & $10 !$ & 11 & 12 \\
\hline Helleborus foetidus & + & -1 & + & $\cdot$ & $\cdot$ & $\cdot$ & $\cdot$ & $\cdot$ & + & + & $\cdot$ & $\cdot$ \\
\hline \multicolumn{13}{|l|}{ Outros taxóns } \\
\hline Brachypodium rupestre & 1 & 3 & 3 & 3 & 1 & 3 & 5 & 3 & 3 & & 4 & $\cdot$ \\
\hline Glandora diffusa & $r$ & + & 1 & 1 & 1 & 2 & 1 & 1 & 1 & 1 & . & . \\
\hline Dianthus hyssopifolius & . & . & 1 & + & + & 1 & 1 & 1 & 1 & 1 & . & . \\
\hline Galium Iucidum & . & . & + & 1 & . & 1 & 1 & 1 & 1 & 1 & . & . \\
\hline Clinopodium vulgare & . & 1 & 1 & 1 & 1 & $\cdot$ & $\cdot$ & $\cdot$ & + & 1 & $\cdot$ & + \\
\hline Origanum virens & . & + & + & 1 & + & 1 & + & . & • & 1 & . & $\cdot$ \\
\hline Rubus sp. & . & $\cdot$ & $r$ & 1 & + & $\cdot$ & + & . & + & 1 & 1 & + \\
\hline Scabiosa columbaria & + & + & 1 & . & + & + & + & . & 1 & . & . & $\cdot$ \\
\hline Sedum album & + & $\cdot$ & + & 1 & + & + & + & 1 & ' & . & $\cdot$ & $\cdot$ \\
\hline Festuca sp. & . & . & + & . & + & 2 & 1 & 3 & 1 & . & . & . \\
\hline Laserpitium nestleri & + & 1 & . & 1 & 1 & 1 & 1 & . & 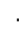 & . & . & . \\
\hline Polygonatum odoratum & 1 & 1 & 1 & + & 1 & . & + & · & • & . & $\cdot$ & . \\
\hline Geranium sanguineum & . & 1 & + & 1 & . & 1 & . & . & + & . & $\cdot$ & $\cdot$ \\
\hline Viola suavis & . & . & 1 & . & + & . & 1 & . & 1 & + & & $\cdot$ \\
\hline Asplenium trichomanes & + & . & 1 & 1 & . & 1 & + & + & . & . & $\cdot$ & $\cdot$ \\
\hline Asplenium adiantum-nigrum & . & . & 1 & 1 & + & + & + & . & + & . & $\cdot$ & $\cdot$ \\
\hline Dactylis glomerata & . & . & . & + & + & + & . & . & + & + & . & 1 \\
\hline Anthyllis alpina & + & + & + & . & $\cdot$ & + & + & + & • & . & $\cdot$ & $\cdot$ \\
\hline Sedum forsterianum & . & . & + & + & . & + & . & 1 & . & . & . & 1 \\
\hline Biscutella valentina & 1 & + & + & . & + & . & . & . & + & . & . & . \\
\hline Erysimum linifolium & 1 & . & . & + & + & + & . & . & . & . & $\cdot$ & . \\
\hline Ceterach officinarum & . & . & + & + & + & + & . & + & . & . & $\cdot$ & . \\
\hline Campanula adsurgens & + & + & + & + & . & . & . & $\cdot$ & . & . & $\cdot$ & . \\
\hline Hippocrepis commutata & . & . & + & + & + & + & . & . & . & . & . & . \\
\hline Arenaria incrassata & . & . & + & + & $\cdot$ & + & + & $\cdot$ & . & . & . & . \\
\hline Helianthemum cantabricum & . & . & + & . & . & + & + & + & & $\cdot$ & . & . \\
\hline Allium sphaerocephalon & . & . & $\cdot$ & + & + & + & 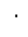 & + & · & . & & . \\
\hline Galium papillosum & . & . & . & . & . & . & + & + & . & + & & + \\
\hline Pteridium aquilinum & . & . & . & . & . & . & . & 1 & - & . & 1 & 2 \\
\hline Arabis hirsuta & 1 & + & . & . & + & . & . & . & . & . & & . \\
\hline Cruciata glabra & . & . & . & . & & . & . & $\cdot$ & + & + & & 1 \\
\hline Sanguisorba minor & . & + & . & . & + & . & + & $\cdot$ & . & . & & $\cdot$ \\
\hline Hypericum perforatum & $\cdot$ & + & . & . & $\cdot$ & - & + & $\cdot$ & & . & $\cdot$ & + \\
\hline Asphodelus macrocarpus & . & . & - & + & & + & + & . & . & . & & . \\
\hline Xiphion latifolium & . & . & . & $\cdot$ & $\cdot$ & + & + & $\cdot$ & . & + & . & . \\
\hline
\end{tabular}

\section{Taxóns de baixa frecuencia:}

$\mathbf{E}_{1}+\mathbf{E}_{2}$ : Acer pseudoplatanus: 1 en 11 e + en 12; Cytisus multiflorus: 1 en 12; Cytisus striatus: + en $12 ;$ Erica arborea: 1 en 11 e + en $12 ;$ Frangula alnus: + en 12; Prunus avium: + en 11 e + en 12; Pyrus cordata: + en 12; Quercus petraea: + en 11; Rosa micrantha: + en 9 e + en 11.

$\mathbf{E}_{3}$ : Característicos de Quercetalia roboris: Hieracium laevigatum: + en 11; Hieracium murorum: + en 11 ; Holcus mollis: 1 en 11 e 1 en 12 ; Lathyrus linifolius: + en 11; Luzula forsteri: 1 en 12; Melampyrum pratense: + en 12; Veronica officinalis: + en 12. Característicos de Fagetalia sylvaticae: Euphorbia dulcis: 1 en 11; Melica uniflora: + en 9 e + en 11; Mercurialis perennis: + en 11; Primula acaulis: 1 en 11. Característicos de Querco-Fagetea: Ajuga reptans: + en 11; Euphorbia amygdaloides: + en 5 e + en 11; Stellaria holostea: + en 9. Característicos de SaliciPopuletea: Polystichum setiferum: 1 en 11. Outros taxóns: Achillea millefolium: + en 7 e + en 10; Agrostis capillaris: 1 en 11 e 1 en 12; Andryala integrifolia: r en 1 e + en 12; Anthoxanthum odoratum: 1 en 12; Antirrhinum braun-blanqueti: + en 2 e 1 en 9; Arrhenatherum bulbosum: 1 en 12; Asplenium ruta-muraria: + en 4; Aster sedifolius: 1 en 2 e + en 7; Avenula sulcata: + en 19 e 1 en $12 ;$ Briza media: + en 7 e 1 en 10; Campanula lusitanica: + en 3; Campanula rapunculus: r en 2; Carex pilulifera: + en 12; Centaurea langeana: + en 2; Centaurea nigra: + en 11; Cirsium arvense: + en 4 e + en 6; Clematis vitalba: + en 2 e + en 3; Crepis asturica: + en 4; Crocus serotinus: + en 11; Digitalis purpurea: + en 12; Echium vulgare: + en 4; Epipactis helleborine: 1 en 3; Festuca elegans: 1 en 12; Fragaria vesca: + en 3 e + en 11; Fumaria sp.: + en 5; Galium mollugo: + en 2 e 1 en 5; Geranium purpureum: + en 5 e 1 en 7; Geranium robertianum: + en 9 e + en 11; Geranium sanguineum: + en 5; Glandora prostrata: + en 11; Hieracium laevigatum: 1 en 12; Hieracium pilosela: 1 en 12; Hypochaeris radicata: 1 en 12; Inula conyza: + en 3 e + en 4; Jasione montana: 1 en 12; Koeleria vallesiana: + en 6; Ligusticum lucidum: + en 5; Lotus corniculatus: 2 en 12; Luzula lactea: + en 12; Luzula multiflora: 1 en 12; Melica ciliata: + en 4 e + en 6; Myosotis sp.: + en 12; Omphalodes nítida: + en 10 e + en $11 ;$ Ornithopus sp.: 2 en 12; Picris hieracioides: + en 1; Polygala vulgaris: + en 3 e + en 12; Prunella grandiflora: + en 11; Prunella vulgaris: 1 en 12; Ranunculus nigrescens: + en 12; Rumex acetosa: + en 9 e 1 en 12; Saxifraga paniculata: + en 6; Saxifraga trifurcata: + en 8; Sedum dasyphyllum: + en 4; Selinum pyrenaeum: + en 6 e 1 en 7 ; Silene latifolia: + en 5 e + en 9; Spiraea ovobata: + en 3 e + en 5; Taraxacum gr. officinale: + en 12; Thalictrum minus: 1 en 7; Thapsia villosa: r en 1; Trifolium medium: + en 7; Trifolium pratense: + en 12; Trifolium repens: + en 11; Vicia sepium: 1 en 11 e + en 12; Vincetoxicum nigrum: 1 en 3.

Localidades (a notación numérica indica a situación na cuadrícula UTM de $1 \mathrm{~km}$, fuso 29T): 1: Lu: Folgoso do Courel, Alto do Couto, 656/4719. 2: Lu: Folgoso do Courel, Moreda, Devesa da Rogueira, vertente S de A Tara, 655/4719. 3: Lu: Folgoso do Courel, Moreda, chegando ao tesodivisoria que baixa desde a Campa dos Carlistas, 655/4719. 4: Lu: Folgoso do Courel, Moreda, Devesa da Rogueira, cume do teso calío inferior, 654/4719. 5: Lu: Folgoso do Courel, Moreda, extremo S de A Tara, 654/4719. 6: Lu: Folgoso do Courel, Moreda, camiño da Rogueira, no primeiro teso calío, 654/4719. 7: Lu: Folgoso de Caurel, Moreda, polo camiño da Devesa da Rogueira, 654/4719 [lzco et al. (1990): táb. V: inv. 12]. 8: Lu: Folgoso de Caurel, Moreda, polo camiño da Devesa da Rogueira, 654/4719 [lzco et al. (1990): táb. V: inv. 13]. 9: Lu: Folgoso do Courel, Visuña, por baixo do piñeiral da pista do Couto a Formigueiros, 656/4719. 10: Lu: Folgoso do Courel, Moreda, teso calío inferior da Devesa da Rogueira, 654/4719. 11: Lu: Folgoso do Courel, Moreda, camiño da Devesa da Rogueira (654/4720); 12: Lu: Folgoso do Courel, Moreda, Teso de Romeán, vertente S (654/4720). 
Desde o punto de vista fitosociolóxico dentro do territorio aquí tratado se daría a confluencia de dúas comunidades de espiñais cuxa composición florística serían reflexo dos condicionantes climáticos baixo os que se desenvolven, diferenciándose unha de zonas baixas, na que están presentes as especies termófilas anteriormente comentadas, así como Fraxinus excelsior (comunidade Rubo ulmifolii-Tametum communis subas. origanetosum virentis)(Giménez de Azcárate et al. 1996). Nestes espiñais faltan, entre outras Thalictrum minus, Rosa villosa e Sorbus aucuparia, que caracterzarían aos espiñais das partes altas, incluídos dentro da asociación Mercuriali perennis-Rosetum villosae (Rodríguez Guitián \& Amigo 2009b). Na Táboa 8 preséntanse un par de inventarios deste tipo de comunidades.

\section{Soutos}

As plantacións tradicionais de castiñeiros (soutos) son, como é ben sabido, un tipo de formación vexetal arborada consubstancial á paisaxe courelá. Desde o punto de vista botánico, a aparente uniformidade que outorga o claro dominio de Castanea sativa no nivel de copas destas plantacións vese matizada por toda unha serie de influencias, tanto ambientais como de manexo humano, que condicionan a cantidade e abundancia da flora que medra á súa sombra (Rodríguez Guitián et al. 2005b).

Dentro do ámbito abordado neste traballo os soutos teñen unha escasa representación $(2,3$ ha) e se restrinxen ás partes baixas $(<780 \mathrm{~m})$ do val do Rego da Rogueira e a un par de localizacións algo máis altas (870-900 m) no val do Carrozo da Muíña (Figura 3), sempre dentro do piso mesotemperado superior. En todos estes casos, os soutos sitúanse sobre materiais litolóxicos silíceos (lousas e xistos) e os solos amosan o carácter fortemente pedregoso que é común ao resto de bosques comentados. O grao de aproveitamento actual que presentan é diverso e se correlaciona inversamente coa complexidade estrutural que amosan, como pode apreciarse no par de inventarios incorporados na Táboa 9. No primeiro deles (inv. 11), o avanzado estado de abandono favorece a presenza de abundantes individuos bravos de Castanea sativa e doutras especies ventureiras, tanto arbóreas (Corylus avellana, Fraxinus excelsior, Crataegus monogyna, Acer pseudoplatanus, Quercus pyrenaica, Quercus petraea, Sorbus aucuparia, Prunus avium, Ilex aquifolium) como arbustivas (Erica arborea, Cytisus scoparius) que se van incorporando progresivamente a estas formacións forestais cando cesa o seu aproveitamento mentres que os que persisten no Teso de Romeán, exemplificados no inventario 12 desa mesma táboa, presentan un claro dominio do castiñeiro no estrato superior e un sotobosque dominado por especies herbáceas, evidencias de que aínda se realizan rozas periódicas nestes soutos para facilitar a recollida da castaña.

En xeral, no nivel inferior dos soutos observase unha mestura de especies con diferentes requirimentos ecolóxicos que conflúen baixo o abrigo proporcionado polos castiñeiros, ás veces ocupando microambientes particulares, como pequenos rochedos ou solos pedregosos (Polypodium vulgare), pequenas valgadas nas que se acumula a materia orgánica (Vicia sepium, Geranium robertianum), áreas que reciben puntualmente máis radiación solar (Hieracium laevigatum, Hieracium murorum, Lathyrus linifolius, Holcus mollis, Teucrium scorodonia, Glandora prostrata, Omphalodes nitida, Fragaria vesca) ou recunchos avesíos menos transitados (Mercurialis perennis, Daphne laureola, Primula acaulis, Polystichum setiferum, Melica uniflora, Euphorbia dulcis, Melittis melissophyllum, Viola riviniana, Ajuga reptans, Euphorbia amygdaloides); completando o panorama vexetal do sotobosque dos soutos non faltan algunas especies termófilas (Tamus communis, Asplenium onopteris), lianas (Hedera hibernica, Lonicera hispanica) e plantas habituais en medios sometidos a perturbacións humanas periódicas, como Agrostis capillaris, Pteridium aquilinum ou Prunella vulgaris.

O tratamento fitosociolóxico dos soutos está ainda por resolver, en parte debido a escaseza de traballos específicos e tamén porque a súa orixe antrópica non permite unha fácil ubicación nos esquemas sintaxonómicos vixentes. Según Rodríguez Guitián et al. (2005b), os soutos do NW ibérico presentan afinidades florísticas por distintos tipos de bosques naturais existentes neste território. A elevada variabilidade florística que presentan responde tanto a factores bioxeográficos como mesoecolóxicos (clima e factores topo-edáficos), e dicir, os mesmos que actúan sobre o resto de bosques do territorio. Desde este enfoque, unha posible alternativa sería consideralos como facies favorecidas polo ser humano dos respectivos tipos de bosques cos que se relacionan desde o punto de vista florístico.

\section{Bosques riparios (edafohigrófilos).}

As condicións de elevada humidade que presentan os solos das marxes dos cursos fluviais de caudal permanente favorecen a formación de bosques ben diferenciados desde o punto de vista florístico con respecto a aqueles cos que contactan ladeira arriba. Na maior parte de Galicia, estes bosques humidos (edafohigrófilos) da beira dos ríos están dominados polo ameneiro (Alnus glutinosa)(Bellot 1968, Amigo et al. 1987); sen embargo, esta especie arbórea está practicamente ausente da cunca alta do Río Lor, por riba dos 600-650 m de altitude (Amigo Vázquez 1984, Rodríguez Guitián et al. 2000), incluída a rede hidrográfica do Rego da Rogueira e a súa prolongación augas abaixo, o Rego da Brancha ou Río Seco. En lugar de ameneirais e a semellanza do que ocorre nas área de cabeceira dos ríos que nacen nas montañas da Cordillera Cantábrica, os cursos fluviais da área de estudo adoitan estar flanqueados por outros tipos de bosques húmidos, cuxas características botánicas varían segundo o ambiente ecolóxico no que se atopen. Como excepción a este feito hai que advertir que, salvo en tramos caudalosos e con marxes abruptas, os regueiros que atravesan os faiais tenden a carecer de formacións boscosas diferenciadas, debido á forte competencia pola luz que exerce esta especie arbórea coas 
que habitualmente forman parte dos bosques de ribeira, como abelairas, salgueiros, bidueiros ou freixos. En función das características hidrolóxicas do tramo fluvial e das especies de árbores que dominan no nivel superior destes bosques, cabe diferenciar no ámbito de estudo os tipos de bosques de ribeira que a continuación se describen.

Táboa 10.- Composición florística de biduedos riparios (inv. 1-2), freixidos riparios (inv. 3-5), e abeledos riparios calcícolas (inv. 6-7)

\begin{tabular}{|c|c|c|c|c|c|c|c|}
\hline $\mathrm{N}^{0}$ de orde & 1 & 2 & 3 & 4 & 5 & 6 & 7 \\
\hline Área $\left(m^{2}\right)$ : & 240 & 150 & 150 & 240 & 200 & 200 & 120 \\
\hline Altura $E_{1}(m)$ & 14 & $6-10$ & 14 & 16 & $10-16$ & $10-18$ & 10 \\
\hline Cob. $E_{1}(>4,0 \mathrm{~m})(\%)$ & 90 & 90 & 95 & 100 & 100 & 100 & 100 \\
\hline Cob. $E_{2}(1,5-4,0 \mathrm{~m})(\%)$ & 20 & 15 & --- & 15 & 40 & 5 & 20 \\
\hline Cob. $E_{3}(<1,5 \mathrm{~m})(\%)$ & 95 & 90 & 100 & 90 & 80 & 50 & 30 \\
\hline Altitude (m) & 1130 & 1265 & 790 & 750 & 715 & 860 & 895 \\
\hline Pendiente $\left({ }^{\circ}\right)$ & $12-40$ & 36 & 5 & 4 & 4 & 20 & 10 \\
\hline Orientación & $\mathrm{N}$ & NNE & $\mathrm{N}$ & NNE & NNW & NW & $\mathrm{N}$ \\
\hline $\mathrm{N}^{0}$ de taxóns & 42 & 32 & 31 & 53 & 51 & 32 & 36 \\
\hline \multicolumn{8}{|c|}{$E_{1}(>4,0 m)+E_{2}(>1,5-4,0 m):$} \\
\hline Corylus avellana & 3 & 2 & 3 & 4 & 3 & 5 & 5 \\
\hline Acer pseudoplatanus & . & . & 3 & 4 & 2 & 1 & 1 \\
\hline Salix atrocinerea & 1 & 2 & 1 & . & 3 & $\cdot$ & $\cdot$ \\
\hline Fagus sylvatica & 1 & 1 & . & . & . & + & 1 \\
\hline Fraxinus excelsior & . & . & 3 & 2 & 3 & . & $\cdot$ \\
\hline Castanea sativa & . & . & 2 & 1 & 1 & . & $\cdot$ \\
\hline Sorbus aucuparia & 1 & 1 & . & . & $\cdot$ & 2 & $\cdot$ \\
\hline Prunus avium & . & . & 2 & . & 1 & . & $\cdot$ \\
\hline Sambucus nigra & . & . & 1 & . & 1 & . & $\cdot$ \\
\hline Betula pubescens & 4 & 4 & . & . & . & . & $\cdot$ \\
\hline Ilex aquifolium & 1 & 1 & . & . & . & . & $\cdot$ \\
\hline Salix caprea & 3 & . & . & . & 1 & . & $\cdot$ \\
\hline
\end{tabular}

\section{$\mathrm{E}_{3}(<1,5 \mathrm{~m})$ :}

Taxóns diferenciais de asociacións

Valeriana montana

Vaccinium myrtillus

Allium victorialis

Lastrea limbosperma

Ranunculus platanifolius

Allium ursinum

Polystichum setiferum

Phyllitis scolopendrium

Saxifraga hirsuta

Primula acaulis

Brachypodium sylvaticum

Polypodium vulgare

Mercurialis perennis

Arum italicum

Helleborus foetidus

Melica uniflora

Hyacinthoides non-scripta

\begin{tabular}{lll|lll|ll}
\hline$N^{0}$ de orde & $\mathbf{1}$ & $\mathbf{2}$ & $\mathbf{3}$ & $\mathbf{4}$ & $\mathbf{5}$ & $\mathbf{6}$ & $\mathbf{7}$ \\
\hline Veronica montana & $\cdot$ & $\cdot$ & + & $\cdot$ & + & $\cdot$ & $\cdot$ \\
Tamus communis & $\cdot$ & $\cdot$ & + & $\cdot$ & + & $\cdot$ & $\cdot$ \\
Ajuga reptans & $\cdot$ & $\cdot$ & $\cdot$ & + & + & $\cdot$ & $\cdot$ \\
Carex sylvatica & $\cdot$ & $\cdot$ & $\cdot$ & + & + & $\cdot$ & $\cdot$ \\
Corydalis cava & $\cdot$ & $\cdot$ & $\cdot$ & $\cdot$ & $\cdot$ & + & + \\
Cystopteris fragilis & $\cdot$ & $\cdot$ & $\cdot$ & $\cdot$ & $\cdot$ & + & +
\end{tabular}

\section{Taxóns característicos de asociacións}

Chaerophyllum hirsutum

Luzula sylvatica

Oxalis acetosella

Valeriana pyrenaica

Euphorbia dulcis

Saxifraga spathularis

Chrysosplenium oppositifolium

Athyrium filix-femina

Dryopteris dilatata

Anemone nemorosa

Adenostyles hybrida

Carex remota

\begin{tabular}{cc|ccc|cc}
++ & 1 & 1 & 1 & 3 & $r$ & + \\
4 & 4 & $\cdot$ & 1 & 1 & + & 1 \\
1 & 1 & 1 & 1 & $\cdot$ & 2 & 1 \\
2 & 1 & + & + & $\cdot$ & + & + \\
1 & 1 & + & 1 & $\cdot$ & $\cdot$ & + \\
1 & 1 & $\cdot$ & + & $\cdot$ & + & 1 \\
1 & 1 & 1 & 1 & 1 & $\cdot$ & $\cdot$ \\
3 & 2 & $\cdot$ & + & 1 & $\cdot$ & $\cdot$ \\
1 & 1 & $\cdot$ & + & $\cdot$ & + & $\cdot$ \\
1 & 1 & $\cdot$ & + & $\cdot$ & $\cdot$ & + \\
1 & 1 & $\cdot$ & + & $\cdot$ & $\cdot$ & $\cdot$ \\
+ & $\cdot$ & $\cdot$ & + & 1 & $\cdot$ & $\cdot$ \\
\hline
\end{tabular}

Taxóns característicos da clase Querco-Fagetea

Hedera hiberna

Lonicera periclymenum

Polygonatum verticillatum

Dryopteris filix-mas

Milium effusum

Daphne laureola

Poa nemoralis

Euphorbia hyberna

Stellaria holostea

Lilium martagon

Crepis lampsanoides

Festuca lasto

Outros taxóns

Rubus sp.

Heracleum sphondylium

Geranium robertianum

Cardamine raphanifolia

Asplenium trichomanes

Brachypodium rupestre

Scrophularia auriculata

\section{Outros taxóns:}

$\mathbf{E}_{1}+\mathrm{E}_{2}$ : Alnus glutinosa: 1 en 5; Crataegus monogyna: + en 6; Erica arborea: + en 2; Frangula alnus: + en 1; Prunus spinosa: + en 3; Quercus pyrenaica: r en 5; Quercus x rosácea: + en 7; Rosa canina: + en 1; Rosa micrantha: 1 en 5.

$\mathrm{E}_{3}$ : Características de Salici-Populetea: Circaea lutetiana: + en 4; Festuca gigantea: + en 4. Características de Fagetalia sylvaticae:

Epilobium montanum: + en 4; Galium odoratum: + en 6; Hypericum androsaemum: + en 5; Lysimachia nemorum: + en 4; Mycelis muralis: + en 4; Ornithogalum pyrenaicum: + en 4; Ranunculus tuberosus: + en 1. Características de Quercetalia roboris: Blechnum spicant: 1 en 2; Holcus mollis: + en 1; Poa chaixii: + en 1; Saxifraga x polita: + en 4. Características de Querco-Fagetea: Aquilegia vulgaris: + en 4; Dryopteris affinis: 1 en 1; Euphorbia amygdaloides: + en 5. Compañeiras: Angelica major: r en 1; Caltha palustris: 1 en 2; Cardamine gallaecica: 1 en 1; Cardamine hirsuta: 1 en 4; Cirsium palustre: 1 en 2; Epilobium sp.: + en 5; Eupatorium cannabinum: + en 5; Fragaria vesca: + en 3; Geum urbanum: + en 4; Limniris pseudacorus: + en 5; Meconopsis cambrica: 1 en 7; Rumex acetosa: + en 5; Ruscus aculeatus: + en 7; Silene dioica: 1 en 5; Taraxacum gr. officinale: + en 5; Urtica dioica: 1 en 5; Vicia sepium: r en 7.

Localidades (a notación numérica indica a situación na cuadrícula UTM de $1 \mathrm{~km}$, fuso 29T): 1: Lu: Folgoso do Courel, Devesa da Rogueira, Rego da Rogueira (654/4718) 2: Lu: Folgoso do Courel, Devesa da Rogueira, Rego do Freixedo (655/4718); 3: Lu: Folgoso do Courel, Devesa da Rogueira, Carrozo da Muiña (654/4720) [Rodríguez Guitián et al. (2000): táboa 6: inv. 6]. 4: Lu: Folgoso do Courel, Moreda, Rego da Rogueira, aguas arriba de su unión con el Carrozo da Muiña (654/4720); 5: Lu: Folgoso do Courel, Moreda, Rego da Rogueira, augas arriba da aldea (654/4720). 6: Lu: Folgoso do Courel, Devesa da Rogueira, As Veigas, Rego do Freixido (654/4719) [Rodríguez Guitián (2011): Anexo IX: táboa 32: inv. 3]; 7: Lu: Folgoso do Courel, Devesa da Rogueira, Rego da Rogueira, augas abaixo da Fervenza (654/4719) [Rodríguez Guitián (2011): Anexo IX: táboa 32: inv. 4]. 


\section{Bidueirais riparios}

Bosques de ribeira dos tramos fluviais máis elevados, caracterizados pola sucesión de rápidos e pequenas fervenzas, dominados polo bidueiro (Betula pubescens), que adoita estar acompañado, por Salix caprea, S. atrocinerea, Corylus avellana e Sorbus aucuparia. No sotobosque destacan os mestos e extensos céspedes formados por Luzula sylvatica, á que xeralmente acompañan Valeriana montana, Blechnum spicant, Lastrea limbosperma, Athyrium filix-femina, Euphorbia dulcis, Oxalis acetosella, Saxifraga spathularis, Dryopteris dilatata ou Anemone nemorosa. Xunto a estas especies, aparecen, en lugares particularmente avesíos ou húmidos, grandes herbas como Chaerophyllum hirsutum, Adenostyles hybrida, Allium victorialis, Cardamine gallaecica ou Valeriana pyrenaica.

Estes bosques riparios ocupan unha superficie moi reducida ( $<1$ ha) na área de estudo e distribúense principalmente por riba dos $1.200 \mathrm{~m}$ de altitude, polo piso bioclimático supratemperado superior, aínda que en condicións favorables poden penetrar no horizonte inferior deste termotipo (Figura 3). Aséntanse sobre solos moi pouco evolucionados (leptosoles) derivados de rochas silíceas (lousas, areíscas) en vertentes con elevada inclinación. Até o momento inclúense na subasociación salicetosum atrocinereae da asociación Luzulo henriquesii-Betuletum celtibericae (Izco et al. 1986a). Na Táboa 10 recóllese a información dispoñible sobre este tipo de bosques na área de estudo.

\section{Freixidos riparios}

Bosques de ribeira que substitúen aos anteriores conforme van descendendo os regos de altitude, polo xeral por baixo dos 1.000-1.100 m. Adoitan conformar un par de bandas paralelas de uns poucos metros de anchura seguindo os cursos fluviais, que polo xeral presentan unha elevada pendente e están máis ou menos encaixados no leito rochoso. En total cobren algo menos de 5 ha no conxunto da área de estudo (Figura 3).

O seu estrato superior caracterízase por unha mestura de especies arbóreas, como Fraxinus excelsior, Acer pseudoplatanus, Salix atrocinerea, Betula pubescens e Corylus avellana, entre as que se intercalan outras de presenza máis puntual, como Castanea sativa, Prunus avium, Sambucus nigra, Salix caprea ou Prunus spinosa. Á sombra destas especies aparecen outras querenciosas polos solos húmidos e os ambientes avesíos, como Allium ursinum, Saxifraga hirsuta, Polystichum setiferum, Chaerophyllum hirsutum, Chrysosplenium oppositifolium, Polygonatum verticillatum, Heracleum sphondylium, Scrophularia auriculata ou Cardamine raphanifolia, ás que se unen outras habituais nos bosques do entorno, como Phyllitis scolopendrium, Tamus communis, Daphne laureola, Poa nemoralis, Hedera hibernica, Primula acaulis, Brachypodium sylvaticum, Lonicera hispanica, Geranium robertianum, Brachypodium pinnatum subsp. rupestre ou Asplenium trichomanes.

Estes bosques riparios inclúense na asociación Festuco giganteae-Fraxinetum excelsioris, presentes polos tramos de cabeceira dos ríos das montañas do extremo occidental da Cordilleira Cantábrica (Díaz González \& Fernández Prieto 1994, Rodríguez Guitián et al. 2000), por riba do límite superior que acadan os ameneirais riparios, dentro dos pisos bioclimáticos mesotemperado superior e, sobre todo, supratemperado inferior. Na Táboa 10 preséntase a información recompilada sobre este tipo de bosques.

\section{Abeledos riparios calcícolas}

Cando os cauces fluviais están moi encaixados no leito rochoso calío, a vexetación das súas marxes empobrécese en especies arbóreas, pasando a ser dominante a abeleira (Corylus avellana). Por baixo, a pesar da elevada pedregosidade que caracteriza a estes tramos de río, concéntranse un número elevado de taxóns vexetais, entre os que destacan pola súa abundancia e constancia Dryopteris filix-mas, Hedera hibernica, Luzula sylvatica, Polypodium vulgare, Polystichum setiferum, Saxifraga spathularis, Milium effusum, Oxalis acetosella, Allium ursinum, Valeriana pyrenaica, Helleborus foetidus, Polygonatum verticillatum, Daphne laureola, Corydalis cava, Phyllitis scolopendrium, Geranium robertianum, Chaerophyllum hirsutum, Cystopteris fragilis ou Heracleum sphondylium.

Dentro da área de estudio, estes abeledos aparecen de xeito exclusivo no extremo inferior da Devesa da Rogueira, nos tramos finais dos regos da Rogueira e do Freixedo, augas arriba da súa confluencia, cobrindo pouco máis 0,5 ha de superficie (Figura 3). Polo momento, está pendente a discusión da ubicación fitosociolóxica desta comunidade e a súa posible vinculación coa asociación dos freixidos riparios antes comentada (Festuco-Fraxinetum), a falla de coñecer polo miúdo a súa distribución e composición florística. $\mathrm{Na}$ Táboa 10 recollese a información aportada polos inventarios dispoñibles para este tipo de bosque.

\section{Discusión}

Desde os anos 80 do pasado século se ven considerando, a raíz dos traballos realizados polo equipo de J. Izco (Amigo Vázquez 1984, Guitián Rivera 1984, Izco et al. 1985), que a comarca do Courel é o territorio de Galicia que presenta unha flora vascular máis variada. As aportacións realizadas polos autores comentados xunto a diversos estudos posteriores (Izco et al. 1986a, 1990; Amigo et al. 1994, Giménez de Azcarate 1993, Giménez de Azcárate et al. 1996, Rodríguez Guitián \& Amigo Vázquez 2009b, Rodríguez Guitián et al. 2000, 2005a, 2205b, 2009) permiten, a día de hoxe, extender esta afirmación ao plano das comunidades vexetais en xeral, e no caso dos bosques en particular. En parte debido a esta realidade, a cartografía da cuberta vexetal realizada no ámbito deste traballo permitiría afirmar que, á espera de poder dispoñer un documento de idénticas características para todo o territorio galego, a Devesa da Rogueira e a súa contorna máis inmediata é a unidade territorial de menor superficie que presenta unha maior variedade de comunidades vexetais arbóreas de Galicia. 
Por outra parte, esta mesma información posibilitaría enmarcar a importancia deste enclave con relación a outras montañas do extremo noroccidental ibérico, coas cales a Serra do Courel garda as afinidades florísticas e vexetacionais máis estreitas (Figura 1). Sen embargo, esta posibilidade presenta algúns problemas de aplicación na práctica debido, principalmente, a inexistencia de cartografía da cuberta vexetal detallada para a maior parte destas áreas montañosas. De feito, soamente o Principado de Asturias conta cun mapa de vexetación de suficiente precisión (E 1:25.000) como para poder facer esta clase de análise, se ben cunha resolución cartográfica sensiblemente menor que a aquí empregada. Outra cuestión que dificulta esta comparación é a diferenza de criterios botánicos aplicados na elaboración destas bases cartográficas en canto aos tipos de comunidades vexetais arboradas identificadas se refire, dado que os mapas de vexetación do Principado foron elaborados no derradeiro decenio do pasado século. Non obstante, esta eiva pode solventarse complementando a información contida nestes mapas coa publicada máis recentemente en diversos traballos de revisión e actualización da distribución de comunidades vexetais no territorio asturiano, como os publicados por Fernández Prieto \& Díaz González (2003), Díaz González (2010), ou no ámbito das montañas da Cordillera Cantábrica (Rivas-Martínez e coautores 2011).

Tendo en conta estes condicionantes, creemos interesante realizar unha comparación coas dúas áreas que tradicionalmente se veñen citanto como de maior valor ecolóxico do SW asturiano, a "Reserva Natural Integral de Muniellos", englobada na actualidade dentro dos límites do "Parque Natural de las Fuentes del Narcea, Degaña e Ibias", e o "Parque Natural de Somiedo". A valoración dos resultados obtidos neste caso (Táboa 11) amosa, en primeiro lugar, que a Devesa da Rogueira presenta unha variedade de tipos de bosques sensiblemente superior á recoñecida dentro da Reserva de Muniellos (Fernández Prieto \& Bueno 1996), debido básicamente á total ausencia neste último espazo natural protexido de vexetación de caracter calcícola, mentras que acada un valor semellante ao obtido para o Parque Natural de Somiedo. En segundo termo, a Rogueira contén até 10 tipos de bosques exclusivos frente aos outros dous espazos considerados, que teñen tres e seis tipos non representados no resto de áreas en cada caso. A relevancia que acada a área de estudo nesta comparación, vese realzada cando a variedade de tipos de bosques presentes dentro destes espazos valórase tendo en conta as súas respectivas superficies (Táboa 11), e dicir, considerando a súa riqueza en comunidades vexetais arboradas aplicando o método de Gleason (1922). Baixo este enfoque, a riqueza de bosques dos tres espazos considerados é de 32,84, 7,46 e 7,71, respectivamente, do que se deduce que A Rogueira é, con moito, o territorio máis rico dos tres, xa que aglutina un número moi elevado de bosques diferentes nunha superficie que equivale tan só $7,9 \%$ da superficie da Reserva de Muniellos e o $1,5 \%$ da do Parque Natural de Somiedo.

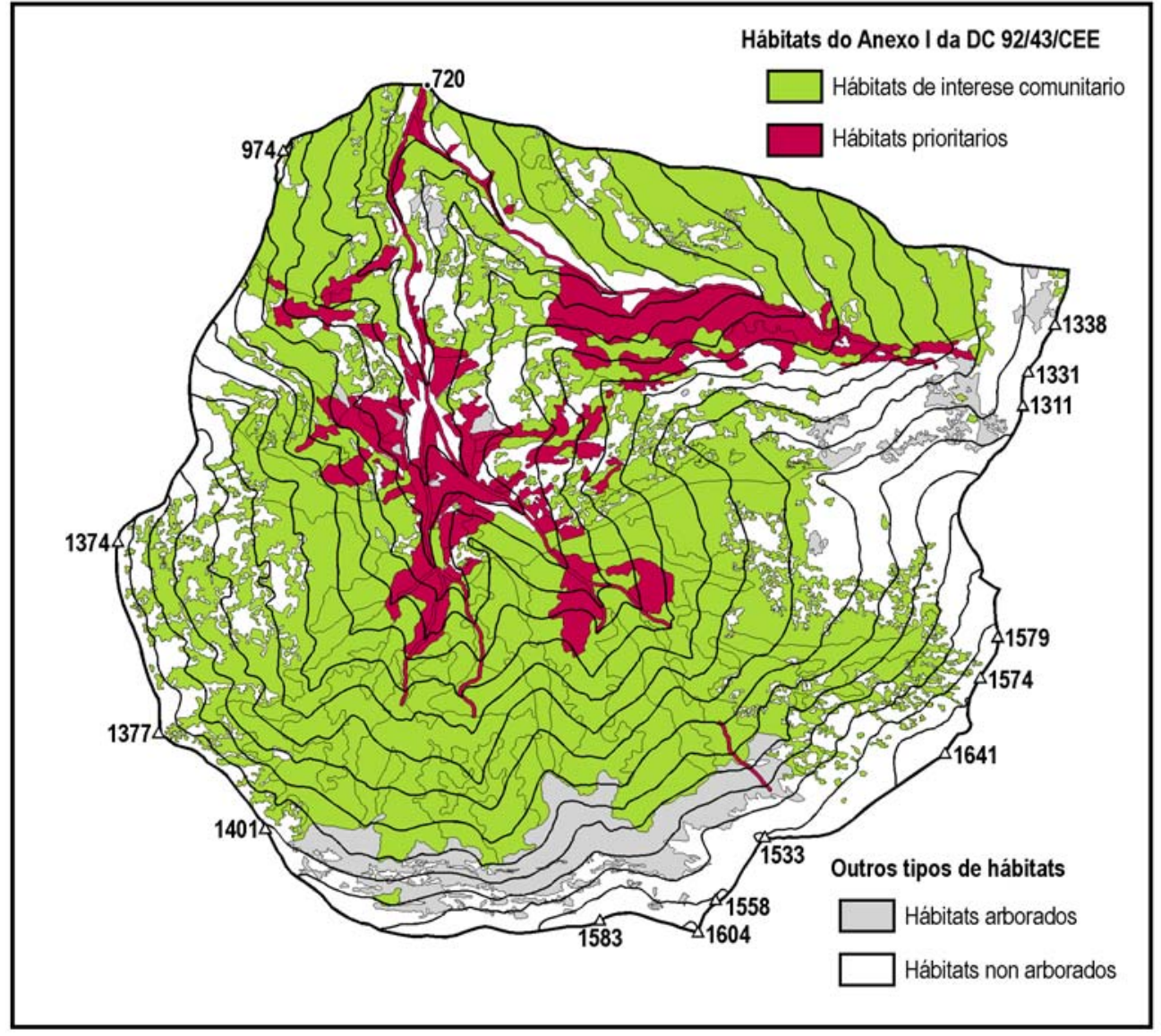

Figura 4.- Correlación dos tipos de hábitats boscosos recoñecidos na área de estudo e os tipos de hábitats arborados do Anexo I da Directiva "Hábitats" 


\begin{tabular}{|c|c|c|c|}
\hline \multirow[b]{2}{*}{ Tipos de bosque } & \multicolumn{3}{|c|}{ Territorio } \\
\hline & Devesa da Rogueira & R. N. I. de Muniellos s $^{1,3,4}$ & P. Nat. de Somiedo ${ }^{2,3,4}$ \\
\hline Bidueirais quionófilos & $\bullet$ & $\bullet$ & 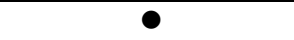 \\
\hline Bidueirais seriais & $\bullet$ & $\ldots$ & $\ldots$ \\
\hline Bosques de capudres e paleiros & $\bullet$ & $\ldots$ & $\ldots$ \\
\hline Prebosques de bidueiro e capudre & $\cdots$ & $\bullet$ & 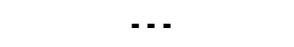 \\
\hline Faiais silicícolas courelao-ancareses & $\bullet$ & $\ldots$ & $\ldots$ \\
\hline Faiais silicícolas orocantábricos centro-orientais & $\cdots$ & $\bullet$ & $\bullet$ \\
\hline Faiais calcícolas courelaos & $\bullet$ & $\ldots$ &.- \\
\hline Faiais calcícolas orocantábricos centro-orientais & $\ldots$ & $\ldots$ & $\bullet$ \\
\hline Carballais albares avesíos & $\bullet$ & $\bullet$ & • \\
\hline Carballais albares de sollío & $\bullet$ & $\bullet$ & $\bullet$ \\
\hline Carballais albares calcícolas & $\bullet$ & $\cdots$ & $\cdots$ \\
\hline Carballais ananos & $\bullet$ & $\bullet$ & $\bullet$ \\
\hline Reboleiras silicícolas & $\bullet$ & $\bullet$ & $\bullet$ \\
\hline Reboleiras calcícolas & $\bullet$ & $\ldots$ & $\ldots$ \\
\hline Bosques de Quercus faginea & $\cdots$ & $\ldots$ & $\bullet$ \\
\hline Bosques mixtos silicícolas orocantabricos & $\bullet$ & $\bullet$ & $\bullet$ \\
\hline Bosques mixtos calcícolas courelao-ancareses & - & $\cdots$ & $\cdots$ \\
\hline Bosques mixtos calcícolas orocantábricos centro-occidentais & $\ldots$ & $\cdots$ & $\bullet$ \\
\hline Abeledos seriais silicícolas & $\bullet$ & $\bullet$ & $\bullet$ \\
\hline Abeledos seriais calcícolas & $\bullet$ & $\ldots$ & $\bullet$ \\
\hline Acebais & $\ldots$ & $\bullet$ & $\bullet$ \\
\hline Aciñeirais courelao-ancareses & $\bullet$ & $\cdots$ & $\cdots$ \\
\hline Aciñeirais orocantábricos centro-orientais & $\ldots$ & $\cdots$ & $\bullet$ \\
\hline Espiñais courelao-ancareses & $\bullet$ & $\ldots$ & 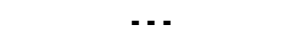 \\
\hline Espiñais orocantábricos centro-orientais & $\ldots$ & $\ldots$ & $\bullet$ \\
\hline Ameneirais riparios orocantábricos occidentais & $\ldots$ & $\bullet$ & $\ldots$ \\
\hline Ameneirais riparios ovetenses & $\ldots$ & $\ldots$ & $\bullet$ \\
\hline Bidueirais riparios & $\bullet$ & $\cdots$ & $\cdots$ \\
\hline Freixidos riparios & $\bullet$ & $\bullet$ & $\bullet$ \\
\hline Abeledos riparios calcícolas & $\bullet$ & $\ldots$ & $\ldots$ \\
\hline Abeledos higrófilos con salgueiro & $\ldots$ & $\bullet$ & $\ldots$ \\
\hline Salgueirais riparios & $\ldots$ & $\cdots$ & $\bullet$ \\
\hline Soutos silicícolas & $\bullet$ & $\ldots$ & • \\
\hline Total tipos & 21 & 13 & 19 \\
\hline Superficie total $\left(\mathrm{km}^{2}\right)$ & 4,36 & 55,41 & 291,22 \\
\hline Riqueza de bosques ( ${ }^{0}$ tipos/ $\log _{10}$ sup.) & 32,84 & 7,46 & 7,71 \\
\hline
\end{tabular}

tipo de bosque presente, $\cdots$ - tipo de bosque ausente.

Fontes: 1: Fernández Prieto \& Bueno (1996); 2: Garcia Mantecaet al. (1989), 3: Diaz González (2010), 4: Rivas-Martínez e coautores (2011)

Táboa 11.- Táboa comparativa dos tipos de bosques existentes na área de estudo e en dous Espazos Naturais Protexidos do SW asturiano e dos seus respectivos valores do índice de riqueza (Gleason 1922)

Finalmente, pode facerse unha reflexión sobre o valor ambiental da área de estudo analizando a correspondencia que existe entre os tipos de bosques identificados e os hábitats arborados incluídos no Anexo I da DC 92/43CEE (CCE 1992, EC 2013), coñecida coloquialmente como "Directiva Hábitats" (Táboa 2 e Figura 4). Desde este punto de vista, as equivalencias establecidas levan a considerar que unhas 306 ha dos bosques cartografíados na Devesa da Rogueira (o 90,7\% do total) son representacións de tipos de hábitats que necesitan protección dentro do ámbito da UE ("hábitats de interese comunitario") e destas, unhas 47 ha ( $15 \%$ do total arborado) cubertas por bosques mixtos e de ribeira, corresponden a "hábitats prioritarios", e dicir, que se atopan nunha condición de especial fraxilidade ou risco de desaparición dentro do ámbito xeográfico comentado.

\section{Conclusións}

Os resultados do estudo realizado sobre a cuberta arborada da Devesa da Rogueira e do seu entorno inmediato revelan a existencia dun total de 21 tipos de bosques diferentes. Si se considera que esta ampla gama de bosques identificados cubre tan só unha superficie de 310 ha, a Devesa da Rogueira (en sensu lato) resulta ser, con base na información actualmente dispoñible, a unidade territorial (cunca hidrográfica) máis reducida na que se presenta unha maior variedade de fitocenoses arbóreas, non só a nivel da comarca courelá, senón no conxunto do territorio galego e das áreas montañosas próximas do cuadrante noroccidental ibérico. Con toda probabilidade, este extraordinario valor botánico e ecolóxico amosarase acrecentado no caso de estenderse o traballo aquí 
presentado ao resto de comunidades vexetais arbustivas e herbáceas presentes neste enclave, cuestión que, en todo caso, queda pendente para un futuro estudio.

Agradecementos.- Os autores agradecen a axuda prestada por Hugo López Castro, Saúl de la Peña Lastra e Manuel Rodríguez Romero durante a realización dos traballos de campo e a Javier Amigo as súas suxestións no eido taxonómico. Igualmente, agradecemos aos dous revisores anónimos as súas contribucións para á mellora da versión orixinal do manuscrito.

\section{Bibliografía}

Amigo Vázquez, J. (1984): Estudio de los matorrales y bosques de la Sierra del Caurel (Lugo). Memoria Doctoral inédita. Facultad de Farmacia. Universidade de Santiago.

Amigo, J., Guitián, J. \& Fernández Prieto, J.A (1987). Datos sobre los bosques ribereños de aliso (Alnus glutinosa) cántabro-atlánticos ibéricos. En: M.J. del Arco \& W. Wildpret (ed.): Vegetación de riberas de agua dulce.II. V Jornadas de Fitosociología. Ser. Informes 22: 159-176. Secretariado de Publicaciones. Universidad de La Laguna. Tenerife.

Amigo, J., Giménez de Azcárate, J. \& Romero, M.I. (1994): Omphalodo nitidae-Coryletum avellanae, a new mesophytic woodland community of the northwest Iberian Peninsula. Botanica Helvetica 104: 103-122.

Amigo, J. \& Romero, M.I. (1998). Abedulares de origen antrópico en Galicia: caracterización fitosociológica. Studia Botanica 17: 37-51.

Barral Silva, M.T., Cabaneiro Albadalejo, A., Calvo de Anta, R., Carballas Fernández, M.T., Díaz-Flerros, F., GarciaRodeja, J., Gil Sotres, F., Giménez de Azcárate, M., Guitián Rivera, F., Leirós de la Peña, M.C. Pérez Moreira, R., Silva Hermo, B. \& Villar Celorio, M.C. (1985). Geología, morfología, hidrología y suelos. En: F. Guitián Ojea (Dir.): Estudio del medio natural de las montañas gallegas. I. O Caurel. Monografias de la Universidad de Santigo de Compostela, 102: 13-71.

Bellot, F. (1951). Notas sobre la Durilignosa en Galicia. Trabajos del Jardín Botánico de Santiago 4: 25-38.

Bellot, F. (1968). La vegetación de Galicia. Anales del Instituto A.J. Cavanilles XXIV: 3-306.

Braun-Blanquet, J. (1979). Fitosociología. Bases para el estudio de las comunidades vegetales. Ed. Blume. Barcelona.

Castroviejo, S. (Coord. xen.)(1986-2012). Flora iberica, vols. I-VIII, X-XV, XVII, XVIII y XXI. Real Jardín Botánico. CSIC. Madrid.

CCE (Consejo de las Comunidades Europeas)(1992): Directiva 92/43/CEE del Consejo, de 21 de mayo de 1992, relativa a la conservación de los hábitats naturales y de la fauna y flora silvestres. Diario Oficial $n^{\circ} 206$ de 22/07/1992, páx.: 7-50.
Díaz González, T.E. (2010). Caracterización de los hábitats de interés comunitario (Red Natura 2000) existentes en el Principado de Asturias. II: bosques y arbustedas arborescentes. Boletín de Ciencias Naturales del R.I.D.E.A. 51: 213-276.

Díaz González, T. E. \& Fernández Prieto, J. A. (1994). La vegetación de Asturias. Itinera Geobotanica 8: 243-528.

EC (2013). Interpretation Manual of the European Union Habitats-EUR 28. DG Environment Nature and biodiversity. Bruxelles.

ESRI (2012). ArcGIS Desktop 10.1. Environmental Systems Research Institute, Inc. Redlands. USA.

Fernández Prieto, J.A. \& Bueno, A. (1996). La Reserva Integral de Muniellos: flora y vegetación. Cuadernos de Medio Ambiente. Naturaleza, $n^{\circ}$ 1. Consejería de Agricultura. Principado de Asturias. Oviedo.

Fernádez Prieto, J.A. \& Díaz Gonzalez, T.E. (2003). Las clasificaciones de los hábitats naturales de la Unión Europea y las Directivas Hábitats. Las formaciones leñosas altas atlánticas ibéricas. Naturalia Cantabricae 2: 25-32.

Fernández Prieto, J.A. \& Vázquez, V.M. (1987). Datos sobre los bosques asturianos orocantábricos occidentales. Lazaroa 7: 363-382.

García Manteca, P., González, Y., Álvarez, M.A., Márquez, J. \& Fernández Prieto, J.A. (1989). Vegetación del Concejo de Somiedo: su integración en una base de datos territorial. Options Méditerranéennes-Série Séminaires 3: 263-266.

GEOVEO (2012). Navegador cartográfico del portal WEB del Instituto Geológico y Minero de España (IGME). Dispoñibel en: http://cuarzo.igme.es/geoveo2/Default.aspx. [10 novembro, 2012].

Gleason, H. A. (1922). On the relation between species and area. Ecology 3(2): 158-162.

Giménez de Azcárate, J. (1993). Estudio fitosociológico de la vegetación de los afloramientos calizos de Galicia. Tese de Doutoramento inédita. Facultade de Ciencias Biolóxicas. Universidade de Santiago de Compostela.

Giménez de Azcárate, J., Romero Buján, M.I. \& Amigo Vázquez, J. (1996). Los espinales de la Pruno-Rubion ulmifolii en Galicia. Lazaroa 16: 89-104.

Guitián Rivera, J. (1984): Estudio de la vegetación herbácea de la Sierra del Caurel (Lugo). Tese de Doutoramento inédita. Universidade de Santiago de Compostela.

Guitián Rivera, J. (2011). Estación Científica do Courel. Lvcensia 43 (vol. XXI): 231-238.

Guitián, J., Izco, J. \& Amigo, J. (1988). El Mesobromion cantábrico y su diferenciación occidental. Documents phytosociologiques XI: 275-282.

Guitián, J., Guitián, P., Magrach, A., Docampo, C., Domínguez, P. \& Guitián, L. (2012). Effect of management and spatial characteristics on plant species richness of Castanea sativa Mill. woodlots in the NW Iberian Peninsula. Journal of Forest Research 17: 98-104. 
IGME (1981). Mapa Geológico de España. E. 1:50.000. Hoja 157 (9-9). Servicio de Publicaciones. Ministerio de Industria y Energía. Madrid.

Izco, J. Amigo, J. \& Guitián, J. (1985): Botánica. En: J. Guitián Ojea (Dir.): Estudio del medio natural de las montañas gallegas. I. O Caurel. Monografias de la Universidad de Santigo de Compostela, 102: 73-139.

Izco, J., Amigo, J.\& Guitián, J. (1986a). Identificación y descripción de los bosques montanos del extremo occidental de la Cordillera Cantábrica. Trabajos Compostelanos de Biología 13: 185-203.

Izco, J., Guitián, J. \& Amigo, J. (1986b). Datos sobre la vegetación herbácea del Caurel. Stvdia Botanica 5: 71-84.

Izco, J., Amigo, J. \& Guitián, J. (1990). Composición, relaciones y sistematización de los bosques esclerófilos del noroeste ibérico. Notiziario della Società di Fitosociologia 22: $83-114$

Merino, B. (1901). Viajes de herborización por Galicia-I. Razón y Fé I: 368-385.

Merino, B. (1902). Viajes de herborización por Galicia-II. Razón y Fé II: 367-373.

Merino, A., Real, C. \& Rodríguez-Guitián, M.A. (2008): Nutrient status of managed and natural forest fragments of Fagus sylvatica in southern Europe. Forest Ecology and Management 255: 3691-3699.

Merino García, A. \& Rodríguez Guitián, M.A: (2011). 5. Solos e nutrición forestal dos faiais. En: M.A. Rodríguez Guitián \& A. Rigueiro Rodríguez (Coords.). Os Faiais de Galicia. Ecoloxía e valor ambiental: 129-160. IBADERHórreum. Lugo.

Rigueiro Rodríguez, A., Ramil Rego, P., Crecente Maseda, R. \& Rodríguez Guitián, M.A. (2005). Plan de Ordenación de los Recursos Naturales del Espacio Natural Protegido Os Ancares-O Courel. Tomo 1. Dirección Xeral de Conservación da Natureza. Consellería de Medio Ambiente. Xunta de Galicia. Santiago de Compostela.

Rivas-Martínez, S., Díaz González, T.E., Fernández Prieto, J.A., Loidi, J. \& Penas, A. (1984). La vegetación de la alta montaña cantábrica: los Picos de Europa. Ediciones Leonesas. León.

Rivas-Martínez, S., Fernández-González, F., Loidi, J., Lousâ, M. \& Penas, A. (2001).Syntaxonomical checklist of vascular plant communities of Spain and Portugal to association level. Itinera Geobotanica 14: 5-341.

Rivas-Martínez, S., Díaz, T.E., Fernández-González, F., Izco, J., Loidi, J., Lousã, M. \& Penas, A. (2002). Addenda to the syntaxonomical checklist of 2001. Itinera Geobotanica 15,2 vols.

Rivas-Martínez e coautores (2007): Mapa de series, geoseries y geopermaseries de vegetación de España. Parte I. Itinera Geobotanica 17: 5-436.

Rivas-Martínez e coautores (2011). Mapa de series, geoseries y geopermaseries de vegetación de España. Parte II. Itinera Geobotanica 18 (2 vol.): 5-800.
Rodríguez Guitián, M.A. (2011). 12. Fitosocioloxía dos faiais e outras comunidades con Fagus sylvatica. En: M.A. Rodríguez Guitián \& A. Rigueiro Rodríguez (Coords.): Os faiais de Galicia: ecoloxía e valor ambiental: 281-349. IBADER-Horreum. Lugo.

Rodríguez Guitián, M.A. \& Amigo Vázquez, J. (2009a): Caracterización florística de los hayedos calcícolas del Distrito Altonarceense (Cordillera Cantábrica occidental). En: F. Llamas \& C. Acedo (Coords.): Botánica PirenaicoCantábrica en el siglo XXI: 540-560. Área de Publicaciones. Universidad de León. León.

Rodríguez Guitián, M.A. \& Amigo Vázquez, J. (2009b): Datos florísticos y ecológicos sobre los espinales y aulagares del extremo occidental de la Cordillera Cantábrica. En: F. Llamas \& C. Acedo (Coords.): Botánica Pirenaico-Cantábrica en el siglo XXI: 579-594. Área de Publicaciones. Universidad de León. León.

Rodríguez Guitián, M.A. \& Ferreiro Da Costa, J. (2011). Caracterización botánica, ecoloxía e distribución de Fagus sylvatica L. En: M.A. Rodríguez Guitián \& A. Rigueiro Rodríguez (Coord.): Os faiais de Galicia. Ecoloxía e valor ambiental: 65-104. IBADER-Horreum. Lugo.

Rodríguez Guitián, M.A. \& Ramil Rego, P. (2007). Revisión de las clasificaciones climáticas aplicadas al territorio gallego desde una perspectiva biogeográfica. Recursos Rurais 1(3): 31-53.

Rodríguez Guitián, M.A. \& Ramil Rego. P. (2008). Fitogeografia de Galicia (NW Iberico): análisis histórico y nueva propuesta corológica. Recursos Rurais 1(4): 19-50.

Rodríguez Guitián, M.A., Amigo Vázquez, J. \& Romero Franco, R. (2000): Aportaciones sobre la interpretación, ecología y distribución de los bosques supratemplados naviano-ancarenses. Lazaroa 21: 45-65.

Rodríguez Guitián, M.A., Fontao, M., Negral Fernández, M.A. \& Merino, A. (2001). Estado nutricional de los hayedos de la Sierra del Caurel (Lugo-León) y su relación con las propiedades de los suelos. Investigación Agraria: Sistemas y Recursos Forestales 10(2): 253-269.

Rodríguez Guitián, M.A., Real, C., Blanco López, J.M. \& Ferreiro da Costa, J. (2005a): Caracterización fitosociológica de la orla forestal de los hayedos silicícolas naviano-ancarenses (Sorbo aucupariae-Salicetum capreae). Bulletin de la Societè de Histoire Natural de Toulouse 141(2): 69-74.

Rodríguez Guitián, M.A., Rigueiro Rodríguez, A., Real, C., Blanco López, J.M. \& Ferreiro da Costa, J. (2005b). El hábitat *9260 Bosques de Castanea sativa* en el extremo noroccidental ibérico: primeros datos sobre la variabilidad florística de los "soutos". Bulletin de la Societè de Histoire Natural de Toulouse, 141(2): 75-82.

Rodríguez Guitián, M.A., Amigo Vázquez, J., Real, C. \& Romero Franco, R. (2009): Revisión de la sintaxonomía de los hayedos del occidente de la Cordillera Cantábrica (NO Ibérico) mediante análisis multivariante. Lazaroa 30: 191218. 
Rodríguez Guitián, M.A., Ramil-Rego, P., Díaz Varela, R.A., Pereira-Espinel, J., González Vecín, T.M. \& Real, C. (2011): Los bosques dominados por Taxus baccata L. del extremo occidental de la Cordillera Cantábrica: caracterización ecológica, valor de conservación y amenazas. En: Botànica Pirenaico-cantàbrica. Actes del IX Col-loqui Internacional de Botànica Pirenaico-cantàbrica: 315-326. Centre d'Estudis de la Neu i de la Muntanya d'Andorra (CENMA) de l'Institut d'Estudis Andorrans (IEA). Andorra.

Rodríguez Guitián, M.A., Ramil-Rego, P. \& Ferreiro Da Costa, J. (2012). Propuesta de clasificación multicriterio para los bosques de Galicia. Recursos Rurais. Serie Cursos 6: 63-106.

Ruíz de la Torre, J. (2006). Flora mayor. Organismo Autónomo Parques Nacionales. Dirección General para la Biodiversidad. Ministerio de Medio Ambiente. Madrid.

Silva-Pando, F.J. (1990). La flora y vegetación de la Sierra de Ancares: base para la planificación y ordenación forestal. Tese de Doutoramento inédita. Universidad Complutense de Madrid.
Silva-Pando, F.J. \& Rigueiro Rodríguez, A. (1992). Guía das árbores e bosques de Galicia. Ed. Galaxia. Vigo.

Taboada Castro, M.T. \& Silva Hermo, B.M. (1999). Factores de formación y propiedades de los suelos formados sobre calizas en Galicia. Cadernos do Laboratorio Xeolóxico de Laxe 24: 121-139.

Tutin, T.G., Heywood, V.H., Burges, N.A., Moore, D.M., Valentine, D.H., Walters, S.M. \& Webb, D.A. (Eds.)(19641980). Flora Europaea, Vols. 1-5. Cambridge University Press. Cambridge.

Xunta de Galicia (2001): Lei 9/2001, do 21 de agosto, de conservación da natureza. Consellería da Presidencia. Diario Oficial de Galicia $\mathrm{n}^{\circ}$ 171: 11.754-11.769, martes, 4 de setembro de 2001. 